Universidade de São Paulo

Departamento de Economia, Administração e Contabilidade

Mestrado em Economia - FEA \IPE \USP

\title{
Impactos de Curto Prazo do Programa Bolsa Família sobre o Abandono e o Desempenho Escolar do
}

Alunado Paulista

Heitor Sandes Pellegrina

Orientador: Prof. Dr. Marcos de Almeida Rangel

Julho de 2011

São Paulo 
Prof. Dr. João Grandino Rodas

Reitor da Universidade de São Paulo

Prof. Dr. Reinaldo Guerreiro

Diretor da Faculdade de Economia, Administração e Contabilidade

Prof. Dr. Denisard Cnéio de Oliveira Alves

Chefe do Departamento de Economia

Prof. Dr. Dante Mendes Aldrighi

Coordenador do Programa de Pós-Graduação em Economia 
Heitor Sandes Pellegrina

\title{
Impactos de Curto Prazo do Programa Bolsa Família sobre o Abandono e o Desempenho Escolar do Alunado Paulista
}

\author{
Dissertação apresentada ao Depar- \\ tamento de Economia da Facul- \\ dade de Economia, Administração \\ e Contabilidade da Universidade de \\ São Paulo como requisito para a \\ obtenção do título de Mestre em \\ Economia.
}

Orientador: Prof. Dr. Marcos de Almeida Rangel

Julho de 2011

São Paulo 
FICHA CATALOGRÁFICA

Elaborada pela Seção de Processamento Técnico do SBD/FEA/USP

\section{Pellegrina, Heitor Sandes}

Impactos de curto prazo do Programa Bolsa Família sobre o abandono e o desempenho do alunado paulista / Heitor Sandes Pellegrina. -- São

Paulo, 2011.

$101 \mathrm{p}$.

Dissertação (Mestrado) - Universidade de São Paulo, 2011.

Orientador: Marcos de Almeida Rangel.

1. Políticas públicas 2. Programa Bolsa Família 3. Economia da educação 4. Econometria I. Universidade de São Paulo. Faculdade de Economia, Administração e Contabilidade II. Título.

CDD - 353.0981 

À minha família e à Raquel 


\section{AGRADECIMENTOS}

Certa vez ouvi que é mais glamouroso falar de economia do que estudá-la. Quando escolhi dissertar em microeconomia aplicada, eu não sabia que essa é uma das áreas onde isto mais se encaixa. Foram horas e horas em frente a um computador cruzando informações e rodando regressões. Apesar de parecer uma tarefa solitária, esse trabalho está longe de ter sido construido sozinho. Direta ou indiretamente, muitos contribuíram fornecendo o que foi, para mim, mais importante do que resultados, idéias e motivação.

Essa dissertação teve participação direta dos professores Ricardo Madeira, Fernando Botelho e Marcos Rangel. Se eu descrevesse todas as aulas, comentários e até suas ajudas técnicas nesse espaço eu gastaria muito papel e ainda seria injusto com suas contribuições. Minha formação como economista foi marcada pelo contato e amizade com esse grupo seleto. Eu gostaria de agradecer ao professor Gabriel Madeira, que também me deu apoio para seguir a vida acadêmica. Particularmente, eu gostaria de agradecer à excelente orientação do Professor Marcos Rangel.

Com meus colegas de curso tive uma convivência única. Espero manter a amizade e o contato com indivíduos tão apaixonados pela profissão. As discussões nunca tinham um lugar para acontecer: fosse no bandejão, no cafezinho da uma e tanto ou nas festas frustradas da USP, sempre discutíamos economia. Toda turma do IPE-USP está incluída nesse grupo. Menciono aqueles com quem trabalhei mais diretamente: Thomaz Gemignani, Lucas Scottini, Dejanir Henrique Silva e Murilo Moraes.

Agradeço aos meus amigos, esses tiveram uma importância, talvez mais indireta, mas fundamental. Entre um copo e outro, discutimos economia, coisas banais ou nossos projetos de vida nessa difícil etapa entre graduação e profissão. Seja em Sorocaba, Brasília, Campinas, Rio de Janeiro ou na Matias Aires com a Bela Cintra, é sempre bom confirmar que, mesmo com os encontros se tornando mais raros, eles permanecem divertidos e prazerosos.

Também, agradeço ao financiamento para a realização desse projeto. Do CNPq e, posteriormente, do Observatório da Educação Projeto 3313 CAPES/FEA-USP .

Agradeço sobretudo à minha mãe, Regina, ao meu pai, Eduardo, e ao meu irmão, Douglas, que me deram suporte e motivação em toda a minha trajetória.

Por fim, agradeço à Raquel, minha querida companheira, que me dá motivação e carinho. Ela foi a pessoa com quem mais discuti esse projeto (e quem mais corrigiu meu português limitado). Ela torna tudo que é difícil mais fácil, e o que é fácil mais bonito. 
Criado na ortografia de meus pais, custava-me a ouvir tais blasfêmias, mas não ousava refutá-lo. Contudo, um dia, proferi algumas palavras de defesa, ao que ele respondeu que era um preconceito, e acrescentou que as idéias aritméticas podiam ir ao infinito, com a vantagem que eram mais fáceis de menear.

Bentinho sobre Escobar 


\section{RESUMO}

Programas de transferência de renda condicionais estão sendo amplamente utilizados ao redor do mundo com um objetivo duplo de aliviar a pobreza no curto e médio prazo. A partir das transferências em dinheiro ou em bens, tais programas procuram atender às necessidades materiais imediatas das famílias beneficiárias. Condicionando a participação à investimentos educacionais, espera-se que os filhos beneficiários acumulem mais capital humano e, consequentemente, adquiram melhores condições para romper com a pobreza no médio-prazo. A partir de uma rica base de dados no nível do indivíduo com informações para o Estado de São Paulo sobre matrículas, boletins, exames padronizados, variáveis sócio-econômicas e transferências mensais do Programa Bolsa Família, avaliamos o impacto desta política sobre diferentes variáveis escolares do aluno beneficiário. Encontramos efeito sobre aquelas que estão diretamente atreladas às condicionalidades do programa, como frequência e matrícula, mas nenhum sobre variáveis de desempenho. Verificamos uma redução no abandono escolar na ordem de $20 \%$, uma redução de $3 \%$ sobre aulas ausentes e nenhuma alteração sobre o desempenho dos alunos no boletim ou em exames padronizados. Além disso, avaliamos diferentes canais teóricos explorando a heterogeneidade do impacto do programa sobre grupos específicos. Por fim, os resultados mantém-se válidos quando utilizamos diferentes técnicas de estimação, testamos as prétendências das variáveis dependentes e imputamos valores para os alunos do grupo de controle que abandonaram a escola.

JEL: I24, O54, I21, J24

Palavras-chave: programas de transferência de renda condicionais, educação, avaliação de políticas públicas. 


\begin{abstract}
Conditional cash transfer programs have been widely implemented in different countries to aleviate poverty in both the short and long run. The transfers in cash or in kind have the objective of aleviating the immediate material needs of the benefited families. The conditionalities in educational issues should improve the accumulation of human capital of the benefited students and, as a consequence, provide the necessary conditions to break with the intergenerational transmission of poverty. Using a rich dataset on the individual level with information about enrollment, transcripts, socio-economic variables and transfers of the Programa Bolsa Família, we evaluated the impact of the brazilian conditional cash transfer program on different educational variables of the benefited student. We found an impact of the program over the variables which are directly related to the conditionalities of the program, enrollment and attendance rate, but no effect over performance variables. The program reduces drop out rates in 20\%, reduces absence rate on $3 \%$ and has no impact on the perfomance of the students on the school transcripts or padronized exams. Furthermore, we investigated different theoretical channels exploring the heterogeneity of the impact over specific groups. Finally, we tested the pré-treatment trends, we used different estimation techniques and we imputed values for the students of the control group who did drop out. Our results remained valid after those robustness checks.
\end{abstract}

JEL: I24, O54, I21, J24

Keywords: conditional cash transfer programs, education, evaluation of public policies. 


\section{Sumário}

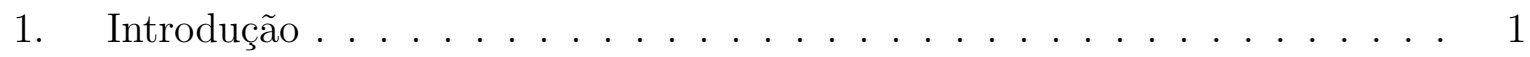

2. Impactos avaliados dos programas de transferência de renda condicionais sobre educação . . . . . . . . . . . . . . . . . . . . . . 4 4

3. Implicações teóricas dos programas de transferência de renda condicional . 7

$3 . .1$ Mercado de trabalho, idade e gênero . . . . . . . . . . . . . . 7

$3 . .2$ Quantidade e qualidade da educação . . . . . . . . . . . . . . 8

$3 . .3$ Interação entre demanda e oferta por educação . . . . . . . . . . . . 9

3.4 Externalidades positivas . . . . . . . . . . . . . 10

4. O Programa Bolsa Família . . . . . . . . . . . . . . . . . . . . 10

5. Bases de dados . . . . . . . . . . . . . . . . . . . . 12

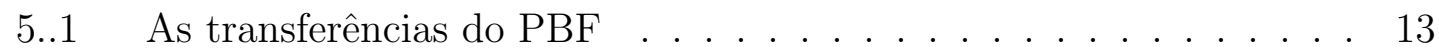

$5 . .2 \quad$ O boletim e a base de matrículas . . . . . . . . . . . . 13

$5 . .3 \quad$ O SARESP . . . . . . . . . . . . . . . . . . . 14

$5.4 \quad$ O perfil do aluno beneficiado . . . . . . . . . . . . . 15

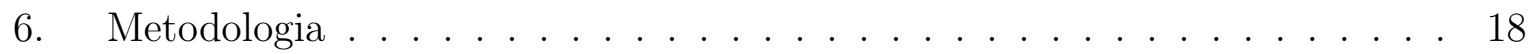

6.1 O problema de avaliação . . . . . . . . . . . . . 18

$6 . .2 \quad$ O parâmetro de interesse . . . . . . . . . . . . . . . . . . . . . . 19

6..3 Estimação por MQO com dados em Cross-Section . . . . . . . . . . 21

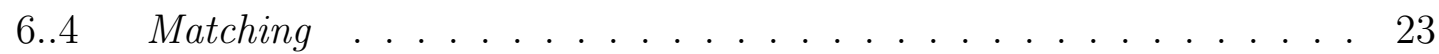

6.5 Diferença em diferenças . . . . . . . . . . . . 25

6..6 Diferença em diferenças com matching . . . . . . . . . . . . . 27

7. Impactos do Programa Bolsa Família . . . . . . . . . . . . . . . . . 28

$7 . .1$ Os grupos de tratamento e os de controle . . . . . . . . . . 28

7..2 Impacto sobre o abandono escolar . . . . . . . . . . . . . . . . 32

$7 . .2 .1 \quad$ Impactos básicos . . . . . . . . . . . . . . . . 32

7..2.2 Robustez dos resultados . . . . . . . . . . . . . 34 
7..2.3 Heterogeneidade do impacto de acordo com as características do aluno . . . . . . . . . . . . . . . . . 38

7..2.4 Heterogeneidade do impacto de acordo com as características da escola . . . . . . . . . . . . . . . . . . 43

7..3 Impacto sobre frequência escolar . . . . . . . . . . . . . . . . . . 45

7..3.1 Impactos básicos . . . . . . . . . . . . . . . . . . 45

7..3.2 Heterogeneidade do impacto em frequência de acordo com as características individuais do aluno . . . . . . . . 50

7..3.3 Heterogeneidade do impacto de acordo com as características da escola . . . . . . . . . . . . . . 55

7.4 Impacto sobre o desempenho no boletim escolar . . . . . . . . . . . 60

7..4.1 Impactos básicos e heterogêneos . . . . . . . . . . . . . 60

7..5 Impactos sobre desempenho num exame padronizado . . . . . . . . 61

7..6 Impactos básicos e heterogêneo . . . . . . . . . . . . . . . . . . . . 64

8. Testes de robustez . . . . . . . . . . . . . . . . . 64

8.1 Análise de tendência pré-tratamento . . . . . . . . . . . . . 64

8..2 Imputando dados para os alunos que abandonaram a escola . . . . 66

9. Conclusões e implicações de políticas públicas . . . . . . . . . . . . . . . 69

10. Referências Bibliográficas . . . . . . . . . . . . . . . . 73

1. Cruzamento das bases de dados . . . . . . . . . . . . . . . 76

$1 . .1$ Descrição do algorítmo . . . . . . . . . . . . . . . . . 76

2. Tabelas e Figuras . . . . . . . . . . . . . . . . . . . . 78 


\section{Lista de Tabelas}

1 Valor das transferências em 2008 (em reais) . . . . . . . . . . . . . 12

2 Grupos de tratamento e de controle . . . . . . . . . . . . . . . . . 32

3 Impacto do PBF sobre o abandono escolar no biênio 2008-2007 (em pontos percentuais). . . . . . . . . . . . . . . . . . . 35

4 Impacto do PBF sobre o abandono escolar no biênio 2009-2008 (em pontos percentuais). . . . . . . . . . . . . . . . . . 36

5 Impacto sobre abandono impondo suporte comum e estimando por mínimos quadrados ordinários e matching . . . . . . . . . . . . . . . . . 37

6 Impacto do PBF sobre o abandono escolar no biênio 2008-2007 amenizando externalidades . . . . . . . . . . . . . . . . . . . . . . 39

7 Impacto do PBF sobre o abandono escolar no biênio 2009-2008 amenizando externalidades . . . . . . . . . . . . . . . . . . . . 4 40

8 Heterogeneidade do impacto I em abandono no biênio 2008-2007 (utilizando grupo de controle restrito $\ldots \ldots$. . . . . . . . . . . . . . . . . 42

9 Heterogeneidade do impacto II em abandono no biênio 2008-2007 (utilizando grupo de controle restrito) . . . . . . . . . . . . . . . . . . . . . . . 44

10 Impactos sobre frequência no biênio 2008-2007. . . . . . . . . . . . . . . 46

11 Impactos sobre frequência no biênio 2009-2008. . . . . . . . . . . . . . 47

12 Impacto sobre frequência escolar impondo suporte comum . . . . . . . . . . 49

13 Heterogeneidade do impacto em ausência . . . . . . . . . . . . . . . . . 52

14 Heterogeneidade do impacto em probabilidade a frequentar a mais de $85 \%$ das aulas . . . . . . . . . . . . . . . . . . . . 53 
15 Heterogeneidade do impacto em probabilidade a frequentar a menos de $95 \%$ das aulas . . . . . . . . . . . . . . . . . . . . . 54

16 Heterogeneidade do impacto em ausência de acordo com características das escolas . . . . . . . . . . . . . . . . . . . . 57

17 Heterogeneidade do impacto na probabilidade de frequêntar a mais de $85 \%$ das aulas de acordo com características das escolas . . . . . . . . . . . . . 58

18 Heterogeneidade do impacto na probabilidade de atender a menos de $95 \%$ das aulas de acordo com características das escolas . . . . . . . . . . . . . 59

19 Impacto sobre o desempenho no boletim no biênio 2008-2007 . . . . . . . . 62

20 Impacto sobre o desempenho no boletim no biênio 2009-2008 . . . . . . . . 63

21 Impacto do programa sobre desempenho num exame padronizado . . . . . 65

22 Impacto do programa sobre desempenho num exame padronizado . . . . . 65

23 Análise de tendência pré-tratamento . . . . . . . . . . . . . . . 67

24 Análise de tendência pré-tratamento . . . . . . . . . . . . . . . 67

25 Impacto sobre a nota do boletim imputando a notas para o grupo de controle que abandonou a escola . . . . . . . . . . . . . . . . . . . . 69

26 Estatística Descritiva para a análise sobre abandono no biênio 2008-2007 79

27 Estatística Descritiva para a análise sobre abandono no biênio 2009-2008 80

28 Estatística Descritiva I (perfil do aluno beneficiado em 2007) . . . . . . . . 81

29 Estatística Descritiva II (perfil do aluno beneficiado em 2007) . . . . . . . 82

30 Estatística Descritiva III (perfil da escola do aluno beneficiado em 2007). Características selecionadas. . . . . . . . . . . . . . . . 83

31 Variáveis incluídas na estimação do propensity score. . . . . . . . . . . 83 


\section{Introdução}

A desigualdade de renda é usualmente associada a diferenças educacionais. Indivíduos em famílias pobres chegam ao mercado de trabalho com um nível educacional abaixo daqueles em famílias mais ricas e, como consequência, obtêm salários inferiores. Quando as famílias com menor renda possuem restrições no mercado de crédito e, portanto, não conseguem antecipar a renda necessária para investir na educação dos filhos, tal fenômeno gera um ciclo no qual a pobreza é carregada de geração para geração. Desse modo, uma das soluções levantadas pela literatura em economia para diminuir a desigualdade de renda e, ainda, romper com a transmissão intergeracional da pobreza, é a promoção de políticas que elevem a acumulação de capital humano nas famílias mais pobres (HECKMAN; MASTEROV, 2007).

Seguindo tal linha, programas de transferência de renda condicional têm sido amplamente utilizados por diversos governos no mundo como um instrumento para gerar maior acumulação de capital humano entre famílias beneficiadas. Em 2006, por exemplo, já existiam mais de 20 países com programas em progresso (De Janvry; SADOULET, 2006). A partir das transferências em dinheiro ou em bens, tais programas buscam o alívio da pobreza no curto prazo. Com as condicionalidades em termos educacionais e de saúde, espera-se que os filhos das famílias beneficiadas adquiram as condições necessárias para romper com a pobreza no médio prazo.

Existe atualmente uma vasta literatura que estima o impacto dos programas de transferência de renda condicional sobre diferentes variáveis de interesse. Os estudos apresentam melhora na nutrição das crianças, redução do trabalho infantil, melhora em variáveis de saúde, aumento da matrícula e diversos outros impactos ${ }^{1}$. Entretanto, o programa do México, Oportunidades (inicialmente Progresa), forneceu a maioria dos resultados até agora. Além disso, as avaliações sobre variáveis educacionais concentram-se em aspectos quantitativos, como frequência e matrícula, e pouco sobre dimensões qualitativas, como o desempenho dos alunos em exames de proficiência.

Esta dissertação complementa a literatura existente em ambos os pontos levantados acima. Em primeiro lugar, avaliamos o impacto de um programa de transferência condicional brasileiro; em segundo, analisamos o impacto sobre variáveis educacionais de ambas naturezas quantitativas e qualitativas. Para tanto, cruzamos as bases de dados de difer-

\footnotetext{
${ }^{1} \mathrm{Um}$ resumo dos impactos do programa mexicano Progresa pode ser encontrado em Skoufias et al. (2001) e Schultz (2004). Ver (RAWLINGS; RUBIO, 2003) para uma revisão dos principais programas de transferência de renda condicional na América Latina.
} 
entes fontes para construir um painel no nível do indivíduo com informações sobre as matrículas das escolas, o boletim elaborado pelos professores, o desempenho dos alunos num exame padronizado e um rico questionário sócio-econômico com informações sobre bens duráveis, educação familiar e características demográficas. Com tais informações, foi possível verificar o impacto do Programa Bolsa Família (doravante PBF) sobre diferentes dimensões da vida escolar do aluno beneficiário.

Com relação à estimação do impacto do programa, o principal desafio é comparar indivíduos beneficiados e não beneficiados de modo que possamos interpretar a diferença entre tais como um efeito causal do PBF. Note que uma comparação simples entre os incluídos no programa e o restante da população desconsidera o fato de que tais grupos são muito diferentes entre si (mesmo na ausência da política). Isto ocorre porque o governo foca o programa sobre populações específicas, criando critérios de elegibilidade com base na renda per capita familiar para a seleção dos beneficiários. Além disso, as famílias reagem a tais critérios e se autosselecionam para a política com base numa gama de informações que o a avaliador não possui.

Para amenizar tais problemas, exploramos a variação na entrada dos indivíduos no programa para gerar grupos de tratamento e controle. Comparamos, por exemplo, um indivíduo que foi incluído no programa no final de 2007 e começo de 2008 com um que só seria beneficiado um ano depois, no final de 2008 e começo de 2009. Além disso, utilizamos diversos procedimentos estatísticos que nos permitem melhorar a precisão da comparação entre os grupos. Procedemos com regressões incluindo efeitos fixos de escola. Tal técnica limita as comparações para indivíduos dentro de uma mesma escola. Utilizamos diversas covariadas para amenizar o viés de variável relevante omitida e, também, técnicas de matching, que comparam indivíduos semelhantes num conjunto de características observadas pelo avaliador. Finalmente, com os alunos e variáveis de interesse para os quais possuímos dados longitudinais, estimamos o efeito do programa com regressão por diferença em diferenças, que controla por características observadas e não observadas que sejam constantes ao longo do tempo.

Para sugerir possíveis canais teóricos que expliquem os resultados obtidos, avaliamos o impacto do programa e sua heterogeneidade de acordo com as implicações teóricas fornecidas pela literatura. Em primeiro lugar, analisamos o impacto de acordo com os custos de oportunidade dos filhos, dados pelo diferencial de idade e gênero. Por um lado, esperamos que o programa possua um impacto maior entre os alunos mais velhos, pois estes estão numa fase crítica com relação à entrada no mercado de trabalho, o que 
gera maior espaço para um efeito sobre a decisão educacional. Por outro, se o programa não compensa suficientemente o custo de oportunidade dos alunos mais velhos, é sobre os mais novos que o impacto será maior, já que o programa compensará o salário que este último grupo obteria trabalhando. Raciocínio análogo pode ser considerado com relação à diferença de gêneros. Analisamos, ainda, a possibilidade do programa gerar um choque de demanda por educação, e de que a intensidade do efeito deve depender das condições de oferta para acomodá-lo. Neste caso, verificamos se o impacto depende da qualidade da escola em termos de desempenho médio num exame padronizado e da quantidade de alunos por sala. Por fim, levantamos a possibilidade de o programa criar externalidades positivas para os alunos que não recebem o benefício. Procedemos com regressões utilizando grupos de controle que são mais isolados dos efeitos do programa e, também, verificamos a heterogeneidade do impacto de acordo com o montante de alunos numa sala que são tratados.

Encontramos impacto do programa sobre variáveis escolares que estão diretamente atreladas às condicionalidades do programa, matrícula e frequência. Na especificação mais rigorosa, o PBF reduz o abandono em, pelo menos, 20\%. Com relação à ausência escolar, encontramos um impacto de menor magnitude de 3\%. Quando estratificamos a amostra, identificamos uma concentração do efeito sobre indivíduos com menores custos de oportunidade, mulheres e alunos com 10 ou menos anos. Seguindo adiante e avaliando o impacto sobre variáveis de desempenho escolar, não identificamos efeito do programa sobre o desempenho dos alunos nas notas do boletim do professor ou em exames padronizados.

Para testar a validade de nossos resultados, estimamos o impacto em diferentes anos e analisamos as tendências no período pré-inclusão no PBF. Além disso, como encontramos um impacto negativo sobre abandono, é possível que isto esteja alterando a composição da amostra de modo a reduzir o impacto estimado sobre desempenho. Para testar tal hipótese, simulamos valores para o desempenho dos alunos do grupo de comparação que abandonaram a escola e, mesmo no cenário que maximizaria a magnitude do nosso impacto, o efeito foi bastante reduzido na ordem de $4 \%$. Os resultados obtidos continuaram válidos após todos os testes de robustez realizados.

Vale ressaltar que a literatura em economia aponta para uma correlação positiva entre desempenho escolar e salário (BOISSIERE et al., 1985) (ASHENFELTER et al., 1985). Ou seja, de que parte das desigualdades observadas no mercado de trabalho estão correlacionadas com diferenças na acumulação de capital humano em estágios anteriores. Portanto, ao avaliarmos o impacto do PBF sobre variáveis de desempenho educacional, estamos indi- 
retamente informando a respeito de um potencial impacto do programa sobre o salário e, consequentemente, sobre a desigualdade de renda no médio prazo.

Além desta introdução, a dissertação está organizada do seguinte modo. Na próxima seção, 2, apresento os principais resultados encontrados na literatura sobre o impacto dos programas de transferência de renda condicionais em variáveis escolares. Na seção 3, descrevo aspectos teóricos relevantes para o presente trabalho. Na seção 4, descrevo o PBF e, na seção 5, as bases de dado utilizadas. Na seção 6, apresento a metodologia utilizada para estimar a relação causal do programa sobre as variáveis de interesse. Na seção 7, analiso os resultados e, na seção 8, apresento os testes de robustez sobre eles. Por fim, na seção 9, concluo e apresento as implicações de políticas públicas dessa dissertação.

\section{Impactos avaliados dos programas de transferência de renda condicionais sobre educação}

Nesta seção, apresentamos os principais resultados encontrados na literatura sobre o impacto dos programas de transferência de renda condicionais em variáveis escolares. Primeiramente, discutimos os resultados estimados a partir de informações sobre o programa mexicano Oportunidades. Como sua implementação foi conduzida utilizando técnicas de experimentos sociais, a maioria dos estudos disponíveis se concentram sobre este caso. Em seguida, apresentamos os resultados obtidos em outros programas ao redor do mundo e, por fim, os encontrados para os casos implementados no Brasil. ${ }^{2}$.

Schultz (2004) estima o impacto do programa Progresa no México utilizando dados experimentais e encontra um impacto positivo sobre a taxa de matrícula na ordem de 2-8 pontos percentuais que é maior em magnitude para alunos com 4 a 6 anos de educação e para aqueles do sexo feminino. Com relação ao esforço escolar, Parker e Skoufias (2000) não encontram impactos significantes sobre o tempo que o aluno gasta na escola ou em lições de casa. Seguindo adiante e avaliando o impacto sobre variáveis que informam sobre o desenvolvimento cognitivo do aluno, Behrman e Sengupta (2000) avaliam o desempenho num exame padronizado e não rejeitam estatisticamente a hipótese de um impacto nulo. Um dos motivos levantados para explicar este resultado foi o fato do beneficiário ser avaliado somente após um ano e meio de inclusão no programa, e os efeitos sobre aspectos cognitivos serem observados, possivelmente, somente no médio e longo prazo. No entanto,

\footnotetext{
${ }^{2}$ Para revisões mais detalhadas sobre o impacto dos programas de transferência de renda condicionais sobre variáveis educacionais e outras, ver Parker et al. (2007) e Fiszbein et al. (2009)
} 
recentemente, a análise foi extendida em Behrman et al. (2008a) para avaliar o impacto do tratamento de 3 anos e meio sobre o desempenho em exames padronizados e, novamente, não foram obtidos resultados estatisticamente diferentes de zero. Em nossa perspectiva, outra explicação plausível para a não verificação de impacto decorre da falta de incentivos que os alunos têm de se esforçar para um exame padronizado, já que bom desempenho não traz recompensas para os alunos (o que a literatura chama de low stakes). Apesar de nossos dados não nos possibilitarem uma análise de médio prazo, utilizamos, além de notas obtidas num exame padronizado, as notas dos alunos no boletim do professor. Neste último caso, os alunos têm incentivos para obter um bom desempenho: além das notas serem um critério para a aprovação, ao contrário dos testes padronizados, elas são divulgadas para os pais e responsáveis.

Com relação a outros programas no mundo, temos o Red de Proteccion Social no Nicaragua, para o qual Maluccio e Flores (2005) encontram um impacto positivo de 18 pontos percentuais na matrícula, 7 pontos percentuais nas taxas de retenção e 11 pontos percentuais na frequência escolar para os alunos de primeira a quarta série. No Paquistão, foi implementado um programa focado em diminuir a disparidade de gênero nas escolas dando um subsídio à educação somente para mulheres. Chaudhury e Parajuli (2006) avaliaram tal programa e encontraram um impacto positivo de $9 \%$ sobre matrícula e um aumento de 6 mulheres por escola. Em Honduras, Glewwe e Olinto (2004) encontram um resultado positivo sobre matrícula e frequência escolar em crianças de 6 a 13 anos de idade incluidas no programa de Asignacion Familiar. Em Bangladesh, Ravallion e Wodon (2000) também encontram impacto positivo de um programa de transferência de renda condicional sobre frequência escolar e matrícula. Note que, em geral, os programas avaliados encontram sistematicamente um impacto positivo sobre a matrícula. Porém, as análises não informam a respeito do impacto sobre o desenvolvimento cognitivo do aluno beneficiário.

Para o caso dos programas brasileiros, apesar do país possuir atualmente o maior programa de transferência de renda condicional do mundo, ainda há poucos estudos disponíveis sobre tal. Bourguignon et al. (2003) utilizam dados de uma pesquisa familiar para estimar um modelo comportamental que simula o impacto do programa Bolsa Escola. Os resultados obtidos sugerem que $40 \%$ das crianças fora da escola se matriculariam em resposta ao programa. Entretanto, para a estimação do impacto os autores utilizam a hipotése forte de que crianças que não estão matriculadas na escola não contribuem para a renda familiar com o trabalho doméstico, somente com trabalho no mercado, o que subestima o custo de oportunidade do filho. Ainda, Cardoso e Souza (2004) estimam o impacto 
do programa a partir de dados em cross-section da PNAD utilizando modelos estruturais para minimizar o viés de seleção e encontram um impacto positivo sobre matrícula. Por fim, Glewwe e Kassouf (2011) utilizam um painel no nível da escola que vai de 1998 a 2005 e encontram um impacto positivo sobre matrícula, negativo em abandono e positivo em progressão nas séries. No entanto, o trabalho se baseia em dados no nível da escola e na informação da existência ou não de alunos incorporados no programa. Além de não ser possível verificar a variação temporal em termos de proporção de alunos beneficiados em cada escola, o período analisado pelo artigo é marcado por intenso esforço do governo em democratizar o acesso ao ensino público. Em 1996, houve uma reforma no sistema educacional brasileiro: a Lei de Diretrizes e Bases da Educação Nacional, pela qual um dos principais objetivos do governo era democratizar o acesso ao ensino. Além disso, muitos Estados adotaram nesse período a política de progressão continuada que passou a reter os alunos somente no final de cada ciclo educacional. Houve, também, uma intensa expansão do PETI (Programa de erradicação do trabalho infantil) que, em 2000, atendia 140 mil crianças e, em 2002, 810.769. Ainda, em 1997, foi criado o FUNDEF, um fundo federal de repasse de recursos para o ensino fundamental que passou a transferir com base no número de alunos matriculados no sistema escolar em questão. Todas essas reformas geram um choque não-observável variante no tempo que pode ou não estar associado ao fato de a escola possuir alunos beneficiados pelo programa.

Resumidamente, os estudos sobre os programas de transferência de renda condicionais se concentram no caso mexicano e sobre variáveis de matrícula, frequência e abandono escolar que, na melhor das hipóteses, possuem um impacto indireto sobre o desenvolvimento cognitivo. Além disso, as estimações para o caso brasileiro sofrem de limitações estatísticas que comprometem a inferência de causalidade do programa. Ou a avaliação adota hipóteses fortes sobre o comportamento do mercado de trabalho do aluno, ou os dados estão em níveis de agregação sujeitos à choques temporários não observáveis que podem invalidar a estratégia de identificação. Dado tal contexto, procuramos contribuir com a literatura de duas maneiras. Em primeiro lugar, fornecendo informações sobre aspectos qualitativos relacionados ao desenvolvimento cognitivo do aluno beneficiado. Em segundo, utilizando dados no nível do indivíduo para estimar o impacto de um programa de grandes dimensões ainda pouco estudado. 


\section{Implicações teóricas dos programas de transferência de renda condicional}

Para analisar as implicações teóricas do PBF, consideramos um ambiente onde as famílias têm a opção de matricular os filhos nas escolas e que esta decisão é influenciada pelo custo de oportunidade de se educar, isto é, na renda que o filho poderia gerar caso deixasse de frequentar a escola. Neste ambiente, a transferência de renda condicional opera como um subsídio à educação, diminuindo o custo de oportunidade de estudo. Diferentemente de um programa de transferência de renda não condicional, que potencialmente aumenta o investimento em educação da família a partir de um efeito renda, a transferência com condicionalidade também gera uma mudança nos preços relativos enfrentados pela família. Caso a educação seja um bem normal, ambos efeitos, renda e preço, têm a mesma direção. É razoável esperar, portanto, que programas de transferência de renda com condicionalidades tenham um efeito maior sobre a educação do que um programa de transferência não condicional.

Além desta breve interpretação do programa como um subsídio à educação, na subseção seguinte apresentamos as implicações empíricas desse framework para um ambiente onde os indivíduos de diferentes idades e gêneros possuem diferentes custos de oportunidade. Em adição, descrevemos os canais teóricos que justificariam um impacto sobre a quantidade (frequência e matrícula) e qualidade (desempenho em exames) da educação. Analisamos, também, o impacto potencial que o programa tem dependendo das condições de oferta da escola e, por fim, exploramos a possibilidade do programa estar gerando efeitos de externalidade.

\section{3..1 Mercado de trabalho, idade e gênero}

Para incorporar o fato de que indivíduos mais velhos possuem maiores custos de oportunidade de ir à escola, os programas de transferência de renda condicionais geralmente aumentam o valor do benefício de acordo com a idade dos filhos da família beneficiada ${ }^{3}$. Note que, se o filho já atendia às condicionalidades do programa antes de ser beneficiado, a condicionalidade não exige uma mudança em sua decisão educacional. Neste

\footnotetext{
${ }^{3}$ Este é o caso do Progresa, que tem um valor maior para filhos mais velhos e, também, para mulheres, que, no caso do méxico, possuem uma taxa de abandono maior do que a dos homens. O PBF, por exemplo, possui um benefício maior e exige uma frequência mínima menor para adolescente de 16 e 17 anos com relação aos jovens com até 15 anos. Para este último grupo, o programa possui o mesmo desenho em termos de condicionalidades e benefícios.
} 
caso, a transferência de renda condicional é, de facto, não condicional (ANGELUCCI et al., 2010). Quanto mais velhos os filhos, maior o custo de oportunidade que eles enfrentam e mais as condicionalidades pesam sobre a decisão educacional. Esperamos, seguindo este raciocínio, que o impacto do $\mathrm{PBF}$ seja maior sobre os alunos mais velhos, pois o programa gera uma mudança nos preços relativos que este grupo enfrenta, onde ambos efeitos renda e substituição estão agindo. Já para os mais novos, há somente o efeito renda, pois os preços relativos não são alterados. Entretanto, se a transferência do programa estiver suficientemente abaixo do custo de oportunidade dos alunos mais velhos, ele terá um impacto somente entre aqueles cujos custos de oportunidade são compensados, ou seja, os alunos mais jovens. De tal modo, temos dois canais teóricos: um sugerindo um impacto maior sobre filhos mais velhos e outro, sobre filhos mais jovens. Com relação às diferenças de gênero, podemos utilizar um raciocínio análogo considerando, por exemplo, que os homens possuem maior custo de oportunidade no mercado de trabalho. De fato, estudos sugerem que o trabalho infantil está concentrado sobre garotos entre 10 e 14 anos (UDRY, 2006).

\section{3..2 Quantidade e qualidade da educação}

\section{Quantidade de educação}

Os programas de transferência de renda exigem das famílias como contrapartida para o benefício um mínimo de investimento em quantidade de educação, isto é, a matrícula na escola e um mínimo de frequência nas aulas. Esperamos que, para o caso da matrícula, o efeito do programa seja sempre positivo. Note que, para o aluno que já frequentava à escola antes da existência do programa, a transferência apenas torna seu custo de permanecer estudando menor. Já para aquele que não a frequentava, é possível que a transferência compense o custo de oportunidade que estava o induzindo a abandonar os estudos. Portanto, o aluno que iria para a escola permanece matriculado e, o que não iria, talvez se matricule em decorrência do programa. Com relação à frequência escolar, entretanto, há canais teóricas que sugerem efeitos do programa em direções opostas. Para os alunos que não atendem à condicionalidade mínima do programa, a existência da transferência sempre resultará num aumento da frequência. Dentro deste grupo, há aqueles que estavam abaixo da condicionalidade mínima e decidem não participar do programa e aqueles que decidem entrar. No primeiro grupo, a frequência permanecerá a mesma, no segundo, ela aumentará. Dentro do grupo de alunos que já atendiam à frequência mínima antes da existência do programa, entretanto, o efeito pode ser ambíguo e depende das elasticidades renda do consumo e da frequência escolar. O aluno que frequentava a $95 \%$ das aulas, 
por exemplo, pode ter incentivos a frequentar menos aulas em decorrência de um efeito renda. Portanto, se encontramos um efeito nulo sobre frequência, ou isto ocorrerá pois, de fato, o impacto do programa é nulo sobre tal dimensão, ou porque efeitos em direções opostas estão se anulando. Para incorporar esta possibilidade, em nossas análises empíricas, avaliamos o impacto do programa sobre diferentes aspectos da frequência escolar dos alunos.

\section{Qualidade da educação}

Mesmo o programa não exigindo qualquer contrapartida com relação ao desempenho escolar do aluno beneficiário, há canais teóricos que sugerem um impacto indireto sobre tal dimensão. Considerando que o desenvolvimento cognitivo dos alunos é determinado por diferentes insumos da escola, da família e do próprio indivíduo e que o programa altera tais insumos, esperamos que haja potencialmente um impacto sobre o desempenho do aluno beneficiado em exames padronizados e no boletim do professor. Em primeiro lugar, o programa possivelmente reduz o abandono escolar e aumenta o convívio do aluno com o ambiente da escola, com os professores e com outros alunos, o que pode ter consequências positivas sobre o seu desenvolvimento cognitivo. Em segundo, o acréscimo na renda familiar pode alavancar a demanda por qualidade de educação, o que potencialmente se traduz em melhor desempenho dos alunos beneficiados. Em terceiro e último lugar, o programa pode ter um impacto positivo sobre a frequência escolar, o que induziria o aluno a passar mais tempo se dedicando aos estudos. Estes três fatores fariam com que o desempenho do aluno melhorasse nos exames. No entanto, como ressaltado em Behrman e Sengupta (2000), se há beneficiários que não frequentariam a escola caso não participassem do programa, esta quantidade adicional de alunos poderá congestionar a escola se ela não tiver condições adequadas para oferecer espaço para este grupo, gerando um efeito negativo sobre o desempenho escolar. Ainda, a inclusão de alunos aumenta a heterogeneidade da sala, o que pode dificultar o trabalho do professor.

\subsection{Interação entre demanda e oferta por educação}

Os programas de transferência de renda condicionais podem ter diferentes impactos dependendo da qualidade das escolas. Se consideramos tais programas como um choque de demanda por educação, é possível que o impacto dependa da interação de tal choque com as condições de oferta. Há na literatura diversos artigos relacionando as características das escolas com o desempenho dos alunos (BEHRMAN et al., 2008b) (BEHRMAN; BIRDSALL, 1983). Um primeiro canal teórico que justificaria um impacto heterogêneo dependendo 
das características da escola seria o já mencionado no parágrafo anterior: de que o efeito pode depender do nível de congestionamento induzido sobre o tamanho das salas de aula. Caso a escola tenha pouca capacidade de incorporar um aluno novo, pois já possui uma alta relação de aluno por professor, o aumento na demanda por educação fica limitado à capacidade da escola de acomodar este choque. Uma segunda possibilidade teórica sugere que, se as famílias reagem mais aos programas quando percebem que o retorno por educação é maior, e, se tal percepção depende da qualidade da escola em que o filho estuda, deveríamos observar impactos maiores nas escolas percebidas como melhores (BEHRMAN et al., 2008a). Para este último caso, esperamos que nas famílias com maior escolaridade o impacto seja maior, pois é possivel que elas tenham uma percepção de retorno maior sobre a educação.

\section{3..4 Externalidades positivas}

Uma última consequência teórica, e mais delicada para nossa estratégia de identificação do impacto do programa, está no fato de que o programa pode ter efeitos de externalidades sobre os colegas de classe dos alunos beneficiários. Há na literatura diversas evidências de que um componente importante para explicar o desempenho escolar de um aluno está no próprio desempenho de seus colegas (SACERDOTE, 2001) (GAVIRIA; RAPHAEL, 2001). De tal modo, o impacto do programa sobre um único indivíduo pode gerar efeitos de equilíbrio geral sobre o comportamento dos alunos de toda a classe e, até mesmo, alterar o padrão de distribuição de notas dos professores. Para verificar evidências desse fenômeno, avaliamos se o impacto do programa depende da proporção de alunos beneficiados na sala de aula. Além disso, realizamos exercícios empíricos utilizando como grupo de controle alunos que estejam em salas de aula mais isoladas dos alunos beneficiários. Os efeitos de equilíbrio geral podem comprometer a avaliação do impacto do programa baseada na comparação de alunos dentro de uma mesma escola, pois o impacto positivo em ambos os grupos de tratamento e controle atenuará as diferenças que existiriam caso o grupo de controle não sofresse influencia do programa.

\section{O Programa Bolsa Família}

O PBF é um programa de transferência de renda condicional que começou em 2003 unificando outros programas de assistência social implementados anteriormente como o Bolsa Escola e o Auxílio Gás. As transferências que atingiam aproximadamente 6 milhões 
Figura 1: Bolsa Família - Evolução dos recursos por região (em milhões de reais)

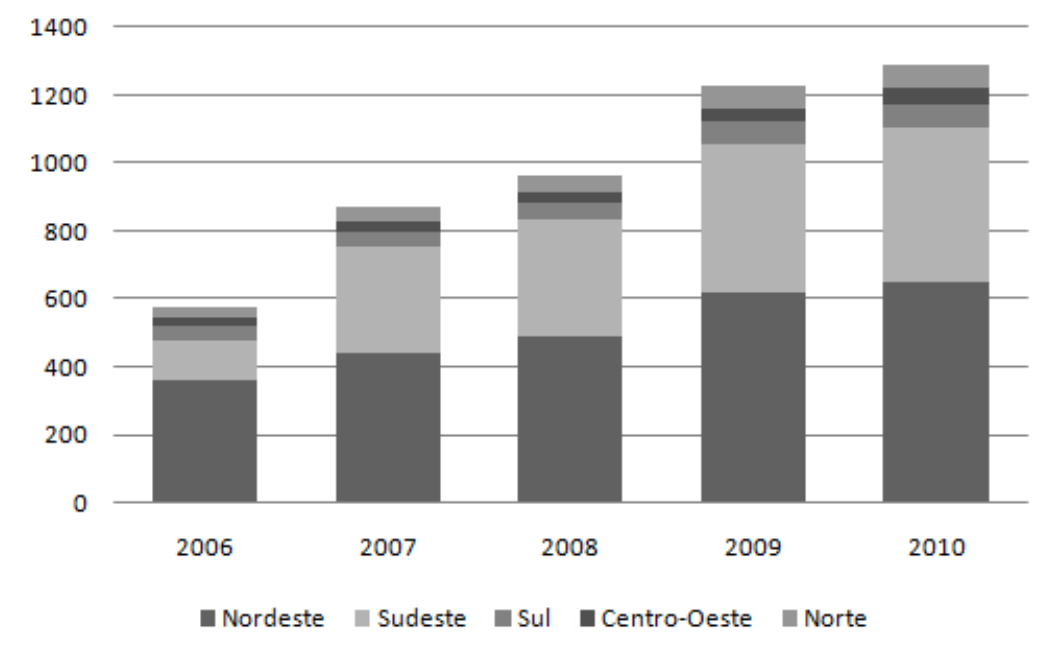

Fonte: Ministério do Desenvolvimento Social e Combate à Fome

de famílias inicialmente, em 2008, chegaram a 11 milhões, o que representa em torno de 1/4 da população brasileira. Hoje, o PBF é o maior programa de transferência de renda condicional do mundo. Na figura (1), apresento a evolução do programa de 2004 a 2009 no Brasil e por região. $\mathrm{Na}(2)$, isolamos a evolução para os estados do sudeste.

Para uma família ser elegível ao PBF, ela deve apresentar uma renda per capita mensal máxima que era, em 2008, de $\mathrm{R} \$ 120,00$. Portanto, o programa é focado na população que vive próxima da linha da pobreza ${ }^{4}$. O valor das transferências depende da estrutura familiar, isto é, da quantidade de filhos e suas respectivas faixas etárias. Há um valor fixo básico, um variável que depende da quantidade de filhos com até 15 anos e outro variável vinculado ao adolescente que depende da quantidade de filhos entre 16 e 17 anos. Uma família pode receber, no máximo, 3 benefícios variáveis e 2 variáveis vinculados ao adolescente. Os valores das transferências para o ano de 2008 estão expressos na tabela $1^{5}$. Note que, para uma família de 5 membros, com 3 filhos até 15 anos recebendo o benefício variável e com uma renda per capita de $\mathrm{R} \$ 100$, o valor transferido representa um aumento de $22 \%$ na renda total familiar.

As condicionalidades do programa são baseadas em aspectos educacionais e de saúde. Para saúde, as famílias devem manter o cartão de vacinação dos filhos com menos de 7 anos atualizados. Em educação, até 2007, todos alunos com até 15 anos deveriam apresentar $85 \%$ de frequência mínima escolar. Até 2008, o programa não atendia aos alunos de 16

\footnotetext{
${ }^{4}$ Em 2008, o Banco Mundial definiu a linha internacional da pobreza em $\$ 1.25$ dólares por dia.

${ }^{5}$ Para os indivíduos com até 15 anos o desenho do programa se manteve praticamente o mesmo em todo o período de 2007-2010, com exceção dos ajustes anuais do benefício para acompanhar a inflação.
} 
Figura 2: Bolsa Família - Evolução dos recursos no Sudeste (em milhões de reais)

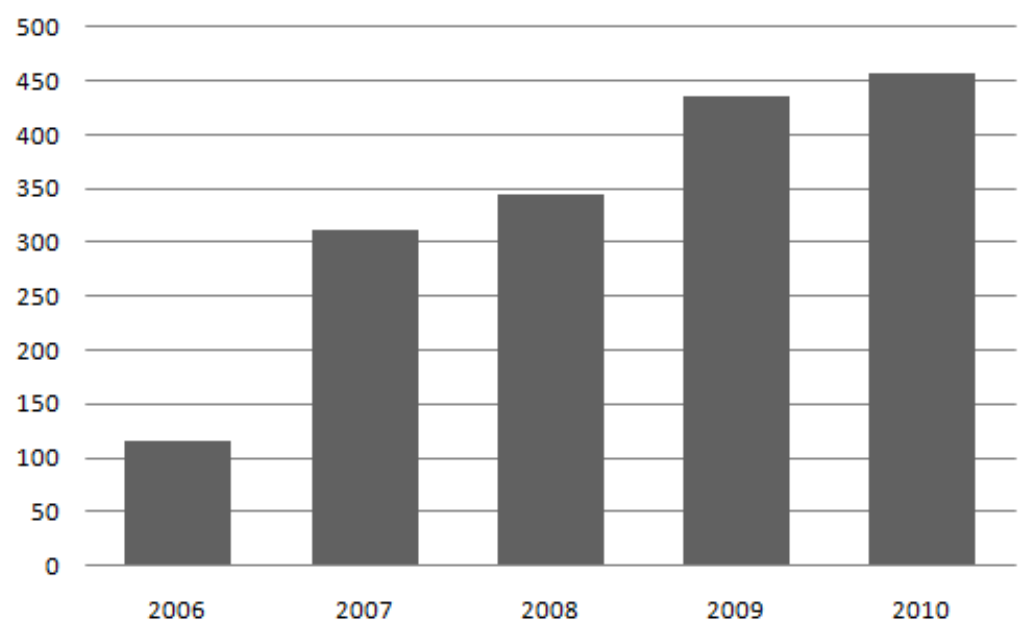

Fonte: Ministério do Desenvolvimento Social e Combate à Fome

Tabela 1: Valor das transferências em 2008 (em reais)

\begin{tabular}{lc}
\hline \hline Benefício Fixo & 58 \\
Variável (filhos até 15 anos) & \\
- 1 filho & 18 \\
- 2 filhos & 36 \\
- 3 filhos & 54 \\
Variável vinculado ao adolescente (16 e 17 anos) & \\
- 1 filho & 30 \\
- 2 filhos & 60 \\
\hline Transferência máxima: & 172 \\
Transferência mínima: & 58 \\
\hline Renda per capita máxima: & 120 \\
\hline
\end{tabular}

Fonte: Ministério do Desenvolvimento Social e Combate à Fome

e 17 anos, e, a partir de então, passou a exigir 75\% de presença escolar para este grupo como contrapartida à transferência variável vinculada ao adolescente.

\section{Bases de dados}

Para construir a base de dados final, utilizamos informações provindas de duas fontes 6: a Caixa Econômica Federal e a Secretaria de Educação do Estado de São Paulo. Da primeira, extraimos informações mensais sobre as transferências para famílias beneficiadas pelo PBF. Da segunda, obtivemos informações escolares do alunado paulista. Como não havia um indicador único dos alunos tal como um RG, foi necessário realizar um cuidadoso

\footnotetext{
${ }^{6}$ A disponibilização dos dados foi concedida sob condições estritas de sigilo. Além disso, o trabalho com tais informações foi aprovado pela Comissão de Ética do Departamento de Economia da FEA-USP.
} 
processo de cruzamento de dados. Explicamos mais detalhadamente tal procedimento no apêndice.

Esta seção está organizada do seguinte modo. Apresentamos cada uma das fontes separadamente e, por fim, utilizamos a base de dados que construímos para discutir o perfil do aluno beneficiado pelo PBF.

\section{5..1 As transferências do PBF}

As informações sobre os beneficiários do PBF foram obtidas a partir do banco de dados da Caixa Econômica Federal disponibilizado pelo Ministério do Desenvolvimento Social e Combate à Fome. A base começa em agosto de 2007 e termina em dezembro de 2010, possui informações sobre as transferências mensais do programa e sobre a estrutura familiar do recipiente: a data de nascimento da mãe e a data de nascimento de cada um dos filhos.

\section{5..2 O boletim e a base de matrículas}

O sistema pré-universitário no Brasil está dividido em 4 ciclos: pré-escola (para crianças com menos de 6 anos), ensino fundamental I (a idade adequada nesse ciclo é de 7 a 10 anos), ginásio ou ensino fundamental II (frequentado por alunos de 11 a 14 anos) e ensino médio (frequentado por alunos de 15 a 17 anos). A divisão por ciclos foi estabelecida em 1996 no Brasil junto à adoção do sistema de progressão continuada no Estado de São Paulo, utilizado para combater a alta taxa de abandono e de defasagem etária por série dos alunos de escola pública. Neste sistema, reprova-se por insuficiência de rendimento escolar somente no final de cada ciclo de ensino, ou seja, na quarta série, na oitava e no terceiro ano do ensino médio ${ }^{7}$.

A partir de 2007, as matrículas dos alunos de todo o sistema educacional do estado (público e privado) foram informatizadas. A cada aluno foi atribuido um identificador único, o que nos possibilita identificar com clareza a localização de cada um deles no começo do ano escolar. Podemos inferir, por exemplo, se o aluno migrou para outra escola do sistema (público ou privado) ou se ele permaneceu na mesma escola.

Além disso, a Secretaria de Educação do Estado de São Paulo adotou em 2007 um

\footnotetext{
${ }^{7} \mathrm{Na}$ realidade, há um mínimo de rendimento de $25 \%$. No entanto, este é um nível bastante baixo e poucos alunos deixam de atingí-lo
} 
Figura 3: Taxas de abandono do sistema de matrículas em 2008 (em \%)

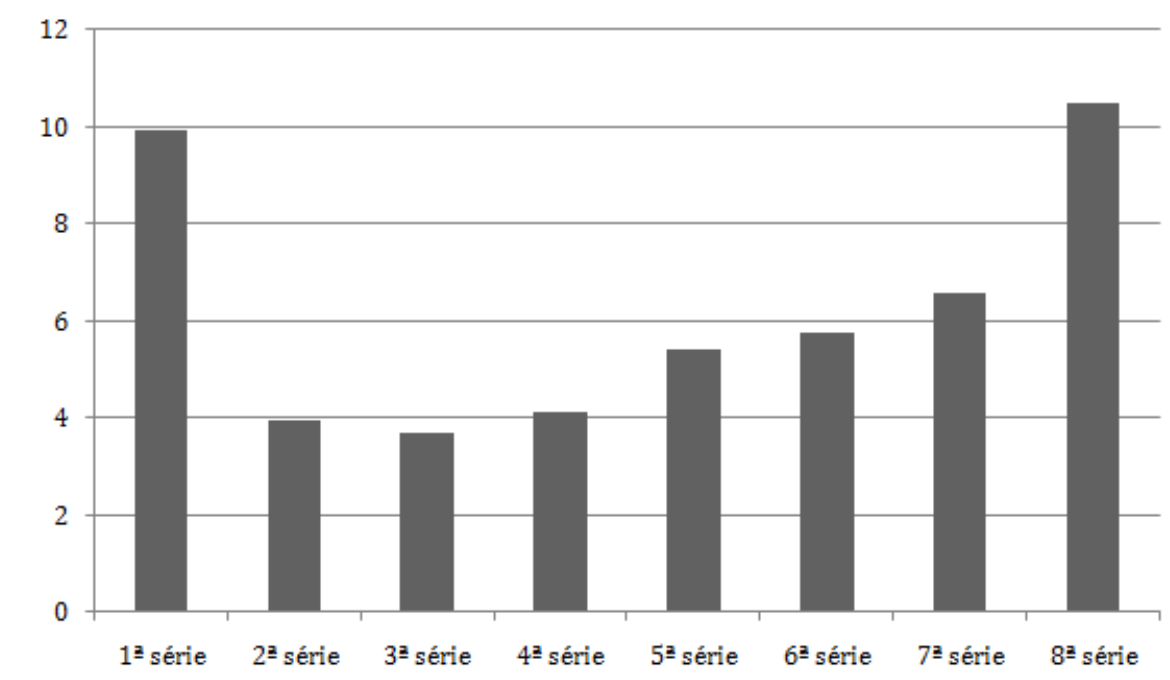

Fonte: Secretaria de Educação do Estado de São Paulo (elaboração própria).

padrão uniforme de distribuição de notas e também informatizou todo o sistema de boletins das escolas públicas estaduais. De acordo com as diretrizes da Secretaria, os professores devem atribuir um valor inteiro de 0 a 10 ao desempenho do aluno. Nos boletins, temos informações sobre o desempenho, reprovação e a frequência de cada aluno em cada uma das disciplinas cursadas durante os anos de 2007, 2008 e 2009. A maior parte dos alunos paulistas está matriculada no sistema estadual de ensino. Em 2008, por exemplo, este grupo possuia aproximadamente 8 milhões de indivíduos, o que representava $85 \%$ do total de alunos do estado. No gráfico (3), apresentamos as taxas de abandono no biênio de 2008-2007.

\section{5..3 O SARESP}

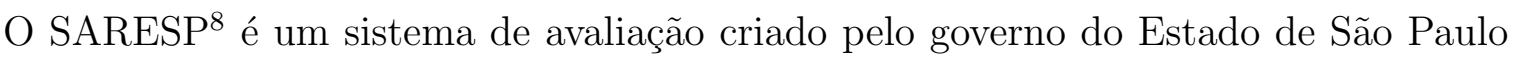
para avaliar a qualidade das escola públicas estaduais. Entre as competências de tal sistema está aplicar um exame padronizado a todas as escolas públicas estaduais do Estado de São Paulo. Tal exame é aplicado anualmente desde 1996 com diferentes formatos nos anos subsequentes. A partir de 2007, ele passou a ser elaborado de modo a possibilitar a comparação entre anos de aplicação diferentes a partir da inferência da proficiência dos alunos a partir da Teoria de Resposta ao Item. Em adição, a métrica do exame é desenhada de modo que a escala de proficiência seja a mesma do SAEB ${ }^{9}$.

\footnotetext{
${ }^{8}$ Sistema de Avaliação de Rendimento Escolar do Estado de São Paulo

${ }^{9}$ Sistema de Avaliação de Educação Básica
} 
Foram utilizadas as edições de 2007, 2008 e 2009 no presente estudo. Nestes anos, o exame foi aplicado aos alunos das escolas públicas estaduais das seguintes séries: $1^{\mathrm{a}}, 2^{\mathrm{a}}$ e $4^{\mathrm{a}}$ séries do ciclo I do ensino fundamental; $6^{\mathrm{a}}$ e $8^{\mathrm{a}}$ séries do ciclo II do fundamental; e $3^{\mathrm{a}}$ série do ensino médio. Acompanha o exame do Saresp de 2007 e 2008 um detalhado questionário socio-econômico com perguntas sobre posse de bens duráveis, educação dos pais, ambiente familiar e outros. Aproximadamente, 2,2 milhões de alunos realizaram a prova em 2007.

O exame é conduzido por uma instituição independente da Secretaria de Educação de São Paulo. Uma prova específica é elaborada de acordo com o conteúdo programado para cada série. Em 2007, foram aplicados exames de português, de matemática e de ciências. Cada matéria possuia 24 questões objetivas com 104 itens avaliados e o exame foi corrigido por uma máquina (sem interferência humana). O SARESP é um exame aplicado em Novembro em cada sala de aula no período em que a turma está matriculada (matutino, vespertino e noturno). Para dar credibilidade ao exame, professores não aplicaram as provas na mesma escola onde lecionavam. Portanto, os estudantes fazem a prova no mesmo horário e local em que estão habituados a terem aula, mas os professores aplicantes são de outras escolas. Além disso, há monitores independentes em cada escola para avaliar se o exame está sendo adequadamente aplicado.

Por fim, vale ressaltar que, a partir de 2008, o exame do Saresp passou a ser utilizado pela Secretaria de Educação do Estado de São Paulo para estabelecer a política de bônus. O desenho da política é feito de modo a gerar incentivos para que os professores tenham interesse no desempenho dos alunos.

\section{5..4 O perfil do aluno beneficiado}

Utilizando informações das três bases apresentadas acima, traçamos nesta subseção o perfil do aluno beneficiado pelo PBF em termos de suas variáveis sócio-econômicas disponíveis no questionário do Saresp e de seu desempenho escolar.

Aproximadamente, $30 \%$ dos alunos da base receberam alguma transferência do PBF entre 2007 e 2010. Em geral, uma vez dentro do programa, os alunos tendem a permanecer nele. Daqueles incluídos em 2007 a partir de setembro, encontramos 96\% recebendo benefício em 2008, 75,8\% em 2009 e 75,7\% em 2010. Dos incluídos em 2008, encontramos $82 \%$ em 2009 e $80 \%$ em 2010.

Analisando as estatísticas descritivas do grupo que recebeu benefício do programa em 
Figura 4: Taxas de reprovação em 2007 nas escolas estaduais paulistas por status de benefício (em \%)

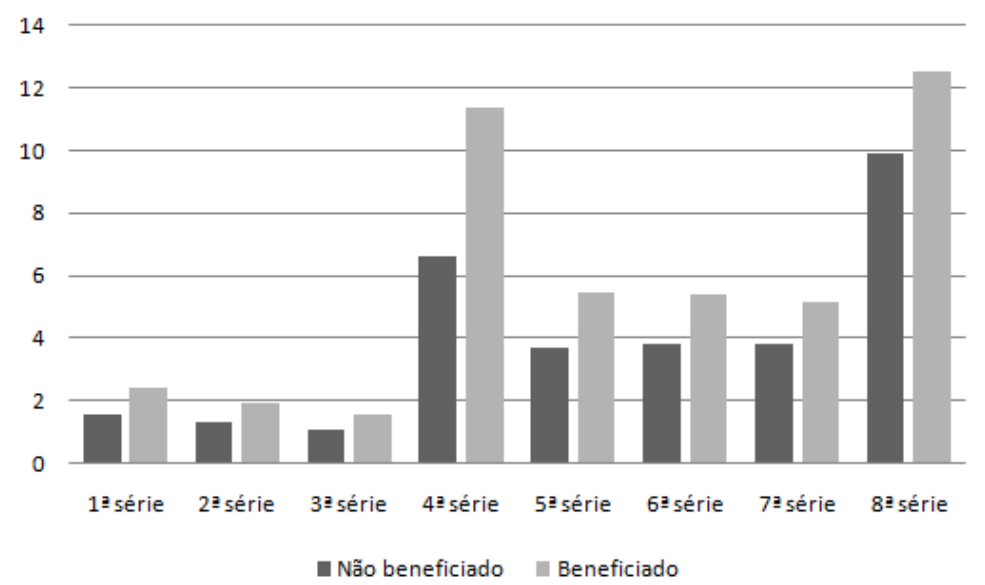

Fonte: Secretaria de Educação do Estado de São Paulo e Caixa Econômica Federal (elaboração própria).

2007 apresentadas nas tabelas (28), (29) e (30) do apêndice, podemos observar que, de fato, ele é mais pobre do que o grupo de alunos que não recebeu. Em média, o grupo de alunos beneficiados possui menos bens duráveis. Por exemplo, a proporção de alunos com somente uma televisão em casa nesse grupo é $16 \%$ maior do que no grupo não beneficiado. Com duas televisões, essa proporção é 18,8\% menor. O mesmo padrão ocorre, também, para a quantidade de banheiros em casa: $74 \%$ dos beneficiados possuem um banheiro em casa contra $62 \%$ dos não beneficiados; com dois banheiros, essas proporções são de, respectivamente, $20 \%$ e $34 \%$. Com o restante dos bens duráveis, quantidade de celulares na casa, carros, máquina-de-lavar roupa, aparelhos de dvd's e outros, a proporção de alunos com posse entre os beneficiados foi sempre menor do que no restante da amostra.

Com relação às informações de estrutura familiar, notamos que o aluno beneficiado tende a pertencer a uma família maior, com uma média de 0,52 indivíduos a mais. Além disso, há diferenças significativas na educação familiar: 4,7\% dos alunos beneficiados possuem mães com educação superior contra 11,8\% dos alunos não-beneficiados e o mesmo ocorre com a escolarização dos pais do aluno beneficiado. O próprio aluno beneficiado tende a entrar na escola depois do aluno não-beneficiado. $85 \%$ deste último grupo começou a estudar a partir da pré-escola contra $76 \%$ do primeiro. Por fim, com relação ao padrão demográfico, há uma proporção maior de brancos e menor de negros, pardos e indígenas entre os não beneficiados.

Quando analisamos o desempenho escolar dos alunos no boletim elaborado pelos professores, os beneficiados possuem menor frequência escolar, maiores taxas de reprovação 
Figura 5: Distribuição acumulada das notas no boletim por status de benefício e disciplina.
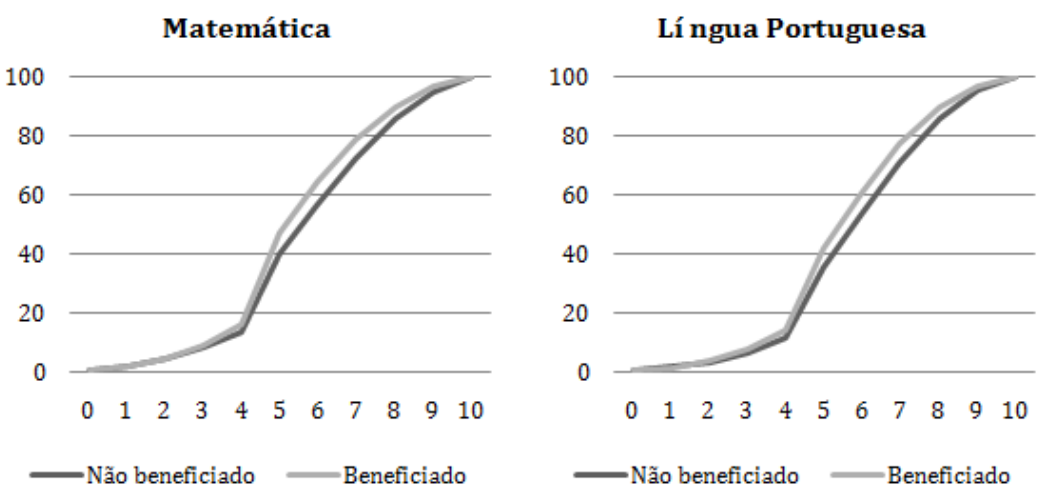

Fonte: Secretaria de Educação do Estado de São Paulo e Caixa Econômica Federal (elaboração própria).

e, também, pior desempenho em termos de percentil da sala. O z-score de um aluno beneficiado está, em média, 0,36 pontos abaixo do não beneficiado. Em percentis, este último grupo está em média 7 pontos acima do primeiro. O que significa que, numa classe de 100 alunos, os não beneficiados estão em média 7 alunos a frente se ordenassemos a classe por desempenho no exame. Além disso, isto ocorre em todas as séries e disciplinas. Na figura (5), apresentamos a função de densidade acumulada dos alunos nas notas dos professores. $\mathrm{Na}$ (6), apresentamos a função de densidade acumulada dos alunos em proficiência no exame do Saresp numa escala de 0 a 10. A curva da função acumulada para o grupo beneficiado está sempre à esquerda do grupo não beneficiado em ambos os exames de Língua Portuguesa e Matemática no boletim do professor ou no exame do Saresp. Isto significa que o grupo de alunos do PBF está concentrado em notas piores com relação ao grupo não beneficiado. Mesmo quando comparamos alunos dentro de uma mesma sala de aula, o aluno beneficiado continua em média ao menos 2 percentis abaixo do resto da sala em cada série e disciplina.

Outro ponto relevante é que há uma grande heterogeneidade entre as escolas do estado em termos de desempenho médio dos alunos no SARESP, alunos por sala e média das características sócio-econômicas dos alunos. Na tabela (30), apresentamos as médias das características dos alunos. Podemos notar que aqueles que recebem o Programa Bolsa Família estão em escolas com alunos mais pobres e piores níveis médios de proficiência no SARESP. Isto significa que o aluno beneficiado não está somente numa família com menor posse de bens duráveis e menor escolarização dos pais, mas também estão inseridos em meios sociais com tais características.

Resumidamente, notamos pela análise das estatísticas descritivas que o PBF atinge 
Figura 6: Distribuição acumulada das notas no exame do Saresp por status de benefício e disciplina.
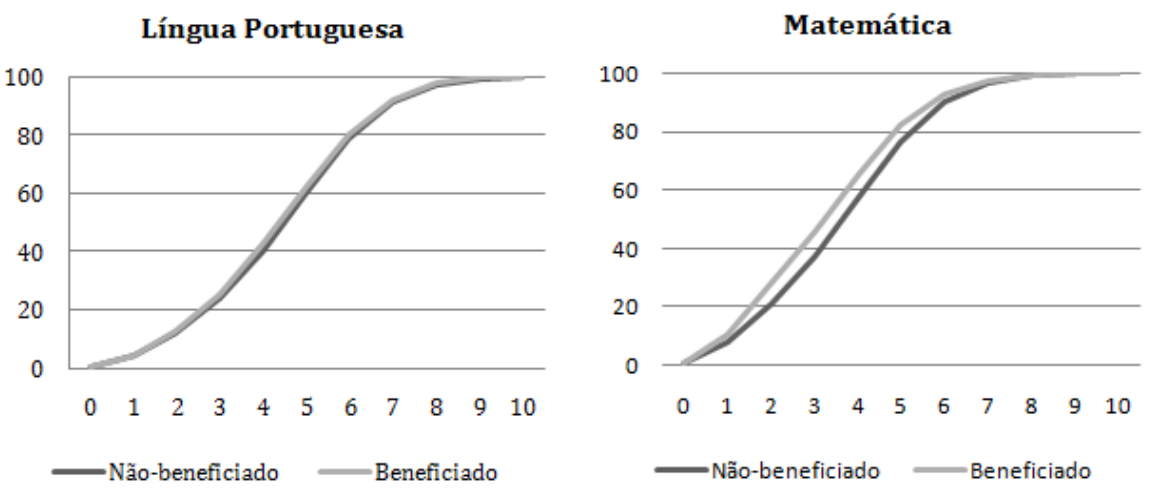

Fonte: Secretaria de Educação do Estado de São Paulo e Caixa Econômica Federal (elaboração própria).

uma população mais pobre que, em média, possui um desempenho escolar abaixo do restante da população. Este perfil sugere a existência de um ciclo no qual a pobreza é transmitida de geração para geração. As famílias que recebem auxílio do programa são mais pobres e, dada a menor escolaridade de seus filhos, as próximas gerações também terão dificuldades de ascender socialmente. Dado tal contexto, é natural que se coloque a seguinte questão: o PBF é capaz de quebrar com este ciclo intergeracional de pobreza, ou, ao menos, amenizá-lo a partir de um impacto positivo sobre a escolaridade dos alunos beneficiados? Na próxima seção, apresentamos a metodologia aplicada para responder a tal questão.

\section{Metodologia}

\section{6..1 O problema de avaliação}

Para estimar a distribuição do impacto de um programa sobre uma variável de interesse da população, seria necessário observá-la em duas circunstâncias: uma em que recebeu o tratamento do programa e outra em que não o recebeu. No entanto, isto é impossível, pois uma vez em que um indivíduo é tratado, não observamos o que teria acontecido caso não recebesse tratamento ${ }^{10}$.

Utilizando a notação tradicional, tome $y_{i}^{1}$ como a variável de interesse quando um indivíduo recebe tratamento e $y_{i}^{0}$ quando não o recebe. O impacto do programa sobre a

\footnotetext{
${ }^{10}$ Isso é conhecido pela literatura como o Problema Fundamental da Inferência Causal. O termo foi primeiramente utilizado por Holland (1986).
} 
variável de interesse é, neste caso:

$$
\tau_{i}=y_{i}^{1}-y_{i}^{0}
$$

Entretanto, observamos a variável $y_{i}^{1}$ somente quando o indivíduo foi tratado e $y_{i}^{0}$ caso contrário. Portanto, o que temos é $y_{i}$, dado pela seguinte equação:

$$
y_{i}=d_{i} y_{i}^{1}+\left(1-d_{i}\right) y_{i}^{0}
$$

Onde $d_{i}$ é uma variável indicadora de tratamento. Nota-se que não é possível recuperar diretamente a distribuição do impacto do tratamento sobre a população, isto é, a distribuição de $\tau_{i}$. Para tanto, seria necessário observar o valor de $y_{i}^{1}$ e $y_{i}^{0}$ em cada indivíduo. No entanto, adotadas algumas hipóteses, é possivel inferir o valor de parâmetros específicos da distribuição de $\tau_{i}$.

\subsection{O parâmetro de interesse}

O objetivo deste estudo é avaliar o impacto do PBF nas variáveis de desempenho escolar sobre os alunos beneficiados. Portanto, o parâmetro de interesse é o impacto médio sobre a população que recebeu tratamento:

$$
\tau^{A T T}\left(\mathbf{x}_{i}\right)=E\left(\tau_{i} \mid d_{i}=1, \mathbf{x}_{i}\right)=E\left(y_{i}^{1}-y_{i}^{0} \mid d_{i}=1, \mathbf{x}_{i}\right)
$$

Onde $\mathbf{x}_{i}$ é um vetor de características observadas. O que queremos estimar é o parâmetro $\tau^{A T T}\left(\mathbf{x}_{i}\right)$ que é a diferença da média para a população tratada com características $\mathbf{x}_{\mathbf{i}}$ entre o resultado da variável de interesse quando ela recebe tratamento contra o resultado quando não o recebe. Separando os termos, temos $E\left(y_{i}^{1} \mid d_{i}=1, \mathbf{x}_{i}\right)$ e $E\left(y_{i}^{0} \mid d_{i}=1, \mathbf{x}_{i}\right)$. O primeiro é diretamente observado nos dados e o segundo não. $\mathrm{O}$ que precisamos, portanto, são de técnicas e hipóteses que nos permitam inferir o valor do segundo termo não observado $E\left(y_{i}^{0} \mid d_{i}=1, \mathbf{x}_{i}\right)$, a média da variável de interesse do grupo tratado com um vetor de características $\mathbf{x}_{i}$ caso não tivesse recebido tratamento.

Uma das técnicas utilizadas para solucionar o problema de não-observabilidade é buscar grupos que não tenham recebido tratamento e que possam servir de contrafactual válido da população tratada. O procedimento menos viesado para gerar grupos de tratamento e de controle comparáveis é a aleatorização do programa. Quando este procedimento é realizado adequadamente, o tratamento é estatisticamente independente das características dos indivíduos, o que permite a estimação consistente e não viesada do 
parâmetro $\tau^{A T T}\left(\mathbf{x}_{i}\right)^{11}$.

Não temos, entretanto, um experimento social com aleatorização do tratamento à nossa disposição para a avaliação do Programa Bolsa Família. Neste caso, ainda é possível inferir uma relação causal do programa desde que estejam presentes certas condições que justifiquem a adoção de hipóteses mais fortes. O principal desafio sem a aleatorização é gerar uma estratégia de identificação do parâmetro $\tau^{A T T}\left(\mathbf{x}_{i}\right)$ que elimine um potencial viés de seleção da amostra. Este viés é gerado, primeiramente, pelo próprio critério de elegibilidade do programa. O governo estabelece critérios como medidas de pobreza para identificar quem será ou não elegível ao benefício do programa. Além disso, as famílias se autosselecionam para o programa com base nesses critérios, podem existir características não observadas correlacionadas ao recebimento do tratamento que também estejam afetando a variável de interesse. Nas próximas subseções, apresentamos os métodos que utilizamos para identificar uma relação causal do programa com dados não-experimentais.

Antes de prosseguir, ressaltamos que as avaliações de programas utilizando dados não-experimentais fornecem maior poder de validação externa ${ }^{12}$. Isto ocorre por dois motivos. Em primeiro lugar, análises baseadas em experimentos sociais costumam ser restritas a ambientes e condições específicos, o que dificulta o exercício de extrapolação do resultado para outras situações. Dados não experimentais, entretanto, são gerados pelo ambiente e pelo programa a que de fato os agentes reagem. Além disso, dados nãoexperimentais geralmente trabalham com um número de observações maior. Isto significa que indivíduos de ambientes mais heterogêneos estão sendo incorporados à análise, o que, novamente, fornece maior poder de generalização dos resultados.

O resto desta seção apresenta os métodos de estimação e está organizada do seguinte modo. Apresentamos as técnicas gradativamente das menos as mais precisas em termos de atenuar o viés de seleção gerado pelo desenho do programa. Começamos com a estimação por mínimos quadrados ordinários (MQO) em dados cross-section, passamos para a estimação por matching, apresentamos o método de diferença em diferenças e, finalmente, descrevemos o método de diferença em diferenças com matching que concilia os dois métodos anteriores.

\footnotetext{
${ }^{11}$ Além disso, neste caso, o parâmetro $\tau^{A T T}\left(\mathbf{x}_{i}\right)$ é igual ao efeito do tratamento médio $E\left(y_{i}^{1}-y_{i}^{0}\right)$, ver Heckman et al. (1997).

${ }^{12}$ Os seguintes artigos discutem questões de validação interna contra validação externa: Deaton (2010), Imbens (2010), Heckman e Urzua (2010)
} 


\section{6..3 Estimação por MQO com dados em Cross-Section}

O modo mais direto de estimar o impacto do programa sobre o grupo tratado é a partir de uma comparação de médias. Isto pode ser feito regredindo a variável de interesse contra uma variável dummy de participação no programa. Para apresentar tal argumento formalmente, apresentamos outro parâmetro de interesse comumente estimado na literatura: o impacto médio do programa sobre a população. Mais adiante, discutimos como o nosso parâmetro de interesse, o impacto médio do programa sobre a população tratada, e a diferença nas hipóteses necessárias para a estimação de cada um deles.

$$
\tau^{A T E}=E\left(\tau_{i}\right)=E\left(y_{i}^{1}-y_{i}^{0}\right)
$$

Para deixar o argumento mais claro, vamos nos ater a uma estrutura mais simples do impacto do programa que abstrai de covariadas. Considere a seguinte estrutura linear e aditiva para o impacto do programa:

$$
\begin{gathered}
y_{i}^{1}=\alpha+\tau_{i}+u_{i} \\
y_{i}^{0}=\alpha+u_{i}
\end{gathered}
$$

Onde $y_{i}$ é a variável de interesse, $\alpha$ é um intercepto, $\tau_{i}$ é o impacto do programa sobre o indivíduo $i$ e $u_{i}$ é um vetor de variáveis não observadas. Quando inserimos (6.5) dentro de (6.2), obtemos o seguinte:

$$
\begin{gathered}
y_{i}=\alpha+\tau^{A T E} d_{i}+\left(\tau_{i}-\tau^{A T E}\right) d_{i}+u_{i} \\
y_{i}=\alpha+\tau^{A T E} d_{i}+e_{i}
\end{gathered}
$$

Caso $d_{i}$ seja não correlacionado com o termo de erro $e_{i}$, podemos estimar esta equação diretamente por mínimos quadrados ordinários. Há duas fontes de viés de seleção na equação acima que comprometeriam a estimação do parâmetro $\tau^{A T E}$ (BLUNDELL; DIAS, 2009). A primeira vem de uma correlação que $d_{i}$ pode ter com o termo não-observado $u_{i}$, conhecida como seleção em não-observáveis. Para amenizar tal problema numa estimação por mínimos quadrados, podemos utilizar covariadas e efeitos fixos de escola. A segunda fonte de viés é gerada por uma relação entre $d_{i}$ e $d_{i}\left(\tau-\tau_{A T E}\right)$, chamada de seleção nos ganhos. Não possuimos meios para evitar isto. Entretanto, esta fonte de viés faz com que o estimador do impacto por mínimos quadrados identifique não o $\tau^{A T E}$, mas justamente o nosso parâmetro de interesse, $\tau^{A T T}$. 
Para demonstrar o ponto acima, note que o estimador do impacto por mínimos quadrados aplicado à equação acima, $\tau^{M Q O}$, identificará o seguinte termo:

$$
E\left(\tau^{M Q O}\right)=\tau^{A T E}+E\left(u_{i} \mid d_{i}=1\right)-E\left(u_{i} \mid d_{i}=0\right)
$$

Quando $E\left(u_{i} \mid d_{i}=1\right)=E\left(u_{i} \mid d_{i}=0\right)$, estimamos consistentemente o impacto médio do programa sobre toda a população ${ }^{13}$. No entanto, caso o impacto seja heterogêneo, na realidade, identificaremos a seguinte equação.

$$
\begin{gathered}
E\left(\tau^{M Q O}\right)=E\left(\tau^{A T E}\right)+E\left(\tau_{i}-\tau^{A T E} \mid d_{i}=1\right) \\
+E\left(u_{i} \mid d_{i}=1\right)-E\left(u_{i} \mid d_{i}=0\right)
\end{gathered}
$$

Como $\tau^{A T T}=E\left(\tau^{A T E}\right)+E\left(\tau_{i}-\tau^{A T E} \mid d_{i}=1\right)$, o parâmetro de interesse que estamos estimando por mínimos quadrados ordinários quando $E\left(d_{i}\left(\tau_{i}-\tau^{A T E}\right)\right)$ é diferente de zero é o impacto do programa sobre os tratados. Portanto, a hipótese necessária para que possamos estimar consistentemente o parâmetro $\tau^{A T T}$ por mínimos quadrados com dados em cross-section é:

$$
(\mathrm{CS} .1) \quad E\left(u_{i} \mid d_{i}=1\right)=E\left(u_{i} \mid d_{i}=0\right)
$$

Há dois pontos que podem invalidar a hipótese acima para o caso da presente dissertação. Em primeiro lugar, não possuimos uma variável que nos indica se o indivíduo é ou não elegível para o programa. Portanto, as famílias estão sendo selecionadas para o benefício com base num critério não-observado. Para amenizar tal problema, propomos a utilização de um grupo de controle constituído de indivíduos que receberam auxílio do programa um ano após o grupo de tratamento. Como o desenho do programa não se alterou substancialmente nesse período nem em termos do benefício, nem da condicionalidade, esperamos que grande parte das variáveis que determinam a entrada no programa não estejam relacionadas à nossa variável de interesse. Além disso, as famílias se autosselecionam para o programa com base numa gama de informações que não possuímos e que podem estar relacionadas conjuntamente com o tratamento e nossa variável de interesse. Para amenizar esta fonte, utilizamos diversos efeitos fixos e covariadas provindas do questionário sócio-econômico.

Além dos pontos levantados acima, se o impacto do programa for heterogêneo entre

\footnotetext{
${ }^{13} \mathrm{O}$ Average Treatment Effect
} 
o grupo de tratamento e parte deste grupo não possuir uma contrapartida no grupo de controle, então a estimativa estará viesada ((HECKMAN et al., 1998), (HECKMAN et al., 1997)). Isto ocorrerá pois a estrutura linear da estimação por mínimos quadrados estimará por extrapolação o impacto do programa para um determinado grupo tratado que não possui uma contrapartida no grupo de controle. Caso o efeito fosse homogêneo, esta extrapolação estaria correta. Outro fator problemático é que a amostra é selecionada e, em muitos casos, a proporção amostral de indivíduos tratados está acima de sua proporção na população. Neste caso, o efeito estimado também estará viesado, pois o peso de cada indivíduo na estimação amostral não estará proporcional ao peso correto daquele grupo na população.

A estimação utilizando o método de matching resolve o viés gerado pela falta de comparabilidade observável entre grupo de tratamento e de controle. O viés gerado por diferenças na distribuição de covariadas pode ser corrigido com uma reponderação das observações do grupo de controle como descrito em Heckman e Todd (2009). Na próxima seção, descrevemos o método de matching que visa eliminar essas duas fontes de viés.

Para finalizar esta subseção, apresentamos a equação estimada por mínimos quadrados cujos resultados são discutidos na seção de resultados dessa dissertação.

$$
y_{i e}=\alpha+\beta_{e}+\tau d_{i}+\gamma \mathbf{x}_{i}+e_{i e}
$$

Onde $y_{i e}$ é a variável de interesse, $\alpha$ o intercepto, $\beta_{e}$ o efeito fixo de escola, $\mathbf{x}_{i}$ é um vetor de covariadas e $e_{i e}$ é o termo de erro. Como controle, utilizamos diversas formulações semiparamétricas para covariadas como notas e ano e mês de nascimento (utilizamos dummies para o valor de cada uma delas). Este procedimento gera maior flexibilidade para a relação entre a variável de interesse e as covariadas. Utilizamos, além do efeito fixo de escola, efeitos fixos de séries, que não apresentamos acima para tornar a equação mais clara e evitar muitos índices.

\section{6..4 Matching}

A técnica de matching consiste em comparar a diferença da variável de interesse dos indivíduos tratados com o resultado de indivíduos semelhantes no grupo controle com relação a um conjunto de características observadas pelo avaliador. Para cada indivíduo no grupo de tratamento, selecionamos de acordo com alguma função indivíduos no grupo de controle para servir como contrafactual. Para que esse procedimento seja válido, é 
necessário que haja um conjunto de características $z_{i}$ que tornem o resultado do programa independente do tratamento.

$$
\text { (MAT.1) } \quad E\left(y_{i}^{0} \mid d_{i}=1, z_{i}\right)=E\left(y_{i}^{0} \mid d_{i}=0, z_{i}\right)
$$

Além disso, o estimador por matching requer a existência de indivíduos comparáveis no grupo de controle e de tratamento com um determinado vetor $\mathbf{z}_{i}$. Isto é resumido pela hipótese de que a probabilidade de um indivíduo não receber o tratamento para o dado vetor de características é sempre maior que zero. Ou seja, de que sempre há um indivíduo no grupo de controle para ser utilizado como comparação.

$$
\text { (MAT.2) } \operatorname{Pr}\left(d_{i}=0 \mid \mathbf{z}_{i}\right)>0
$$

Esta condição é usualmente chamada de hipótese de suporte comum. Não é possível inferir o impacto do tratamento para o grupo tratado que não possui contrapartida no grupo de controle, mas ainda é possivel estimar o impacto para aqueles que o têm. Basta retirar da amostra os indivíduos do grupo de tratamento que não possuem contrapartida no grupo de controle e estimar o impacto no grupo restante. Definiremos a região de suporte comum das covariadas $\mathbf{z}_{i}$ onde a probabilidade de haver um indivíduo de controle é sempre maior que zero como $S_{c}$.

Finalmente, utilizando as hipóteses (MAT.1) e (MAT.2), o parâmetro $\tau^{A T T}$ pode ser estimado pela seguinte equação:

$$
\hat{\tau}^{A T T}=\frac{1}{n_{1}} \sum_{i \in S_{c} \mid d_{i}=1}\left\{y_{i}^{1}-\sum_{j \in S_{c} \mid d_{i}=0} w(i, j) y_{j}^{0}\right\}
$$

Onde $w(i, j)$ é uma função que dá diferentes pesos para os indivíduos no grupo de controle de modo a gerar um valor esperado contrafactual do que teria acontecido com cada indivíduo tratado caso não tivesse recebido tratamento.

No nosso caso, utilizamos como função de matching a neireast neighbor. Esta função utiliza as observações do grupo de controle mais próximas de um indivíduo tratado em termos de distância num conjunto de covariadas. Neste caso, o econometrista se depara com duas questões. (i) Quantos indivíduos no grupo de controle serão utilizados para estimar o contrafactual? Note que, quanto mais indivíduos, maior o viés gerado pela distância que haverá entre as covariadas daquele tratado e o de controle, ao mesmo tempo que maior será a precisão do estimador, pois mais informação da base de dados será 
utilizada; (ii) Quais variáveis serão utilizadas como critério para estabelecer a distância entre dois indivíduos? A decisão de inclusão de variáveis dentro da função $w(i, j)$ pode ser tornar bastante complicada quando a quantidade de características disponíveis para o matching aumenta. Em primeiro lugar, por uma questão de arbitrariedade, a escolha dos pesos de cada variável na distância entre um indivíduo tratado e outro de controle pode afetar os resultados. Em segundo, diferentes pesos podem ser dados para cada variável considerada para a distância, e fórmulas de distância alternativas podem gerar resultados diferentes.

Para solucionar este problema de matching em diferentes características, Rosenbaum e Rubin (1983) demonstram que o pareamento baseado em covariadas $\mathbf{x}_{i t}$ é equivalente a um realizado em $p\left(d_{i}=1 \mid \mathbf{x}_{i t}\right)$, chamado de propensity score. A idéia é de que o matching com diversas covariadas, que tornaria o problema de distância um de $n$ dimensões dado pela número de características utilizadas como critério, pode ser resumido a um problema de distância em uma única dimensão. As hipóteses necessárias para identificação são semelhante com as que foram apresentadas, basta substituir $\mathbf{z}_{i}$ por $p\left(d_{i}=1 \mid \mathbf{x}_{i t}\right)$ em (MAT.1) e (MAT.2). Em outras palavras, é necessário supor que, dada uma região de suporte comum do propensity score, a diferença nas características não observáveis entre o grupo tratado e o de controle são aleatórias ao tratamento.

Pelo lado da estimação, o pareamento dos indivíduos pode ser feito em uma única dimensão, a do propensity score, ou o avaliador pode truncar o pareamento em algum critério que ache relevante como idade e gênero. De tal modo, as distâncias entre dois indivíduos seriam determinadas em mais de uma dimensão. No nosso caso, preferimos flexibiliar o processo de matching utilizando somente o pareamento na dimensão do propensity score.

\section{6..5 Diferença em diferenças}

A princípio, esperamos que muitas das características não observáveis que podem viesar a estimação do parâmetro de interesse sejam fixas ao longo do tempo como, por exemplo para o nosso caso, as condições sócio-econômicas do ambiente em que o indivíduo tratado vive e o conhecimento que as famílias possuem a respeito do interesse escolar do filho. Quando possuimos um painel e comparamos não a diferença da variável dependente entre dois grupos mas a diferença na variação entre dois períodos, controlamos pelas características observáveis e não observáveis fixas no tempo que podem estar correlacionadas simultaneamente com o tratamento e com a variável de interesse. Portanto, ao contrário dos métodos anteriores, em que precisavamos supor que todo o viés de seleção já estava 
controlado a partir do uso de variáveis observáveis que temos disponíveis em nossa base de dados, agora podemos adotar hipóteses mais fracas sobre o processo de seleção no programa. Para apresentar este argumento formalmente, considere a seguinte estrutura para o impacto do programa:

$$
y_{i t}=\alpha_{0}+\alpha_{1} d_{i}+\alpha_{2} T_{t}+\alpha_{i}+\tau_{i} d_{i} T_{t}+u_{i t}
$$

Onde $y_{i t}$ é a variável de interesse, $d_{i t}$ é um indicador igual a 1 quando o indivíduo recebe tratamento e 0 caso contrário, $T_{t}$ é um indicador igual a 1 caso o indivíduo esteja no segundo periodo e 0 caso esteja no período base e $u_{i t}$ as variáveis não observadas do indivíduo que podem afetar tanto a variável dependente quanto o tratamento. Neste modelo, $\tau_{i}$ é o impacto do programa sobre a variável de interesse $y_{i t}$ para cada indivíduo. Temos um efeito fixo de indivíduo dado por $\alpha_{i}$, outro de tempo dado por $\alpha_{2}$ e, por fim, um de grupo $\alpha_{1}$. Novamente, vamos abstrair de covariadas para tornar a apresentação mais clara. O estimador de diferença em diferenças pode ser obtido através da solução de mínimos quadrados ordinários de $\tau$ na seguinte equação:

$$
y_{i 1}-y_{i 0}=\tau_{i} d_{i}+u_{i 1}-u_{i 0}
$$

Note que tal especificação, numa estrutura de painel, controla por variáveis não observadas do indivíduo que são fixas no tempo, por características específicas do período (por exemplo, mudanças no sistema de avaliação ou do questionário sócio-econômico) e, por fim, por características fixas no tempo do grupo de tratamento ou de controle. O estimador de mínimos quadrados aplicado à equação acima fornece o nosso parâmetro de interesse:

$$
\begin{gathered}
E\left(y_{i 1}-y_{i 0} \mid d_{i}=1\right)-E\left(y_{i 1}-y_{i 0} \mid d_{i}=0\right)=E\left(\tau_{i} \mid d_{i}=1\right) \\
+E\left(u_{i 1}-u_{i 0} \mid d_{i}=1\right)-E\left(u_{i 1}-u_{i 0} \mid d_{i}=0\right)
\end{gathered}
$$

Para que o parâmetro $\tau$ possa ser interpretado como um impacto causal da política sobre a variável dependente na estrutura acima, é necessário adotar a seguinte hipótese.

$$
\text { (DID.1) } \quad E\left(u_{i 1}-u_{i 0} \mid d_{i}=1\right)=E\left(u_{i 1}-u_{i 0} \mid d_{i}=0\right)
$$

Utilizando (DID.1) sobre a estrutura (4.4), a tendência temporal do grupo de controle se torna um contrafactual válido para a do grupo tratado. Não é possível testar 
diretamente tal hipótese, porém, Heckman e Hotz (1989) propõem um teste da tendência no período pré-tratamento entre os dois grupos. Caso ela seja igual, é mais provável que ela também fosse a mesma no período pós-tratamento caso o grupo tratado não tivesse recebido o programa. Posteriormente neste estudo, prosseguimos com tal análise.

Para a estimação do impacto por diferença em diferenças, vamos adotar uma estrutura linear, separável e aditiva para as covariadas $\mathbf{x}_{i}$ do seguinte modo.

$$
y_{i t e}=\alpha+\beta_{e}+\alpha_{i}+\gamma \mathbf{x}_{i}+\tau_{i} d_{i} T_{t}+\phi \mathbf{x}_{i} T_{t}+\delta_{e} T_{t}+u_{i t e}
$$

Onde $y_{i t e}$ é a variável de interesse, $\beta_{e}$ é o efeito fixo da escola, $\alpha_{i}$ o efeito fixo do indivíduo e $u_{i t e}$ o termo de erro. A estimação será feita sobre a primeira diferença. Note que utilizamos apenas covariadas no período base. Procedemos de tal modo, pois queremos evitar inserir variáveis que sejam, elas mesmas, afetadas pelo tratamento. No entanto, controlamos por possíveis tendências que elas possam carregar do período base para o seguinte. Finalmente, estimaremos a seguinte equação por mínimos quadrados ordinários.

$$
y_{i 1 e}-y_{i 0 e}=\tau_{i} d_{i}+\phi \mathbf{x}_{i}+\delta_{e}+u_{i 1 e}-u_{i 0 e}
$$

Novamente, como no caso da estimação por cross-section, apresentamos aqui somente a equação com efeito fixo de escola, para dar mais clareza ao argumento. Utilizaremos, entretanto, diversos outros efeitos fixos para a estimação.

\section{6..6 Diferença em diferenças com matching}

Nesta seção, apresentamos as hipóteses necessárias para identificar o parâmetro de interesse $\tau^{A T T}\left(\mathbf{x}_{i}\right)$ utilizando o método de matching sobre a estrutura de diferença em diferenças (HECKMAN et al., 1997). A idéia deste método é contruir, como no caso anterio de matching, um grupo de controle que seja similar ao grupo de tratamento em termos de um vetor de características $\mathbf{x}_{i t}$. No entanto, adicionamos aqui o fato de que controlamos por variáveis não-observáveis fixas no tempo que possam estar correlacionadas conjuntamente com o tratamento e com a variável de interesse. Para apresentar formalmente o estimador de matching com diferença em diferenças, considere que o resultado quando o indivíduo é tratado ou não como uma função separável de um vetor de características individuais observadas $\mathbf{x}_{i}$ e outro de características não-observadas pelo econometrista $u_{i t}$. 


$$
\begin{aligned}
& y_{i t}^{1}=g_{1}\left(\mathbf{x}_{i}\right)+u_{i t}^{1} \\
& y_{i t}^{0}=g_{0}\left(\mathbf{x}_{i}\right)+u_{i t}^{0}
\end{aligned}
$$

$y_{i t}$ é a variável de interesse, $t$ é um indexador do período. Dentro dessa estrutura, o parâmetro de interesse adota o seguinte formato:

$$
\tau^{A T T}\left(\mathbf{x}_{i t}\right)=E\left(g_{1}\left(\mathbf{x}_{i t}\right)-g_{0}\left(\mathbf{x}_{i t}\right) \mid d_{i}=1, \mathbf{x}_{i t}\right)
$$

Note, primeiramente, que a estimação de diferença em diferenças com o uso de matching não impõe uma estrutura linear para o efeito do tratamento. Análogo ao caso do matching em cross-section, para estimar adequadamente $\tau^{A T T}\left(\mathbf{x}_{i t}\right)$, necessito de um conjunto de variáveis observadas $\mathbf{z}_{i}$ determinando a autosseleção do indivíduo no programa que gere a seguinte condição:

$$
\text { (DIDM.1) } \quad E\left(u_{i 1}^{1}-u_{i 0}^{0} \mid d_{i}=1, \mathbf{z}_{i}\right)=E\left(u_{i 1}^{1}-u_{i 0}^{0} \mid d_{i}=0, \mathbf{z}_{i}\right)
$$

Além disso, o estimador por matching requer, como anterioremente, uma hipótese de suporte comum, que é resumida pela seguinte desigualdade.

$$
\text { (DIDM.2) } \operatorname{Pr}\left(d_{i}=0 \mid \mathbf{z}_{i}\right)>0
$$

Finalmente, utilizando as hipóteses (DIDM.1) e (DIDM.2), o parâmetro $\tau^{A T T}\left(\mathbf{x}_{i t}\right)$ pode ser estimado pela seguinte equação:

$$
\hat{\tau}=\frac{1}{n_{1}} \sum_{i \in S_{c} \mid d_{i}=1}\left\{\left(y_{1 i}^{1}-y_{0 i}^{1}\right)-\sum_{j \in S_{c} \mid d_{i}=0} w(i, j)\left(y_{1 j}^{0}-y_{0 j}^{0}\right)\right\}
$$

\section{Impactos do Programa Bolsa Família}

\section{7..1 Os grupos de tratamento e os de controle}

Nossos dados estão organizados por ano, porém temos informações mensais sobre a inclusão das famílias no PBF. Para gerar grupos de controle e tratamento, exploramos tal variação mensal. Selecionamos como grupo de controle os indivíduos que são incluídos no programa apenas alguns meses após o grupo de tratamento. Como nem o critério de 
elegibilidade ${ }^{14}$ nem as condicionalidades do programa se alteraram significativamente no período analisado para o grupo de alunos considerados (de 7 a 14 anos), esperamos que grande parte das diferenças entre o grupo de controle e o de tratamento se dê por questões aleatórias ao benefício.

Em primeiro lugar, geramos grupos de controle e tratamento para analisar o impacto sobre o abandono escolar. Para este exercício, não procedemos com uma análise de diferença em diferenças, mas somente com uma de cross-section. Note que esta variável de interesse possui, por natureza, um aspecto estático. Pois, uma vez que o aluno abandonou o sistema de matrícula, não possuímos mais a variação em seu comportamento em períodos posteriores. Como possuímos informações para os anos de 2007, 2008 e 2009, dividimos a nossa investigação em dois biênios. Para o de 2008 e 2007, selecionamos como grupo tratado os alunos que foram incluídos no programa a partir de outubro de 2007 até o começo das aulas em março de 2008. Definimos o tratamento de tal modo para incorporar na análise o fato de que a matrícula nas escolas públicas estaduais é realizada, geralmente, no período de novembro com alguns casos remanescentes no começo do ano seguinte. Com tal definição de tratamento, estamos avaliando o impacto de entrar no programa PBF sobre o abandono escolar. Porém, como apresentamos em seções anteriores, a maior parte dos alunos permanece no programa uma vez que foram incluídos ${ }^{15}$. Já para o grupo de controle, utilizamos duas definições diferentes. Primeiramente, comparamos todos os alunos que receberam tratamento com aqueles que não o receberam e que não fazem parte do programa. Em seguida, utilizamos nossa definição de grupo de tratamento atrasando todos os valores para um ano depois ${ }^{16}$. Ou seja, comparamos os tratados com aqueles indivíduos que seriam tratados um ano depois, no biênio de 2009-2008. Note que, de tal modo, o segundo grupo de controle é uma versão restrita do grupo de controle mais geral: impomos sobre o primeiro grupo a restrição de que os indivíduos deveriam ser beneficiados um ano após o grupo de tratamento. Para o biênio de 2009-2008, procedemos com definições análogas às apresentadas para o biênio anterior atrasando as definições para o ano seguinte.

Nas análises seguintes sobre as variáveis de desempenho escolar disponíveis no boletim

\footnotetext{
${ }^{14}$ Alguns ajustes nos valores dos benefícios e no critério de elegibilidade foram feitos para acompanhar a inflação.

${ }^{15}$ Poderíamos, por exemplo, forçar que o aluno permanecesse no programa em períodos posteriores. Entretanto, para este período crítico de entrada no programa, estaríamos abrindo mão de uma parcela considerável da amostra e isto aumentaria a imprecisão de nossa estimação.

${ }^{16}$ Utilizamos a janela de uma ano para evitar que o grupo de controle antecipe o efeito do programa. Em nossa base, sabemos se as famílias estão cadastradas no programa e se a transferência foi liberada ou não. De tal modo, evitamos famílias que estejam cadastradas e esperando para receber auxílio do programa.
} 
do aluno, utilizamos a estimação por diferença em diferenças. Para tais variáveis, possuímos variações longitudinais. Começamos verificando o impacto do programa no biênio 2008-2007. Neste caso, definimos o grupo de tratamento como os indivíduos incluídos no programa no primeiro semestre de 2008. O grupo de controle foi definido como os alunos que foram incluídos no programa no primeiro semestre de 2009. Em seguida, procedemos do mesmo modo com o biênio de 2009-2008.

Num terceiro conjunto de resultados, exploramos o impacto do programa sobre o desempenho dos alunos num exame padronizado. Note que, da forma como é aplicada a prova do Saresp, um mesmo aluno não a realiza em dois anos seguidos com exceção daqueles na $1^{\mathrm{a}}$ série do ensino fundamental. Portanto, para acompanhar um aluno ao longo do tempo, foi necessário utilizar bases da prova do Saresp com dois anos de intervalo: 2007 e 2009. De tal modo, sabemos, por exemplo, a evolução de um aluno que prestou o SARESP na $4^{\mathrm{a}}$ série em 2007 e, em 2009, na $6^{\mathrm{a}}$. Neste caso, geramos o grupo de tratamento do seguinte modo: selecionamos os indivíduos que foram incluídos no programa em 2008. Para o controle, escolhemos aqueles que foram incluídos no programa somente no ano de 2010.

Como foi colocado na seção de implicações teóricas, um dos elementos que explica o desempenho de um aluno numa turma é o desempenho de seus colegas de classe. Se considerarmos que há um impacto sobre o aluno tratado que tem externalidade sobre o grupo de controle, a estratégia de identificação apresentada até o momento estaria comprometida por um viés de atenuação. Portanto, exploramos alguns resultados utilizando os grupos de controle acima impondo a seguinte restrição: utilizamos somente os alunos que estavam em salas de aula onde nenhum outro aluno foi tratado. Além disso, no lugar do efeito fixo de escola, controlamos pelas médias por escola de todas as variáveis sócio-econômicas e de desempenho disponíveis na base de dados do Saresp. De tal modo, procuramos isolar o grupo de controle de um potencial efeito indireto do tratamento.

Na tabela (2), resumo a seleção de grupos de tratamento e de controle. Na tabela (26) e (27) do apêndice, apresento as diferenças entre o grupo de tratamento e o de controle em suas covariadas. Para os grupos de controle da análise em cross-section no biênio de 2008-2007, o grupo de controle restrito possui a maior parte de suas covariadas balanceadas com relação ao grupo de tratamento. Isto ocorre, principalmente, sobre as variáveis de interesse educacionais, o que reforça a validade do grupo de controle para a nossa análise. Para o biênio de 2009-2008, entretanto, não obtemos balanceamento nas variáveis educacionais. O grupo de tratamento possui um desempenho escolar pior que 
o grupo de controle restrito. Se considerarmos que isto gera um viés de seleção positivo sobre a probabilidade de um aluno abandonar a escola, sabemos que o impacto estimado será subestimado com relação ao seu verdadeiro valor. De qualquer modo, procedemos com regressões utilizando os métodos apresentados anteriormente para amenizar tal viés e estimamos o impacto utilizando técnicas de matching.

Para cada par de grupo de controle e tratamento, consideramos um propensity score diferente. Estimamos o propensity score por logit incluindo para todos os casos como variáveis explicativas características demográficas, sócio-econômicas e de ambiente familiar. Utilizamos, também, como controle nas análises de diferença em diferenças a média dos alunos no exame do SARESP para o ano base. Evitamos utilizar tais variáveis para as análises de abandono que são feitas em cross-section pois elas poderiam ter sido elas mesmas afetadas pelo tratamento, o que violaria as condições para o uso do propensity score. Além disso, incluímos variáveis interadas e ao quadrado de acordo com o que a teoria indicaria ${ }^{17}$. Testamos diferentes especificações de propensity score e escolhemos a que trouxe melhor resultado nos seguintes critérios: (i) porcentagem de acerto utilizando a técnica "hit or miss"18; (ii) balanceamento das covariadas de acordo com quintils e decils do propensity score.

Como a amostra é selecionada, a proporção da população tratada não é equivalente com a proporção amostral utilizada, para corrigir por tal problema, utilizamos o log da razão dos propensity score ${ }^{19}$. Analisando a distribuição do logarítmo da razão dos propensity scores entre os grupos de controle e de tratamento, notamos que, em alguns casos, há um potencial problema de região de suporte comum. Portanto, excluímos as observações nos extremos dos valores do propensity score original do seguinte modo: extraímos da amostra as observações abaixo do maior valor do propensity score na metade do primeiro percentil do grupo tratado e as observações acima do menor valor da metade do último percentil do grupo de controle ${ }^{20}$.

\footnotetext{
${ }^{17}$ Idade ao quadrado e interação entre idade e gênero

${ }^{18}$ Tal técnica é realizada do seguinte modo. Para cada observação com propensity score acima da média dos propensity scores (ou seja, $\hat{p}>\bar{p}$ ), atribuo o valor de um. Em seguida, verifico a porcentagem de acerto amostral obtido.

${ }^{19}$ Isto é, utilizamos $\hat{q}\left(\mathbf{x}_{i}\right)=\log \hat{p}\left(\mathbf{x}_{i}\right) /\left(1-\hat{p}\left(\mathbf{x}_{i}\right)\right)$.

${ }^{20}$ Técnica semelhante foi utilizada em Galiani et al. (2005)
} 
Tabela 2: Grupos de tratamento e de controle

\begin{tabular}{ll}
\hline \hline $\begin{array}{l}\text { Tratamento } \\
\text { Controle } 1\end{array}$ & $\begin{array}{l}\text { Abandono (biênio 2008-2007) } \\
\text { Todos que não são tratamento em toda a rede pública de ensino } \\
\text { e que não participaram do programa em 2007 } \\
\text { Foi incluído no PBF de outubro de 2008 a março de 2009 }\end{array}$ \\
\hline $\begin{array}{l}\text { Controle 2 } \\
\text { Tratamento }\end{array}$ & $\begin{array}{l}\text { Foletim (biênio 2008-2007) } \\
\text { Controle }\end{array}$ \\
$\begin{array}{ll}\text { Foi incluído no PBF no primeiro semestre de } 2008 \\
\text { Tratamento PBF no primeiro semestre de } 2009 \\
\text { Controle }\end{array}$ & $\begin{array}{l}\text { Foi incluído no PBF no ano de 2008 } \\
\text { Foi incluído no PBF no ano de 2010 }\end{array}$ \\
\hline
\end{tabular}

\section{7..2 Impacto sobre o abandono escolar}

A primeira exigência do PBF é que as famílias beneficiadas matriculem seus filhos na escola. Após a matrícula, a transferência pode ser cancelada caso o aluno não frequente a pelo menos $85 \%$ das aulas. Neste primeiro momente, analisamos o impacto do PBF sobre o abandono escolar para, nas próximas subseções, reportar os exercícios utilizando a frequência e o desempenho escolar dos beneficiários. Definimos abandono como a probabilidade de um aluno em 2007 não estar matriculado no sistema de ensino em 2008. Em adição, extendemos a mesma análise para o biênio de 2009 e 2008. Como não é possível acompanhar a evolução do aluno ao longo do tempo, utilizamos somente uma comparação em dados cross-section. Em primeiro lugar, apresentamos os impactos básicos do programa utilizando diferentes efeitos fixos e amostras de grupo de controle. Em seguida, procedemos com uma estimação por matching e, por fim, reportamos os exercícios de heterogeneidade do impacto do PBF.

\section{7..2.1 Impactos básicos}

Nossa estimação do impacto com dados em cross-section é a que mais sofre de um potencial viés de seleção, pois, diferente do caso de diferença em diferenças, não somos capazes de controlar por variáveis não-observáveis que sejam constantes ao longo do tempo. Para gerar grupos de controle que sejam comparáveis ao de tratamento, utilizamos três amostras e duas definições de grupo de controle. Primeiramente, exploramos os resultados de acordo com o grupo de controle completo afunilando o sistema de educação de acordo com o conjunto de informações que possuímos para cada indivíduo. Os resultados estão reportados nas tabelas (3) e (4). Apresentamos os exercícios empíricos gradativamente 
inserindo diferentes efeitos fixos e controles para que isso possa nos dar uma indicação da direção do viés de seleção. Para obter uma intuição do rigor de nossa análise estatística, na última especificação, comparamos alunos tratados e no controle dentro de uma mesma escola e de uma mesma série controlando pelo efeito da idade e do mês de nascimento, pelo gênero, pelas notas e frequência em português e matemática no final do ano, pela educação dos pais e pelas variáveis sócio-econômicas incluídas no questionário do Saresp.

Em primeiro lugar, identificamos uma baixa proporção de abandono escolar. No grupo de controle irrestrito do sistema público completo, a proporção é de 4,9\%. Restringindo a amostra para os alunos no sistema público estadual e aqueles com informações sócio-econômicas do Saresp, a proporção é de 2,9\% e 2,3\% respectivamente. Em geral, analisando a amostra completa no biênio de 2008-2007 descritos na tabela (3), todos os coeficientes foram negativos. Isto ocorre mesmo com o grupo de tratamento possuindo renda menor e pior desempenho na escola, o que sugere um viés positivo sobre o estimador. Quando analisamos a primeira coluna, onde possuimos todo o sistema público de ensino, o impacto do programa se mantém no intervalo de -1,8 e -2,2 pontos percentuais. Quando controlamos por efeito fixo de escola, o impacto do programa cai de $-2,2$ para -1,4. Isto sinaliza para o fato de que os alunos tratados estão concentrados em escolas com média de abandono menor. Seguindo para a segunda coluna, que representa o conjunto de alunos das escolas estaduais, a magnitude do impacto em pontos percentuais decai e fica no intervalo de -1,1 e -1,3. No entanto, a média do grupo de controle sobre a qual estamos comparando o grupo de tratamento também é reduzida. De tal modo, tais quedas representam, na base de 2,94\% de abandono, um impacto de 37 e 44\%, respectivamente, na probabilidade de um aluno tratado abandonar a escola. Por fim, na úlima coluna, selecionamos os alunos para os quais possuimos informações sobre o questionário sócioeconômico do Saresp. Novamente, a magnitude do impacto diminui junto com a redução no abandono do grupo de controle. O coeficiente não se altera substancialmente entre o primeiro e o último exercício da mesma coluna e se mantém no intervalo de 1 a 0,9 pontos percentuais. É interessante notar que, ao controlarmos pelas variáveis sócio-econômicas do Saresp, o impacto se alterou em 0,03 pontos percentuais, o que sugere que a maior parte das variáveis não-observáveis que poderiam estar viesando a estimação do parâmetro já estão controladas no penúltimo exercício.

Num segundo conjunto de resultados, ainda na tabela (3), apresentamos os resultados utilizando o grupo de controle restrito. Todos os coeficientes permaneceram negativos e estatisticamente significantes a $10 \%$ de significância. O padrão foi bastante semelhante com o obtido com o grupo de controle anterior: a magnitude do impacto diminui quando 
nos deslocamos para colunas da direita, porém, a taxa de abandono base do grupo de controle também se torna menor. O coeficiente na última coluna da direita se manteve entre 0,35 e 0,42 pontos percentuais. Novamente, o coeficiente não se alterou substancialmente quando controlamos a regressão por variáveis sócio-econômicas. A mudança foi de, somente, 0,06 pontos percentuais. Portanto, sobre a base de 1,72 com a especificação mais rigorosa, encontramos um impacto negativo de 19 a $23 \%$ sobre a taxa de abandono do grupo de tratamento.

Para o biênio de 2009-2008, os resultados estão apresentados na tabela (4). Para o grupo de controle completo, o padrão foi bastante semelhante com o encontrado para o biênio anterior. A magnitude do impacto diminui quando nos deslocamos para colunas da direita e o efeito fixo de escola gera uma queda no coeficiente ao passo que controles, em geral, aumentam a seu impacto. Na última coluna, a magnitude do coeficiente oscila entre 0,36 e 0,61 o que representa, respectivamente, um impacto negativo de 11 e $19 \%$ sobre a probabilidade de um aluno que recebeu tratamento abandonar a escola. Quando analisamos o impacto utilizando o grupo de controle restrito, os coeficientes foram, em geral, positivos e estatisticamente significante nas duas primeiras colunas. Mesmo utilizando todos os controles e efeitos fixos, o efeito encontrado foi positivo. Em nossa interpretação, isso decorre do fato do grupo de controle não ser válido. Ele é diferente em diversas características sócio-econômicas e, principalmente, nas características educacionais. O grupo de controle gerado para o biênio de 2008-2007, por outro lado, apresentou balanceamento na maior parte das covariadas sócio-econômicas e todas as variáveis educacionais. Esse exercício realça a importância de se definir adequadamente os grupos de controle. Após a escolha de um grupo de controle válido, as covariadas e efeitos fixos alteraram marginalmente o efeito que seria obtido inicialmente a partir de uma comparação direta de médias.

\section{7..2.2 Robustez dos resultados}

\section{Técnicas de matching}

Nesta subseção, apresentamos os resultados utilizando a técnica de matching para estimar o impacto do programa. Esperamos que, caso a estimação por mínimos quadrados ordinários esteja inferindo corretamente o impacto do programa, a utilização de um método alternativo mais preciso não deveria gerar resultados substancialmente diferentes. Na tabela (5), apresentamos os resultados obtidos a partir da estimação por matching. Além disso, estimamos o impacto do programa por mínimos quadrados ordinários utilizando a especificação mais completa da seção anterior impondo o suporte comum definido 
Tabela 3: Impacto do PBF sobre o abandono escolar no biênio 2008-2007 (em pontos percentuais).

\begin{tabular}{|c|c|c|c|}
\hline \multicolumn{4}{|c|}{ Grupo de controle completo } \\
\hline & $\begin{array}{l}\text { Todo sistema } \\
\text { público }\end{array}$ & $\begin{array}{l}\text { Sistema público } \\
\text { estadual }\end{array}$ & $\begin{array}{c}\text { Sistema público } \\
\text { estadual } \\
\text { c/ sócio-econômico }\end{array}$ \\
\hline $\begin{array}{l}\text { Média do grupo } \\
\text { de controle }\end{array}$ & $\begin{array}{c}4,944 \\
(0,012)\end{array}$ & $\begin{array}{c}2,942 \\
(0,013)\end{array}$ & $\begin{array}{c}2,398 \\
(0,020)\end{array}$ \\
\hline & & Impacto & \\
\hline Base & $\begin{array}{c}-2,243^{* * *} \\
(0,106)\end{array}$ & $\begin{array}{c}-1,133^{* * *} \\
(0,081)\end{array}$ & $\begin{array}{c}-1,048^{* * *} \\
(0,110)\end{array}$ \\
\hline + Efeito fixo de escola & $\begin{array}{c}-1,497^{* * *} \\
(0,066)\end{array}$ & $\begin{array}{c}-0,924^{* * *} \\
(0,080)\end{array}$ & $\begin{array}{c}-0,750^{* * *} \\
(0,010)\end{array}$ \\
\hline + Efeito fixo de série & $\begin{array}{c}-1,515^{* * *} \\
(0,065)\end{array}$ & $\begin{array}{c}-0,922^{* * *} \\
(0,080)\end{array}$ & $\begin{array}{c}-0,705^{* * *} \\
(0,111)\end{array}$ \\
\hline $\begin{array}{c}\text { + Ano e mês de nascimento } \\
\text { e dummy de gênero }\end{array}$ & $\begin{array}{c}-1,838^{* * *} \\
(0,065)\end{array}$ & $\begin{array}{c}-1,141^{* * *} \\
(0,080)\end{array}$ & $\begin{array}{c}-0,818^{* * *} \\
(0,111)\end{array}$ \\
\hline + Frequência em 2007 e notas & - & $\begin{array}{c}-1,324^{* * *} \\
(0,079)\end{array}$ & $\begin{array}{c}-0,883^{* * *} \\
(0,111)\end{array}$ \\
\hline + Variáveis sócio-econômicas & - & - & $\begin{array}{c}-0,917^{* * *} \\
(0,112)\end{array}$ \\
\hline Observações & 2896821 & 1592525 & 560026 \\
\hline \multicolumn{4}{|c|}{ Grupo de controle restrito } \\
\hline & $\begin{array}{l}\text { Todo sistema } \\
\text { público }\end{array}$ & $\begin{array}{l}\text { Sistema público } \\
\text { estadual }\end{array}$ & $\begin{array}{c}\text { Sistema público } \\
\text { estadual } \\
\text { c/ sócio-econômico }\end{array}$ \\
\hline $\begin{array}{l}\text { Média do grupo } \\
\text { de controle }\end{array}$ & $\begin{array}{c}3,230 \\
(0,071)\end{array}$ & $\begin{array}{c}2,202 \\
(0,086)\end{array}$ & $\begin{array}{c}1,781 \\
(0,138)\end{array}$ \\
\hline & & Impacto & \\
\hline Base & $\begin{array}{c}-0,532^{* * *} \\
(0,112)\end{array}$ & $\begin{array}{c}-0,402^{* * *} \\
(0,123)\end{array}$ & $\begin{array}{c}-0,424^{* *} \\
(0,173)\end{array}$ \\
\hline + Efeito fixo de escola & $\begin{array}{c}-0,319^{* * *} \\
(0,107)\end{array}$ & $\begin{array}{c}-0,367^{* *} \\
(0,144)\end{array}$ & $\begin{array}{l}-0,356 \\
(0,228)\end{array}$ \\
\hline+ Efeito fixo de série & $\begin{array}{c}-0,319^{* * *} \\
(0,107)\end{array}$ & $\begin{array}{c}-0,367^{* * *} \\
(0,144)\end{array}$ & $\begin{array}{l}-0,368 \\
(0,228)\end{array}$ \\
\hline $\begin{array}{c}\text { + Ano e mês de nascimento } \\
\text { e dummy de gênero }\end{array}$ & $\begin{array}{c}-0,368^{* * *} \\
(0,106)\end{array}$ & $\begin{array}{c}-0,386^{* * *} \\
(0,142)\end{array}$ & $\begin{array}{l}-0,395^{*} \\
(0,229)\end{array}$ \\
\hline + Frequência em 2007 e notas & - & $\begin{array}{c}-0,393^{* * *} \\
(0,142)\end{array}$ & $\begin{array}{l}-0,409^{*} \\
(0,227)\end{array}$ \\
\hline + Variáveis sócio-econômicas & - & - & $\begin{array}{c}-0,403^{*} \\
(0,227)\end{array}$ \\
\hline Observações & 141297 & 65498 & 21337 \\
\hline
\end{tabular}

(1) *significante à $10 \%,{ }^{* *}$ significante à $5 \%,{ }^{* * *}$ significante à $1 \%$; (2) Erro padrão ajustado pelo cluster no nível da escola em parênteses; (3) Utilizo apenas os alunos de 7 a 14 anos; (4) Estimações por mínimos quadrados ordinários. 
Tabela 4: Impacto do PBF sobre o abandono escolar no biênio 2009-2008 (em pontos percentuais).

\begin{tabular}{|c|c|c|c|}
\hline \multicolumn{4}{|c|}{ Grupo de controle completo } \\
\hline & $\begin{array}{l}\text { Todo sistema } \\
\text { público }\end{array}$ & $\begin{array}{c}\text { Sistema público } \\
\text { estadual }\end{array}$ & $\begin{array}{c}\text { Sistema público } \\
\text { estadual } \\
\text { c/ sócio-econômico }\end{array}$ \\
\hline $\begin{array}{l}\text { Média do grupo } \\
\text { de controle }\end{array}$ & $\begin{array}{c}6,618 \\
(0,015)\end{array}$ & $\begin{array}{c}3,465 \\
(0,015)\end{array}$ & $\begin{array}{c}3,268 \\
(0,022)\end{array}$ \\
\hline \multicolumn{4}{|c|}{ Impacto } \\
\hline Base & $\begin{array}{c}-1,549^{* * *} \\
(0,198)\end{array}$ & $\begin{array}{c}-0,305^{* *} \\
(0,148)\end{array}$ & $\begin{array}{c}-0,619^{* * *} \\
(0,204)\end{array}$ \\
\hline + Efeito fixo de escola & $\begin{array}{c}-0,559 * * * \\
(0,098)\end{array}$ & $\begin{array}{c}-0,209^{*} \\
(0,116)\end{array}$ & $\begin{array}{c}-0,511^{* * *} \\
(0,159)\end{array}$ \\
\hline + Efeito fixo de série & $\begin{array}{c}-0,577^{* * *} \\
(0,098)\end{array}$ & $\begin{array}{l}-0,194^{*} \\
(0,115)\end{array}$ & $\begin{array}{c}-0,440 * * * \\
(0,158)\end{array}$ \\
\hline $\begin{array}{c}\text { + Ano e mês de nascimento } \\
\text { e dummy de gênero }\end{array}$ & $\begin{array}{c}-0,855^{* * *} \\
(0,097)\end{array}$ & $\begin{array}{c}-0,370^{* * *} \\
(0,115)\end{array}$ & $\begin{array}{c}-0,516^{* * *} \\
(0,158)\end{array}$ \\
\hline + Frequência em 2008 e notas & - & $\begin{array}{c}-0,511^{* * *} \\
(0,113)\end{array}$ & $\begin{array}{c}-0,516^{* * *} \\
(0,069)\end{array}$ \\
\hline + Variáveis sócio-econômicas & - & - & $\begin{array}{c}-0,363^{* *} \\
(0,158)\end{array}$ \\
\hline Observações & 2526424 & 1506900 & 630321 \\
\hline \multicolumn{4}{|c|}{ Grupo de controle restrito } \\
\hline & $\begin{array}{l}\text { Todo sistema } \\
\text { público }\end{array}$ & $\begin{array}{c}\text { Sistema público } \\
\text { estadual }\end{array}$ & $\begin{array}{c}\text { Sistema público } \\
\text { estadual } \\
\text { c/ sócio-econômico }\end{array}$ \\
\hline $\begin{array}{l}\text { Média do grupo } \\
\text { de controle }\end{array}$ & $\begin{array}{c}4,733 \\
(0,073)\end{array}$ & $\begin{array}{c}2,638 \\
(0,075)\end{array}$ & $\begin{array}{c}2,378 \\
(0,112)\end{array}$ \\
\hline & & Impacto & \\
\hline Base & $\begin{array}{c}-0,334^{*} \\
(0,185)\end{array}$ & $\begin{array}{c}0,520^{* * *} \\
(0,149)\end{array}$ & $\begin{array}{c}0,270 \\
(0,212)\end{array}$ \\
\hline+ Efeito fixo de escola & $\begin{array}{c}0,789^{* * *} \\
(0,139)\end{array}$ & $\begin{array}{c}0,621^{* * *} \\
(0,166)\end{array}$ & $\begin{array}{c}0,327 \\
(0,254)\end{array}$ \\
\hline+ Efeito fixo de série & $\begin{array}{l}0,209^{* *} \\
(0,087)\end{array}$ & $\begin{array}{c}0,620^{* * *} \\
(0,166)\end{array}$ & $\begin{array}{c}0,326 \\
(0,254)\end{array}$ \\
\hline $\begin{array}{c}\text { + Ano e mês de nascimento } \\
\text { e dummy de gênero }\end{array}$ & $\begin{array}{c}0,684^{* * *} \\
(0,138)\end{array}$ & $\begin{array}{c}0,550^{* * *} \\
(0,165)\end{array}$ & $\begin{array}{c}0,301 \\
(0,252)\end{array}$ \\
\hline + Frequência em 2008 e notas & - & $\begin{array}{c}0,441^{* * *} \\
(0,164)\end{array}$ & $\begin{array}{c}0,267 \\
(0,253)\end{array}$ \\
\hline + Variáveis sócio-econômicas & - & - & $\begin{array}{c}0,272 \\
(0,252)\end{array}$ \\
\hline Observações & 136664 & 71471 & 28476 \\
\hline
\end{tabular}

(1) *significante à $10 \%,{ }^{* *}$ significante à $5 \%,{ }^{* * *}$ significante à $1 \%$; (2) Erro padrão ajustado pelo cluster no nível da escola em parênteses; (3) Utilizo apenas os alunos de 7 a 14 anos; (4) Estimações por mínimos quadrados ordinários. 
Tabela 5: Impacto sobre abandono impondo suporte comum e estimando por mínimos quadrados ordinários e matching

\begin{tabular}{lcc}
\hline \hline & MQO & Matching \\
\cline { 2 - 3 } Biênio 2008-2007 & $\begin{array}{c}-0,329 \\
(0,227)\end{array}$ & $-0,313^{*}$ \\
Observações & \multicolumn{2}{c}{21486} \\
\cline { 2 - 3 } Biênio 2009-2008 & 0,288 & $0,363^{*}$ \\
Observações & $(0,251)$ & $(0,216)$ \\
\hline
\end{tabular}

(1) *significante à $10 \%,{ }^{* *}$ significante à $5 \%,{ }^{* * *}$ significante à $1 \%$; (2) São utilizados 4 vizinhos para o matching; (3) Utilizo apenas os alunos de 7 a 14 anos em 2007 ou 7 a 14 anos; (4) A estimação por cross-section inclui efeitos fixos de escola e série, covariadas de ano e mês de nascimento, dummy de gênero e notas e frequência do aluno.

pelo propensity score (para que a diferença obtida no impacto não seja consequência de uma diferença na composição da amostra).

Como podemos ver, o resultado não se alterou com relação ao obtido pelo procedimento de mínimos quadrados ordinários. Para o biênio de 2008-2007, o coeficiente obtido foi de -0,329. Porém, ele não é significante estatisticamente a 10\% de confiança. Quando utilizamos a estimação por matching, o coeficiente se alterou marginalmente para -0,313 pontos percentuais e se tornou estatisticamente significante a 10\%. Em termos estatísticos, tais coeficientes são iguais, pois o intervalo de confiança de cada um deles possui uma região de intersecção. No caso do biênio de 2009-2008, o coeficiente permaneceu positivo, como o obtido na seção anterior.

Resumidamente, os resultados obtidos na seção anterior continuaram válidos quando estimamos o impacto do programa com outras técnicas. Quando encontramos um efeito estimado negativo por mínimos quadrados ordinários no biênio de 2008-2007, ele permaneceu negativo e se alterou marginalmente em magnitude. Quando ele era positivo no biênio de 2009-2008, o efeito se manteve positivo com a utilização de matching. Isto sugere que a maior parte das diferenças observáveis entre o grupo de controle e tratamento já estavam sendo incorporados anteriormente quando estimamos o impacto do programa com um grupo de controle restrito.

\section{Amenizando externalidades}

Um fator que pode invalidar as estimações realizadas anteriormente é a possibilidade do tratamento gerar efeitos de externalidade sobre o grupo de controle. Neste caso, subestimamos o impacto do programa. Para testar tal possibilidade, seguimos com o 
seguinte procedimento. Selecionamos como grupo de controle somente os alunos que estão em salas de aula sem nenhum aluno tratado. Além disso, não utilizamos efeitos fixos de escola para flexibilizar a comparação dos indivíduos. No lugar dos efeitos fixos, geramos médias no nível da escola para as variáveis sócio-econômicas disponíveis no questionário do Saresp, média de alunos por sala e total de alunos na escola e controlamos a regressão por tais características. Na tabela (6) e (7) apresentamos, como anteriormente, os resultados introduzindo, gradativamente, os diferentes controles e efeitos fixos.

Em geral, o padrão de alteração dos coeficiente foi o mesmo do obtido sem amenizar as externalidades. Não apresentamos o resultado para todas as escolas do sistema público de ensino, pois não possuimos as características do Saresp para as escolas públicas federais e municipais. Para o biênio de 2008-2007, a magnitude do impacto diminui quando passamos de colunas da esquerda para direita. Novamente, quando inserimos as características das escolas, a magnitude do impacto cai. Com os alunos para os quais possuimos informações a respeito do questionários sócio-econômico no grupo de controle restrito, o impacto se manteve no intervalo entre $-0,5$ e -0,44 pontos percentuais que, representam, respectivamente, 27 e $24 \%$ de redução na taxa de abandono escolar. Os coeficiente para o biênio de 2009-2008 também apresentaram um comportamento semelhante ao obtido quando analisamos o impacto do programa sem amenizar as externalidades.

Os exercícios realizados nessa etapa sugerem que efeitos de externalidade não comprometem a nossa estimação do impacto. Em geral, as magnitudes dos coeficientes obtidos permaneceram semelhantes aos da subseção anterior. Além disso, o padrão de alteração dos coeficientes quando inserimos diferentes efeitos fixos e covariadas também foi o mesmo.

\section{7..2.3 Heterogeneidade do impacto de acordo com as características do aluno}

Na tabela (8) apresentamos os resultados obtidos nesta seção. Utilizamos o grupo de controle restrito do biênio de 2008-2007, pois foi o único que se apresentou válido na subseção anterior. Todos os resultados representam, respectivamente, o exercício mais completo dentro de cada amostra em termos de controles e efeitos fixos. Ou seja, a última linha da coluna de cada exercício das tabelas (3) e (4).

Notamos, primeiramente, que impacto do programa está concentrado sobre as mulheres. Independente da amostra utilizada, o impacto foi significante estatisticamente para os alunos do sexo feminino e não para os do masculino. No último exercício, encontramos um impacto de $-0,7$ pontos percentuais significante a $10 \%$ para as mulheres e não rejeita- 
Tabela 6: Impacto do PBF sobre o abandono escolar no biênio 2008-2007 amenizando externalidades

\begin{tabular}{|c|c|c|c|}
\hline \multicolumn{4}{|c|}{ Grupo de controle completo } \\
\hline & $\begin{array}{l}\text { Todo sistema } \\
\text { público }\end{array}$ & $\begin{array}{l}\text { Sistema público } \\
\text { estadual }\end{array}$ & $\begin{array}{c}\text { Sistema público } \\
\text { estadual } \\
\text { c/ sócio-econômico }\end{array}$ \\
\hline $\begin{array}{l}\text { Média do grupo } \\
\text { de controle }\end{array}$ & - & $\begin{array}{c}3,147 \\
(0,036)\end{array}$ & $\begin{array}{c}2,645 \\
(0,025)\end{array}$ \\
\hline & \multicolumn{3}{|c|}{ Impacto } \\
\hline Base & - & $\begin{array}{c}-1,339^{* * *} \\
(0,086)\end{array}$ & $\begin{array}{c}-1,295^{* * *} \\
(0,114)\end{array}$ \\
\hline + Características da escola & - & $\begin{array}{c}-1,199 * * * \\
(0,086)\end{array}$ & $\begin{array}{c}-1,027^{* * *} \\
(0,115)\end{array}$ \\
\hline + Efeito fixo de série & - & $\begin{array}{c}-1,196^{* * *} \\
(0,086)\end{array}$ & $\begin{array}{c}-0,970 * * * \\
(0,115)\end{array}$ \\
\hline $\begin{array}{c}+ \text { Ano e mês de nascimento } \\
\text { e dummy de gênero }\end{array}$ & - & $\begin{array}{c}-1,397^{* * *} \\
(0,086)\end{array}$ & $\begin{array}{c}-1,074^{* * *} \\
(0,115)\end{array}$ \\
\hline + Frequência em 2007 e notas & - & $\begin{array}{c}-1,581^{* * *} \\
(0,086)\end{array}$ & $\begin{array}{c}-1,132^{* * *} \\
(0,115)\end{array}$ \\
\hline + Variáveis sócio-econômicas & - & - & $\begin{array}{c}-1,166^{* * *} \\
(0,116)\end{array}$ \\
\hline Observações & - & 1164617 & 412980 \\
\hline \multicolumn{4}{|c|}{ Grupo de controle restrito } \\
\hline & $\begin{array}{l}\text { Todo sistema } \\
\text { público }\end{array}$ & $\begin{array}{l}\text { Sistema público } \\
\text { estadual }\end{array}$ & $\begin{array}{c}\text { Sistema público } \\
\text { estadual } \\
\text { c/ sócio-econômico }\end{array}$ \\
\hline $\begin{array}{l}\text { Média do grupo } \\
\text { de controle }\end{array}$ & - & $\begin{array}{c}2,363 \\
(0,109)\end{array}$ & $\begin{array}{c}1,873 \\
(0,172)\end{array}$ \\
\hline & \multicolumn{3}{|c|}{ Impacto } \\
\hline Base & - & $\begin{array}{c}-0,563^{* * *} \\
(0,140)\end{array}$ & $\begin{array}{c}-0,517^{* *} \\
(0,205)\end{array}$ \\
\hline + Características da escola & - & $\begin{array}{c}-0,464^{* * *} \\
(0,142)\end{array}$ & $\begin{array}{c}-0,517^{* * *} \\
(0,205)\end{array}$ \\
\hline + Efeito fixo de série & - & $\begin{array}{c}-0,464^{* * *} \\
(0,142)\end{array}$ & $\begin{array}{c}-0,442^{* *} \\
(0,209)\end{array}$ \\
\hline $\begin{array}{c}\text { + Ano e mês de nascimento } \\
\text { e dummy de gênero }\end{array}$ & - & $\begin{array}{c}-0,460 * * * \\
(0,141)\end{array}$ & $\begin{array}{c}-0,448^{* *} \\
(0,208)\end{array}$ \\
\hline + Frequência em 2007 e notas & - & $\begin{array}{c}-0,453^{* * *} \\
(0,140)\end{array}$ & $\begin{array}{c}-0,451^{* *} \\
(0,207)\end{array}$ \\
\hline + Variáveis sócio-econômicas & - & - & $\begin{array}{c}-0,449^{* *} \\
(0,208)\end{array}$ \\
\hline Observações & - & 54732 & 18327 \\
\hline
\end{tabular}

(1) *significante à $10 \%, * *$ significante à $5 \%, * * *$ significante à $1 \% ;(2)$ Erro padrão ajustado pelo cluster no nível da escola em parênteses; (3) Utilizo apenas os alunos de 7 a 14 anos; (4) Estimações por mínimos quadrados ordinários. 
Tabela 7: Impacto do PBF sobre o abandono escolar no biênio 2009-2008 amenizando externalidades

\begin{tabular}{|c|c|c|c|}
\hline \multicolumn{4}{|c|}{ Grupo de controle completo } \\
\hline & $\begin{array}{l}\text { Todo sistema } \\
\text { público }\end{array}$ & $\begin{array}{l}\text { Sistema público } \\
\text { estadual }\end{array}$ & $\begin{array}{c}\text { Sistema público } \\
\text { estadual } \\
\text { c/ sócio-econômico }\end{array}$ \\
\hline $\begin{array}{l}\text { Média do grupo } \\
\text { de controle }\end{array}$ & - & $\begin{array}{c}3,475 \\
(0,017)\end{array}$ & $\begin{array}{c}3,278 \\
(0,026)\end{array}$ \\
\hline & \multicolumn{3}{|c|}{ Impacto } \\
\hline Base & - & $\begin{array}{l}-0,320^{*} \\
(0,167)\end{array}$ & $\begin{array}{c}-0,633^{* * *} \\
(0,228)\end{array}$ \\
\hline + Características da escola & - & $\begin{array}{l}-0,024 \\
(0,163)\end{array}$ & $\begin{array}{l}-0,926 \\
(0,223)\end{array}$ \\
\hline + Efeito fixo de série & - & $\begin{array}{l}-0,008 \\
(0,163)\end{array}$ & $\begin{array}{l}-0,265 \\
(0,142)\end{array}$ \\
\hline $\begin{array}{c}+ \text { Ano e mês de nascimento } \\
\text { e dummy de gênero }\end{array}$ & - & $\begin{array}{l}-0,194 \\
(0,116)\end{array}$ & $\begin{array}{l}-0,344 \\
(0,225)\end{array}$ \\
\hline + Frequência em 2008 e notas & - & $\begin{array}{c}-0,346^{* *} \\
(0,163)\end{array}$ & $\begin{array}{l}-0,337 \\
(0,224)\end{array}$ \\
\hline + Variáveis sócio-econômicas & - & - & $\begin{array}{l}-0,200 \\
(0,225)\end{array}$ \\
\hline Observações & - & 1119950 & 471903 \\
\hline \multicolumn{4}{|c|}{ Grupo de controle restrito } \\
\hline & $\begin{array}{l}\text { Todo sistema } \\
\text { público }\end{array}$ & $\begin{array}{l}\text { Sistema público } \\
\text { estadual }\end{array}$ & $\begin{array}{c}\text { Sistema público } \\
\text { estadual } \\
\text { c/ sócio-econômico }\end{array}$ \\
\hline $\begin{array}{l}\text { Média do grupo } \\
\text { de controle }\end{array}$ & - & $\begin{array}{c}2,641 \\
(0,091)\end{array}$ & $\begin{array}{c}2,366 \\
(0,137)\end{array}$ \\
\hline & \multicolumn{3}{|c|}{ Impacto } \\
\hline Base & - & $\begin{array}{c}0,513^{* * *} \\
(0,179)\end{array}$ & $\begin{array}{c}0,278 \\
(0,254)\end{array}$ \\
\hline + Características da escola & - & $\begin{array}{c}0,605^{* * *} \\
(0,185)\end{array}$ & $\begin{array}{c}0,396 \\
(0,264)\end{array}$ \\
\hline + Efeito fixo de série & - & $\begin{array}{c}0,608^{* * *} \\
(0,186)\end{array}$ & $\begin{array}{c}0,400 \\
(0,264)\end{array}$ \\
\hline $\begin{array}{c}\text { + Ano e mês de nascimento } \\
\text { e dummy de gênero }\end{array}$ & - & $\begin{array}{c}0,526^{* * *} \\
(0,186)\end{array}$ & $\begin{array}{c}0,379 \\
(0,264)\end{array}$ \\
\hline + Frequência em 2008 e notas & - & $\begin{array}{c}0,381^{* *} \\
(0,185)\end{array}$ & $\begin{array}{c}0,345 \\
(0,264)\end{array}$ \\
\hline + Variáveis sócio-econômicas & - & - & $\begin{array}{c}0,327 \\
(0,263)\end{array}$ \\
\hline Observações & - & 56005 & 22284 \\
\hline
\end{tabular}

(1) *significante à $10 \%, * *$ significante à $5 \%, * * *$ significante à $1 \% ;(2)$ Erro padrão ajustado pelo cluster no nível da escola em parênteses; (3) Utilizo apenas os alunos de 7 a 14 anos; (4) Estimações por mínimos quadrados ordinários. 
mos a hipótese nula de que o programa tem um impacto nulo sobre os homens. Note este coeficiente significa uma redução de $33 \%$ na taxa de abandono das mulheres.

Quando extratificamos a amostra entre os alunos com mais de 10 anos. Também obtemos um efeito menor em magnitude do que o obtido para o grupo de alunos com 10 ou menos anos. Conjuntamente com o resultado obtido para o caso das mulheres, isto nos sugere que o custo de oportunidade dos alunos possui um poder preditivo sobre o impacto do programa. Se considerarmos que os alunos com menos de 10 anos e do sexo feminino estão menos sujeitos ao trabalho infantil, parece razoável que um programa que possui o mesmo desenho para toda a nossa amostra tenha um efeito diferenciado sobre aqueles que obteriam salários menores no mercado de trabalho.

Além de verificar a possibilidade do programa possuir um impacto heterogêneo a depender do custo de oportunidade dos alunos, verificamos a possibilidade do impacto depender da educação da mãe. Se a hipótese de que este elemento está relacionado com uma percepção de retorno maior do investimento em capital humano e que, de tal modo, o benefício do programa flui com maior intensidade para o investimento em educação (pois a elasticidade renda da educação é maior, por exemplo), deveriamos observar um impacto maior sobre os alunos beneficiários que possuem mães com melhor educação. No quarta conjunto de resultados apresentamos os efeitos separando a educação da mãe entre aquelas com educação acima do ensino médio (ensino médio ou universitário) contra aquelas com 8 anos ou menos de ensino. Apesar do canal teórico, não encontramos um efeito significante em nenhum dos casos.

Por fim, verificamos se um bom desempenho anterior do aluno está relacionado a um maior impacto do programa. Caso a família enfrente um problema de moral hazard na decisão educacional de seus filhos. É possível que um aluno que já tivesse interesse pela escola seja mais afetado pela transferência do programa, pois a preferência dos pais por educação está alinhada com as dos filhos (BURSZTYN; COFFMAN, 2011). Estimamos o impacto e o apresentamos no terceiro conjunto de coeficientes de cima para baixo. Na primeira amostra, não parece haver diferença entre o desempenho de um aluno que já tinha nota maior do que 5 no boletim com relação a um que não possuia. No entanto, quando utilizamos somente os indivíduos para os quais conseguimos controlar por variáveis sócio-econômicas, encontramos um efeito significante somente entre aqueles que já tinham um bom desempenho. Parte deste resultado parte do fato da estimação perder precisão no segundo caso. De tal modo, obtemos evidências fracas de que este canal teórico esteja gerando heterogeneidade no impacto do programa. 
Tabela 8: Heterogeneidade do impacto I em abandono no biênio 2008-2007 (utilizando grupo de controle restrito)

\begin{tabular}{|c|c|c|c|c|c|c|}
\hline & \multicolumn{2}{|c|}{$\begin{array}{l}\text { Todo sistema } \\
\text { público }\end{array}$} & \multicolumn{2}{|c|}{$\begin{array}{l}\text { Sistema público } \\
\text { estadual }\end{array}$} & \multicolumn{2}{|c|}{$\begin{array}{c}\text { Sistema público } \\
\text { estadual } \\
\text { c/ sócio-econômico }\end{array}$} \\
\hline & Impacto & Obs. & Impacto & Obs. & Impacto & Obs. \\
\hline Homens & $\begin{array}{l}-0,215 \\
(0,155)\end{array}$ & 71708 & $\begin{array}{l}-0,282 \\
(0,201)\end{array}$ & 32712 & $\begin{array}{l}-0,180 \\
(0,368)\end{array}$ & 10485 \\
\hline Mulheres & $\begin{array}{c}-0,415^{* * *} \\
(0,148)\end{array}$ & 69589 & $\begin{array}{c}-0,420^{* *} \\
(0,198)\end{array}$ & 32786 & $\begin{array}{l}-0,703^{*} \\
(0,037)\end{array}$ & 10852 \\
\hline Mais de 10 anos & $\begin{array}{l}-0,306^{*} \\
(0,173)\end{array}$ & 63647 & $\begin{array}{l}-0,281^{*} \\
(0,170)\end{array}$ & 42676 & - & \\
\hline 10 ou menos & $\begin{array}{c}-0,410^{* * *} \\
(0,133)\end{array}$ & 77649 & $\begin{array}{c}-0,534^{* *} \\
(0,238)\end{array}$ & 22822 & - & \\
\hline $\begin{array}{l}\text { Acima da mediana } \\
\text { na sala }\end{array}$ & - & - & $\begin{array}{c}-0,322^{* *} \\
(0,158)\end{array}$ & 38433 & $\begin{array}{l}-0,530^{*} \\
(0,318)\end{array}$ & 13145 \\
\hline $\begin{array}{l}\text { Abaixo da mediana } \\
\text { na sala }\end{array}$ & - & - & $\begin{array}{c}-0,536^{* *} \\
(0,261)\end{array}$ & 27065 & $\begin{array}{l}-0,215 \\
(0,473)\end{array}$ & 8192 \\
\hline Alta educação da mãe & - & - & - & - & $\begin{array}{l}-0,087 \\
(0,590)\end{array}$ & 10873 \\
\hline Baixa educação da mãe & - & - & - & - & $\begin{array}{l}-0,087 \\
(0,357)\end{array}$ & 5859 \\
\hline
\end{tabular}

(1) *significante à $10 \%,{ }^{* *}$ significante à $5 \%, * * *$ significante à $1 \%$; (2) Erro padrão ajustado pelo cluster no nível da escola em parênteses; (3) Utilizo apenas os alunos de 7 a 14 anos; (4) Controlamos por efeito fixo da escola, da série, por idade e mês de nascimento na análise com todo o sistema público de ensino. Adicionamos controle de notas e frequência no boletim para a amostra dos alunos no sistema público estadual e, por fim, controlamos por variáveis sócio-econômicos; (5) Estimações por mínimos quadrados ordinários. 


\section{7..2.4 Heterogeneidade do impacto de acordo com as características da escola}

Além de verificarmos um impacto heterogêneo com relação às características próprias de cada indivíduo, analisamos o efeito do programa considerando escolas e salas de aula com perfis diferentes. Esperamos, por exemplo, que o impacto sobre abandono seja menor quando as salas de aulas já estão cheias. Ou seja, quando a escola tem pouca capacidade de acomodar a permanência de mais alunos. Para testar esta hipótese, comparamos o impacto do programa nos alunos que estão abaixo da mediana em termos de alunos por sala (a mediana está em 35 alunos em ambos biênios de 2008-2007 e 2009-2008) com aqueles em salas acima desta mediana. Para tornar a apresentação mais clara, chamamos as salas que estão acima da mediana como classes grandes e, aquelas abaixo, como classes pequenas. Outro canal teórico indica que, caso o abandono da escola dependa da percepção que a família tem sobre a qualidade dela, é possível que o impacto seja maior onde o desempenho da escola é melhor com relação ao exame do Saresp. Por outro lado, caso as escolas com pior desempenho sejam justamente aquelas mais sensíveis ao problema de abandono escolar, é possível que o efeito seja maior quanto pior a qualidade da escola. Num último exercício, avaliamos a hipótese de que o programa tem um impacto heterogêneo dependendo da quantidade de alunos beneficiados pelo programa. Este é um argumento de equilíbrio geral, onde a proporção de alunos tratados tem um efeito além do impacto individual sobre cada aluno.

Reportamos os coeficientes estimados na tabela (9) contendo os exercício dessa subseção. Podemos verificar que a magnitude do impacto do programa é maior quando a classe está abaixo da mediana em número de alunos. Como estamos utilizando efeito fixo de escola, isto significa que, para alunos dentro de uma mesma escola, aqueles em salas menores sofrem maior influência do programa. Na última especificação, onde controlamos pelas variáveis sócio-econômicas, obtemos um impacto negativo de 0,87 pontos percentuais sobre abandono, ou seja, uma redução de 44\%. Quando analisamos a precisão da estimação do impacto em cada uma das amostras, este resultado se torna ainda mais forte. Note que, mesmo possuindo uma amostra bastante reduzida para as classes pequenas, o resultado foi maior em magnitude e mais significante estatisticamente.

Quando seguimos a análise para verificar o impacto de acordo com o montante de alunos beneficiários na sala, obtemos evidências ambíguas. No nosso primeiro corte, onde consideramos todos os alunos do sistema público de ensino, o impacto está concentrado sobre as escolas com maior proporção de tratados. Entretanto, o efeito estimado dentro das escolas estaduais públicas parece ocorrer nas salas que estão acima da média no 
Tabela 9: Heterogeneidade do impacto II em abandono no biênio 2008-2007 (utilizando grupo de controle restrito)

\begin{tabular}{|c|c|c|c|c|c|c|}
\hline & \multicolumn{2}{|c|}{$\begin{array}{l}\text { Todo sistema } \\
\text { público }\end{array}$} & \multicolumn{2}{|c|}{$\begin{array}{l}\text { Sistema público } \\
\text { estadual }\end{array}$} & \multicolumn{2}{|c|}{$\begin{array}{l}\text { Sistema público } \\
\text { estadual } \\
\text { c/ sócio-econômico }\end{array}$} \\
\hline & Impacto & Obs. & Impacto & Obs. & Impacto & Obs. \\
\hline Classe grande & $\begin{array}{l}-0,309^{*} \\
(0,180)\end{array}$ & 45367 & $\begin{array}{l}-0,287^{*} \\
(0,165)\end{array}$ & 43537 & $\begin{array}{l}-0,202 \\
(0,266)\end{array}$ & 15510 \\
\hline Classe pequena & $\begin{array}{c}-0,772^{* * *} \\
(0,292)\end{array}$ & 23281 & $\begin{array}{c}-0,773^{* * *} \\
(0,271)\end{array}$ & 21961 & $\begin{array}{l}-0,895^{*} \\
(0,524)\end{array}$ & 5827 \\
\hline $\begin{array}{l}\text { Classe está acima da média } \\
\text { em número de tratados }\end{array}$ & $\begin{array}{l}-0,105 \\
(0,231)\end{array}$ & 70726 & $\begin{array}{r}-0,640^{*} \\
(0,361)\end{array}$ & 31791 & $\begin{array}{l}-0,013 \\
(0,498)\end{array}$ & 10817 \\
\hline $\begin{array}{l}\text { Classe está abaixo da média } \\
\text { em número de tratados }\end{array}$ & $\begin{array}{c}-0,338^{* *} \\
(0,149)\end{array}$ & 70751 & $\begin{array}{l}-0,233 \\
(0,188)\end{array}$ & 33707 & $\begin{array}{l}-0,256 \\
(0,335)\end{array}$ & 10520 \\
\hline $\begin{array}{l}\text { Escola está acima da mediana } \\
\text { no desempenho no Saresp }\end{array}$ & - & & $\begin{array}{l}-0,227 \\
(0,214)\end{array}$ & 26651 & $\begin{array}{l}-0,251 \\
(0,336)\end{array}$ & 8463 \\
\hline $\begin{array}{l}\text { Escola está abaixo da mediana } \\
\text { no desempenho no Saresp }\end{array}$ & - & & $\begin{array}{c}-0,516^{* * *} \\
(0,188)\end{array}$ & 38847 & $\begin{array}{r}-0,499^{*} \\
(0,304)\end{array}$ & 12874 \\
\hline
\end{tabular}

(1) *significante à $10 \%,{ }^{* *}$ significante à $5 \%, * * *$ significante à $1 \%$; (2) Erro padrão ajustado pelo cluster no nível da escola em parênteses; (3) Utilizo apenas os alunos de 7 a 14 anos; (4) Controlamos por efeito fixo da escola, da série, por idade e mês de nascimento na análise com todo o sistema público de ensino. Adicionamos controle de notas e frequência no boletim para a amostra dos alunos no sistema público estadual e, por fim, controlamos por variáveis sócio-econômicos; (5) Estimações por mínimos quadrados ordinários.

número de tratados. Por fim, no último corte, não encontramos efeito em nenhum dos casos. Neste canal teórico, portanto, não surge uma evidência clara sobre qual efeito está predominando. Tais evidências corroboram as obtidas anteriormente de que o programa não possui efeitos de equilíbrio geral sobre o abandono.

Por fim, quando exploramos o abandono de acordo com o fato da escola estar acima da mediana no desempenho do Saresp, o impacto do programa se concentrou nas escolas abaixo da mediana. Este resultado sugere que o programa tem maior impacto sobre abandono nas escolas que possuem pior qualidade de ensino, possivelmente, pois estas são as escolas que estão mais sujeitas a tal problema. Entretanto, parte do efeito estimado parece ser gerado por diferenças na precisão da estimação

Resumidamente, dos três canais teóricos avaliados, o que nos forneceu evidências mais fortes foi o caso das salas menores. Tanto para o número de alunos tratados quanto para o fato da escola estar acima da mediana no desempenho do Saresp as evidências foram ambíguas ou imprecisas. 


\section{7..3 Impacto sobre frequência escolar}

Neste seção, apresentamos os impactos estimados com base nas variáveis de desempenho escolar que obtemos a partir do boletim dos alunos. Passamos de uma análise sobre o abandono do aluno para uma que nos fornece mais evidências a respeito de seu esforço escolar. Como possuímos a variação da frequência escolar do aluno ao longo do tempo, agora é possível flexibilizar as hipóteses necessárias para a identificação de um efeito causal do programa. Procedemos, primeiramente, com a estimação por diferença em diferenças, que controla por variáveis observáveis e não observáveis constantes ao longo do tempo. Além dos efeitos fixos e controles utilizados na seção anterior, agora também controlamos pela trajetória escolar do aluno. Isto é, comparamos indivíduos que estavam numa mesma escola no periodo inicial e que foram para a mesma escola no período seguinte. Por fim, verificamos se o parâmetro de interesse estimado se mantém semelhante quando estimamos pela técnica de mathing Reportamos os resultados desta subseção nas tabelas (10) e (11).

\section{7..3.1 Impactos básicos}

O PBF exige dos alunos com até 15 anos uma frequência escolar mínima de 85\%. Em geral, grande parte do grupo de tratamento já atende a tal condicionalidade antes mesmo de receber o benefício. Em 2007, por exemplo, $80 \%$ dos alunos do grupo de tratamento já frequentavam a mais de $85 \%$ das aulas. De qualquer modo, o programa pode ainda ter um impacto sobre a frequência daqueles que já atendem a esta condicionalidade. O efeito renda do programa pode ser grande o suficiente para fazer com que o aluno se dedique mais aos estudos. Nesta seção, analisamos três variáveis relacionadas à frequência escolar do aluno: a porcentagem de aulas ausentes, uma dummy igual a um se o aluno está acima da condicionalidade mínima exigida pelo programa e zero caso contrário e uma dummy igual a um se o aluno está abaixo de $95 \%$ de frequência.

Com relação à porcentagem de aulas ausentes, os resultados estão reportados na primeira coluna da tabela (10) e (11). Apresentamos os resultados do mesmo modo que os exercício em abandono, inserindo gradativamente diferentes controles e efeitos fixos. A diferença é que, para o presente caso, não podemos proceder com uma análise utilizando todo o sistema público de ensino, mas somente o estadual, que é para o qual possuimos informações do boletim escolar do aluno. Na primeira coluna, o efeito base no biênio de 2008-2007 é de -0,153 pontos percentuais e significante estatisticamente a 10\%, quando inserimos controles e efeitos fixos, o coeficiente cresce em magnitude atingindo $-0,274$ e 
Tabela 10: Impactos sobre frequência no biênio 2008-2007.

\begin{tabular}{lccc}
\hline \hline \multicolumn{4}{c}{ Amostra completa } \\
\hline Variável & Ausência & Acima de 85\% & Abaixo de $95 \%$ \\
dependente & $(0-100 \%)$ & de frequência & de frequência
\end{tabular}

\begin{tabular}{|c|c|c|c|}
\hline $\begin{array}{l}\text { Média } \\
\text { do controle } \\
\text { em } 2007\end{array}$ & $\begin{array}{c}9,52 \\
(0,038)\end{array}$ & $\begin{array}{c}83,61 \\
(0,160)\end{array}$ & $\begin{array}{c}69,82 \\
(0,199)\end{array}$ \\
\hline \multicolumn{4}{|c|}{ Impactos } \\
\hline Base & $\begin{array}{r}-0,153^{*} \\
(0,089)\end{array}$ & $\begin{array}{c}0,486 \\
(0,359)\end{array}$ & $\begin{array}{c}-1,130^{* * *} \\
(0,424)\end{array}$ \\
\hline+ EF de escola & $\begin{array}{l}-0,085 \\
(0,098)\end{array}$ & $\begin{array}{l}0,660 \\
(0,413)\end{array}$ & $\begin{array}{r}-0,911^{*} \\
(0,469)\end{array}$ \\
\hline+ EF de série & $\begin{array}{l}-0,149 \\
(0,097)\end{array}$ & $\begin{array}{r}0,860^{* *} \\
(0,411)\end{array}$ & $\begin{array}{c}-0,957^{* *} \\
(0,470)\end{array}$ \\
\hline $\begin{array}{l}\text { + Anoe e mês de nascimento } \\
\text { e gênero }\end{array}$ & $\begin{array}{c}-0,197^{* *} \\
(0,097)\end{array}$ & $\begin{array}{r}0,918^{* *} \\
(0,411)\end{array}$ & $\begin{array}{c}-0,923^{* *} \\
(0,471)\end{array}$ \\
\hline $\begin{array}{c}\text { + Notas e frequência } \\
\text { em } 2007\end{array}$ & $-0,110$ & 0,600 & $-0,513$ \\
\hline $\begin{array}{r}\text { EF de trajetória } \\
\text { de escolas }\end{array}$ & $\begin{array}{c}-0,274^{* * *} \\
(0,096)\end{array}$ & $\begin{array}{l}1,093^{* *} \\
(0,449)\end{array}$ & $\begin{array}{l}-0,400) \\
-0,636 \\
(0,511)\end{array}$ \\
\hline Observações & 82022 & 82043 & 82043 \\
\hline \multicolumn{4}{|c|}{ Subamostra com variáveis sócio-econômicos do Saresp } \\
\hline $\begin{array}{l}\text { Média } \\
\text { do controle } \\
\text { em } 2007\end{array}$ & $\begin{array}{c}8,97 \\
(0,046)\end{array}$ & $\begin{array}{c}84,66 \\
(0,221)\end{array}$ & $\begin{array}{c}84,63 \\
(0,273)\end{array}$ \\
\hline & Impacto & & \\
\hline Base & $\begin{array}{l}-2,593 \\
(0,139)\end{array}$ & $\begin{array}{c}0,067 \\
(0,617)\end{array}$ & $\begin{array}{l}-0,102 \\
(0,699)\end{array}$ \\
\hline+ EF de escola & $\begin{array}{l}-0,153 \\
(0,183)\end{array}$ & $\begin{array}{l}1,107 \\
(0,834)\end{array}$ & $\begin{array}{l}-0,238 \\
(0,895)\end{array}$ \\
\hline + EF de série & $\begin{array}{l}-0,195 \\
(0,182)\end{array}$ & $\begin{array}{l}1,289 \\
(0,834)\end{array}$ & $\begin{array}{l}-0,137 \\
(0,896)\end{array}$ \\
\hline $\begin{array}{c}+ \text { Ano e mês de nascimento } \\
\text { e gênero }\end{array}$ & $\begin{array}{l}-0,287 \\
(0,181)\end{array}$ & $\begin{array}{l}0,978 \\
(0,839)\end{array}$ & $\begin{array}{l}-0,102 \\
(0,898)\end{array}$ \\
\hline $\begin{array}{c}+ \text { Notas e frequência } \\
\text { em } 2007\end{array}$ & $-0,231$ & 1,296 & 0,381 \\
\hline $\begin{array}{c}\text { em } 2007 \\
+ \text { EF de trajetória }\end{array}$ & $\begin{array}{l}(0,171) \\
-0,313\end{array}$ & $\begin{array}{c}(0,942) \\
1,360\end{array}$ & $\begin{array}{c}(0,802) \\
0,957\end{array}$ \\
\hline $\begin{array}{l}\text { de escolas } \\
\text { + Variáveis SE }\end{array}$ & $\begin{array}{c}(0,192) \\
-0,327^{*} \\
(0,193)\end{array}$ & $\begin{array}{c}(0,946) \\
1,328 \\
(0,946)\end{array}$ & $\begin{array}{c}(0,991) \\
0,883 \\
(0,996)\end{array}$ \\
\hline Observações & 28163 & 28174 & 28174 \\
\hline
\end{tabular}

(1) *significante à $10 \%, * *$ significante à $5 \%, * * *$ significante à $1 \%$; (2) Erro padrão ajustado pelo cluster no nível da escola em parênteses; (3) Utilizo apenas os alunos de 7 a 14 anos; (4) Estimações por mínimos quadrados ordinários. 
Tabela 11: Impactos sobre frequência no biênio 2009-2008.

\begin{tabular}{lccc}
\hline \hline \multicolumn{4}{c}{ Amostra completa } \\
\hline Variável & Ausência & Acima de 85\% & Abaixo de 95\% \\
dependente & $(0-100 \%)$ & de frequência & de frequência
\end{tabular}

\begin{tabular}{|c|c|c|c|}
\hline $\begin{array}{l}\text { Média } \\
\text { do controle } \\
\text { em } 2008\end{array}$ & $\begin{array}{c}9,61 \\
(0,041)\end{array}$ & $\begin{array}{c}83,85 \\
(0,130)\end{array}$ & $\begin{array}{c}82,99 \\
(0,182)\end{array}$ \\
\hline \multicolumn{4}{|c|}{ Impactos } \\
\hline Base & $\begin{array}{c}-0,180 * * * \\
(0,066)\end{array}$ & $\begin{array}{c}1,095^{* * *} \\
(0.300)\end{array}$ & $\begin{array}{c}-1,033^{* * *} \\
(0,364)\end{array}$ \\
\hline+ EF de escola & $\begin{array}{c}-0,188 * * * \\
(0,069)\end{array}$ & $\begin{array}{c}1,070^{* * *} \\
(0,322)\end{array}$ & $\begin{array}{c}-1,499 * * * \\
(0,393)\end{array}$ \\
\hline+ EF de série & $\begin{array}{c}-0,198 * * * \\
(0,069)\end{array}$ & $\begin{array}{c}1,094^{* * *} \\
(0,322)\end{array}$ & $\begin{array}{c}-1,497^{* * *} \\
(0,393)\end{array}$ \\
\hline $\begin{array}{c}+ \text { Ano e mês de nascimento } \\
\text { e gênero }\end{array}$ & $\begin{array}{c}-0,195^{* * *} \\
(0,069)\end{array}$ & $\begin{array}{c}1,084^{* * *} \\
(0.322)\end{array}$ & $\begin{array}{c}-1,494^{* * *} \\
(0,393)\end{array}$ \\
\hline $\begin{array}{c}+ \text { Notas e frequência } \\
\text { em } 2008\end{array}$ & $\begin{array}{c}-0,176^{* * *} \\
(0,062)\end{array}$ & $\begin{array}{c}1,043^{* * *} \\
(0,305)\end{array}$ & $\begin{array}{c}-1,498^{* * *} \\
(0,383)\end{array}$ \\
\hline $\begin{array}{r}\text { + EF de trajetória } \\
\text { de escolas }\end{array}$ & $\begin{array}{c}-0,220^{* * *} \\
(0,066)\end{array}$ & $\begin{array}{c}1,256^{* * *} \\
(0,331)\end{array}$ & $\begin{array}{c}-1,451^{* * *} \\
(0,416)\end{array}$ \\
\hline Observações & 104686 & 104686 & 104686 \\
\hline \multicolumn{4}{|c|}{ Subamostra com variáveis sócio-econômicos do Saresp } \\
\hline $\begin{array}{l}\text { Média } \\
\text { do controle } \\
\text { em } 2008\end{array}$ & $\begin{array}{c}8,97 \\
(0,046)\end{array}$ & $\begin{array}{c}91,14 \\
(0,054)\end{array}$ & $\begin{array}{c}85,58 \\
(0,270)\end{array}$ \\
\hline \multicolumn{4}{|c|}{ Impactos } \\
\hline Base & $\begin{array}{l}-0,167^{*} \\
(0,091)\end{array}$ & $\begin{array}{c}1,333^{* * *} \\
(0,451)\end{array}$ & $\begin{array}{c}-1,572^{* * *} \\
(0,569)\end{array}$ \\
\hline + EF de escola & $\begin{array}{l}-0,134 \\
(0,101)\end{array}$ & $\begin{array}{c}0,603 \\
(0,530)\end{array}$ & $\begin{array}{c}-1,778^{* * *} \\
(0,670)\end{array}$ \\
\hline + EF de série & $\begin{array}{l}-0,149 \\
(0,101)\end{array}$ & $\begin{array}{c}0,641 \\
(0,530)\end{array}$ & $\begin{array}{c}-1,777^{* * *} \\
(0,670)\end{array}$ \\
\hline $\begin{array}{c}+ \text { Ano e mês de nascimento } \\
\text { e gênero }\end{array}$ & $\begin{array}{l}-0,141 \\
(0,101)\end{array}$ & $\begin{array}{c}0,632 \\
(0,530)\end{array}$ & $\begin{array}{c}-1,754^{* * *} \\
(0,671)\end{array}$ \\
\hline $\begin{array}{c}\text { Notas e frequência } \\
\text { em } 2008\end{array}$ & $\begin{array}{c}-0,157^{*} \\
(0,093)\end{array}$ & $\begin{array}{c}0,707 \\
(0,504)\end{array}$ & $\begin{array}{c}-1,839 * * * \\
(0,647)\end{array}$ \\
\hline $\begin{array}{r}\text { EF de trajetória } \\
\text { de escolas }\end{array}$ & $\begin{array}{l}-0,198^{*} \\
(0,105)\end{array}$ & $\begin{array}{c}0,869 \\
(0,573)\end{array}$ & $\begin{array}{r}-1,412^{*} \\
(0,729)\end{array}$ \\
\hline + Variáveis SE & $\begin{array}{r}-0,196^{*} \\
(0,105)\end{array}$ & $\begin{array}{c}0,858 \\
(0,574)\end{array}$ & $\begin{array}{r}-1,415^{*} \\
(0,729)\end{array}$ \\
\hline Observações & 41886 & 41886 & 41886 \\
\hline
\end{tabular}

(1) *significante à $10 \%, * *$ significante à $5 \%, * * *$ significante à $1 \%$; (2) Erro padrão ajustado pelo cluster no nível da escola em parênteses; (3) Utilizo apenas os alunos de 7 a 14 anos; (4) Estimações por mínimos quadrados ordinários. 
se torna significante estatisticamente a $1 \%$. Isto representa, numa base de 9,52 porcento de aulas ausentes, um redução de aproximadamente 2,8\%. Considerando que o ano letivo contém 200 dias de aula, este efeito consiste em, aproximadamente, 0,55 dias a mais de aulas frequentadas pelo aluno. Apesar do impacto ser pequeno, ele persiste quando utilizamos a especificação completa extratificando a amostra para os alunos cujas informações sócio-econômicos estão disponíveis. Neste último caso, o coeficiente vai para -0,32 pontos percentuais e é significante estatisticamente a $10 \%$.

Quando analisamos a mesma variável no biênio de 2009-2008, obtemos maior precisão estatística (em parte, pois nossa amostra é maior) mas as magnitudes encontradas foram similares com as obtidos para o biênio anterior. O efeito base de 2008-2007 foi de -0,180 pontos percentuais e cresceu em absoluto para -0,220. Quando utilizamos uma subamostra para os quais possuimos informações do questionário sócio-econômico, o efeito continuou semelhante em magnitude e, novamente, rejeitamos a hipótese nula de que o programa tem um impacto zero na última especificação. Neste caso, o programa apresentou um impacto de $-0,327$ pontos percentuais sobre ausência escolar. O que significa uma redução de $3,5 \%$ sobre a base de 8,97 porcento de aulas ausentes.

Como muitos dos alunos já atendem à condicionalidade mínima do programa antes mesmo de serem beneficiados, é possível que o impacto esteja concentrado sobre a probabilidade do aluno frequentar a mais de $85 \%$ das aulas exigidas pelo programa. Os resultados estão reportados na segunda coluna das tabelas (10) e (11). Para o biênio de 2008-2007, encontramos um impacto de 1,093 pontos percentuais. Novamente, isto representa um redução pequena em magnitude de somente 1,3\% a mais sobre a probabilidade do aluno de frequentar a mais de $85 \%$ das aulas.

No biênio de 2009-2008, embora o resultado tenha sido semelhante ao obtido em 20082007 em termos de magnitude do coeficiente, rejeitamos a hipótese de que o programa tem um impacto nulo em todos as especificações com a amostra completa a pelo menos $1 \%$ de significância estatística. Entretanto, ao selecionarmos a subamostra dos alunos para os quais temos informações sobre o sócio-econômico, só encontramos efeito na especificação base.

Gostaríamos de saber, também, se os alunos são afetados no topo da distribuição de frequência escolar dos alunos. Testamos, portanto, se eles deixam de frequentar a mais de $95 \%$ das aulas. Encontramos, no exercício para o biênio de 2008-2007, um efeito significante na base que perde significância quando controlamos pelas notas e frequência do aluno. Entretanto, no biênio de 2009-2008, obtemos coeficientes estatisticamente signifi- 
Tabela 12: Impacto sobre frequência escolar impondo suporte comum

\begin{tabular}{|c|c|c|c|c|c|c|}
\hline \multirow[b]{3}{*}{ Biênio 2008-2007 } & \multicolumn{2}{|c|}{ Ausência } & \multicolumn{2}{|c|}{$\begin{array}{c}\text { Acima de } 85 \% \\
\text { de frequência }\end{array}$} & \multicolumn{2}{|c|}{$\begin{array}{c}\text { Abaixo de } 95 \% \\
\text { de frequência }\end{array}$} \\
\hline & DID & MDID & DID & MDID & DID & MDID \\
\hline & $\begin{array}{l}-0,342^{*} \\
(0,195)\end{array}$ & $\begin{array}{c}-0,353^{* * *} \\
(0,353)\end{array}$ & $\begin{array}{c}1,511 \\
(0,959)\end{array}$ & $\begin{array}{c}0,738 \\
(0,695)\end{array}$ & $\begin{array}{c}0,879 \\
(1,009)\end{array}$ & $\begin{array}{c}0,118 \\
(0,767)\end{array}$ \\
\hline Observações & \multicolumn{2}{|c|}{27383} & \multicolumn{2}{|c|}{27383} & \multicolumn{2}{|c|}{27383} \\
\hline Biênio 2009-2008 & $\begin{array}{c}-0,209^{* *} \\
(0,106)\end{array}$ & $\begin{array}{c}-0,298^{* * *} \\
(0,095)\end{array}$ & $\begin{array}{c}0,852 \\
(0,581)\end{array}$ & $\begin{array}{c}1,638^{* * *} \\
(0,490)\end{array}$ & $\begin{array}{c}-1,381^{*} \\
(0,738)\end{array}$ & $\begin{array}{c}-2,433^{* * *} \\
(0,603)\end{array}$ \\
\hline Observações & \multicolumn{2}{|c|}{40909} & \multicolumn{2}{|c|}{40909} & \multicolumn{2}{|c|}{40909} \\
\hline
\end{tabular}

(1) *significante à $10 \%,{ }^{* *}$ significante à $5 \%, * * *$ significante à $1 \%$; (2) Erro padrão ajustado pelo cluster no nível da escola em parênteses; (3) Todas as regressões estimadas por DID estão controladas por efeito fixo de série, trajetória de escola, frequência e notas no ano base, gênero e variáveis sócio-econômicas; (4) Utilizo apenas os alunos de 7 a 14 anos em cada ano; (5) Utilizo 4 vizinhos para o matching.

cantes em todos os exercícios. A magnitude obtida foi de 1,415 na última especificação. O que representa uma queda de 1,6 porcento na probabilidade do aluno de frequentar a menos de $95 \%$ das aulas.

Por fim, estimamos os impactos a partir dos métodos de matching. Em geral, os resultados encontrados são ligeiramente maior em magnitudes a partir do método de matching e possuem maior precisão estatística. Mais importante, a direção do efeito se manteve a mesma em todos os casos.

Resumidamente, encontramos um impacto positivo e significante estatisticamente nas diferentes dimensões da frequência escolar do aluno beneficiado. Entretanto, a magnitude do efeito foi próxima de zero. Novamente, isto sugere que o impacto do programa sobre a decisão educacional da família ocorre na margem extensiva do programa, ou seja, na decisão de matricular ou não o filho na escola e não sobre a decisão do quanto ele irá frequentá-la. Em geral, a maioria dos alunos já atendem à condicionalidade do programa antes mesmo de serem tratados. No entanto, como foi visto na seção anterior sobre o impacto do programa em abandono escolar, é possível que diferentes grupos estejam reagindo diferentemente ao programa. Nas subseções seguintes, portanto, exploramos a heterogeneidade do impacto de acordo com diferentes características individuais do aluno e da escola que ele frequenta. 


\section{7..3.2 Heterogeneidade do impacto em frequência de acordo com as características individuais do aluno}

Analisamos a heterogeneidade do impacto de acordo com as características individuais do aluno do mesmo modo que na seção de abandono escolar. Primeiramente, verificamos se o impacto é diferente entre o grupo de alunos do sexo feminino. Em seguida, verificamos se o impacto depende da idade do aluno. Exploramos a possibilidade de alunos com melhor desempenho no período inicial reagirem mais ao programa e, por fim, a possibilidade do efeito depender da educação da mãe. Os exercícios realizados nesta seção são apresentados nas tabelas (13),(14) e (15).

Verificando a ausência escolar, para o biênio de 2008-2007, encontramos um impacto maior e mais significante do programa entre as mulheres. Entretanto, a magnitude permaneceu baixa nos dois exercícios, entre $-0,3$ pontos e $-0,531$ pontos percentuais. Este padrão se mantém em todos os casos analisados, com exceção do biênio de 2009-2007, onde impacto foi marginalmente maior para as mulheres em ausência. Nos casos remanescentes, o impacto foi sempre maior neste grupo. As mulheres tem maior probabilidade de frequentar a mais $85 \%$ das aulas quando recebem tratamento e menor probabilidade de estarem presentes a menos de $95 \%$ das aulas.

Quando seguimos a análise para a faixa etária do aluno, não obtemos evidências claras de que o programa possui um impacto maior sobre um grupo específico. Para ausência escolar, os alunos com 10 ou menos anos reagem menos ao programa no biênio de 20082007 e mais no biênio seguinte. Com a probabilidade do aluno de frequentar a mais de 85\%, novamente, o impacto está concentrado sobre aqueles mais velhos, entretanto, no biênio de 2009-2008, ambos coeficientes estimados são iguais do ponto de vista de intervalo de confiança de 5\%. Por fim, com relação à probabilidade de frequentar a menos de $95 \%$ das aulas. Todo o impacto está concentrado, no biênio de 2009-2008, no grupo de alunos mais novos.

Com relação ao desempenho do aluno, as evidências sugerem que o programa tem um impacto maior sobre os alunos que possuem melhor desempenho no ano base com relação a sua sala de aula. No biênio de 2008-2007, em ambas as estratificações da amostra o impacto estimado foi maior entre aqueles com melhor desempenho. No biênio seguinte, os impactos estimados são semelhantes quando estimamos o impacto utilizando toda a amostra, mas somente o efeito sobre o grupo com melhor desempenho se mantém quando utilizamos a amostra com informações sócio-econômicas. Para a probabilidade do aluno frequentar a menos de $95 \%$ das aulas, o padrão foi o mesmo. 
Por fim, explorando a heterogeneidade do impacto de acordo com a educação da mãe, encontramos evidências fracas de que o efeito do programa seja maior sobre o grupo com maior escolaridade. O impacto foi negativo no caso de ausência escolar e ligeiramente significante para os filhos que possuem mães com maior escolaridade. Porém, o padrão não se mantém para o biênio seguinte. Para a probabilidade do aluno de frequentar a mais de $85 \%$, a estimação é mais precisa. Mas, novamente, não encontramos a mesma evidência em 2009-2008.

De modo geral, podemos observar que o impacto é maior dependendo do sexo e da faixa etária do aluno beneficiário, o que reforça a hipótese de que alunos com um custo de oportunidade maior são afetados diferentemente pelo programa. Entretanto, os coeficientes encontrados foram, como os estimados nos impacto básicos, pequenos em magnitude. Ao contrário do exercício sobre abandono, onde não encontramos evidências mais fortes para sustentar a possibilidade do programa ter um impacto maior sobre alunos com melhor desempenho, agora encontramos evidências mais fortes de que o efeito do programa depende deste canal teórico. Possivelmente, isto ocorre, pois, quando analisamos uma variável que possui uma relação mais estrita com uma dimensão do esforço escolar do aluno, é maior a importância de sua disposição para atender às condicionalidade do programa. 


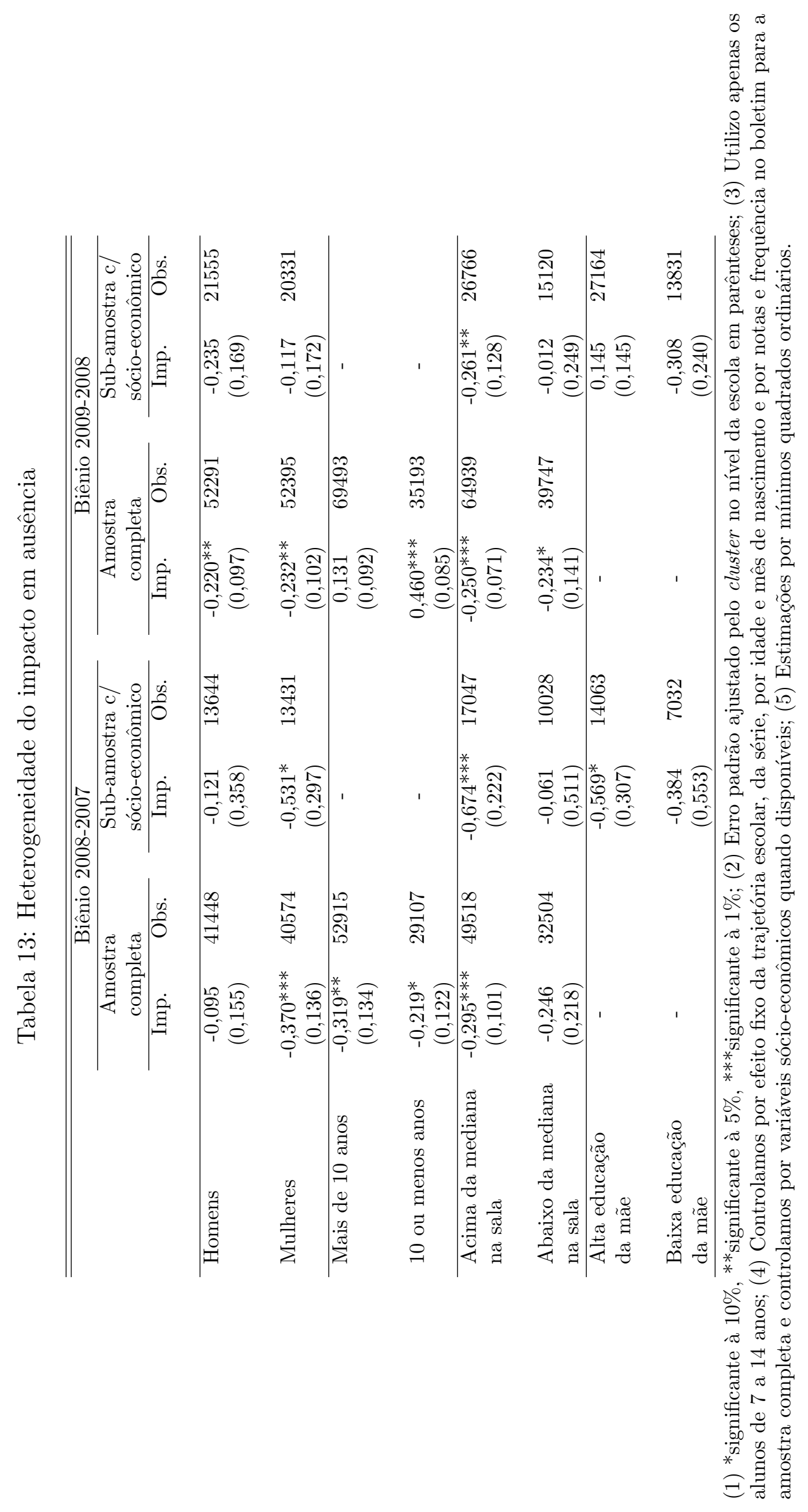




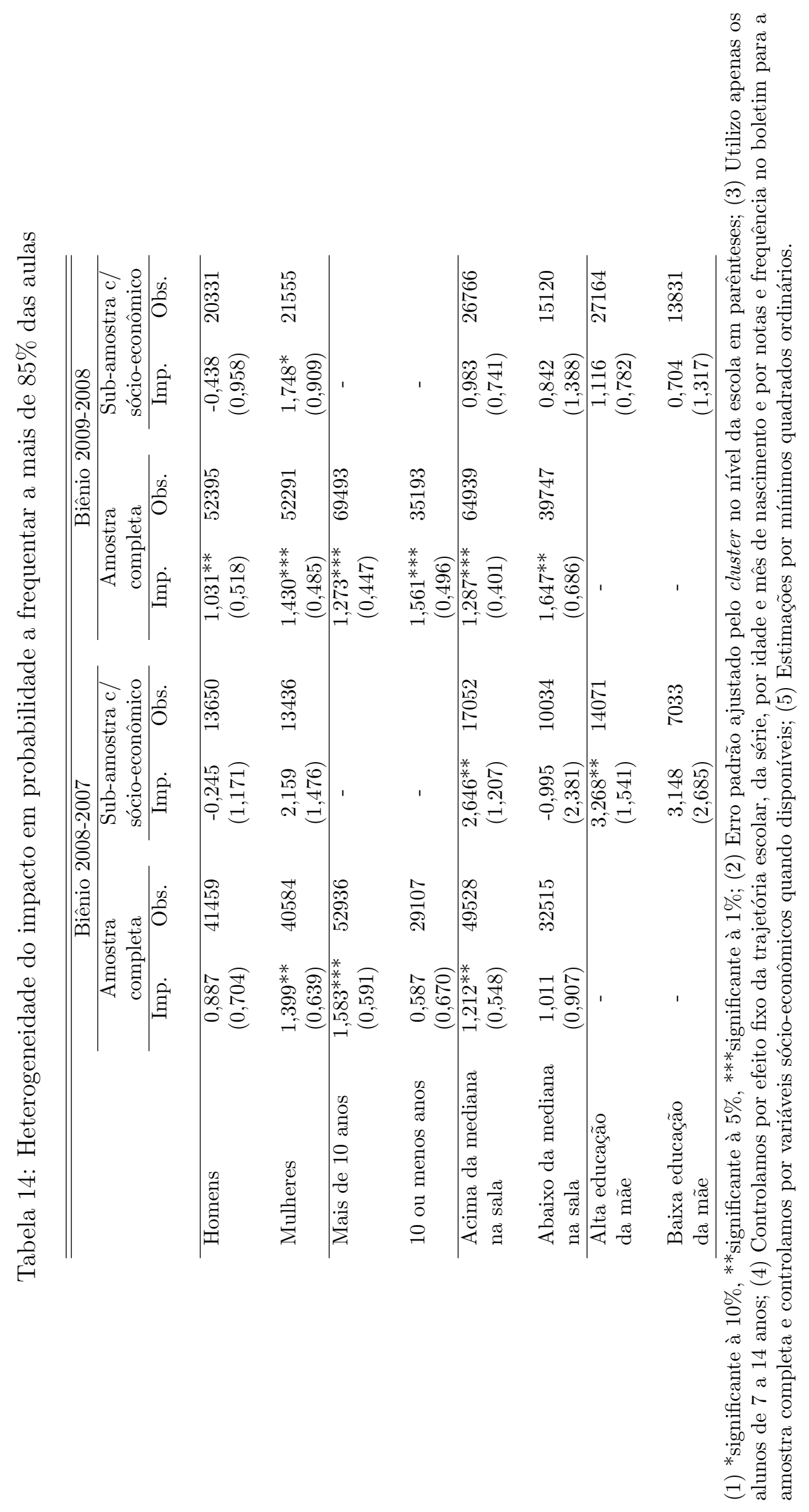




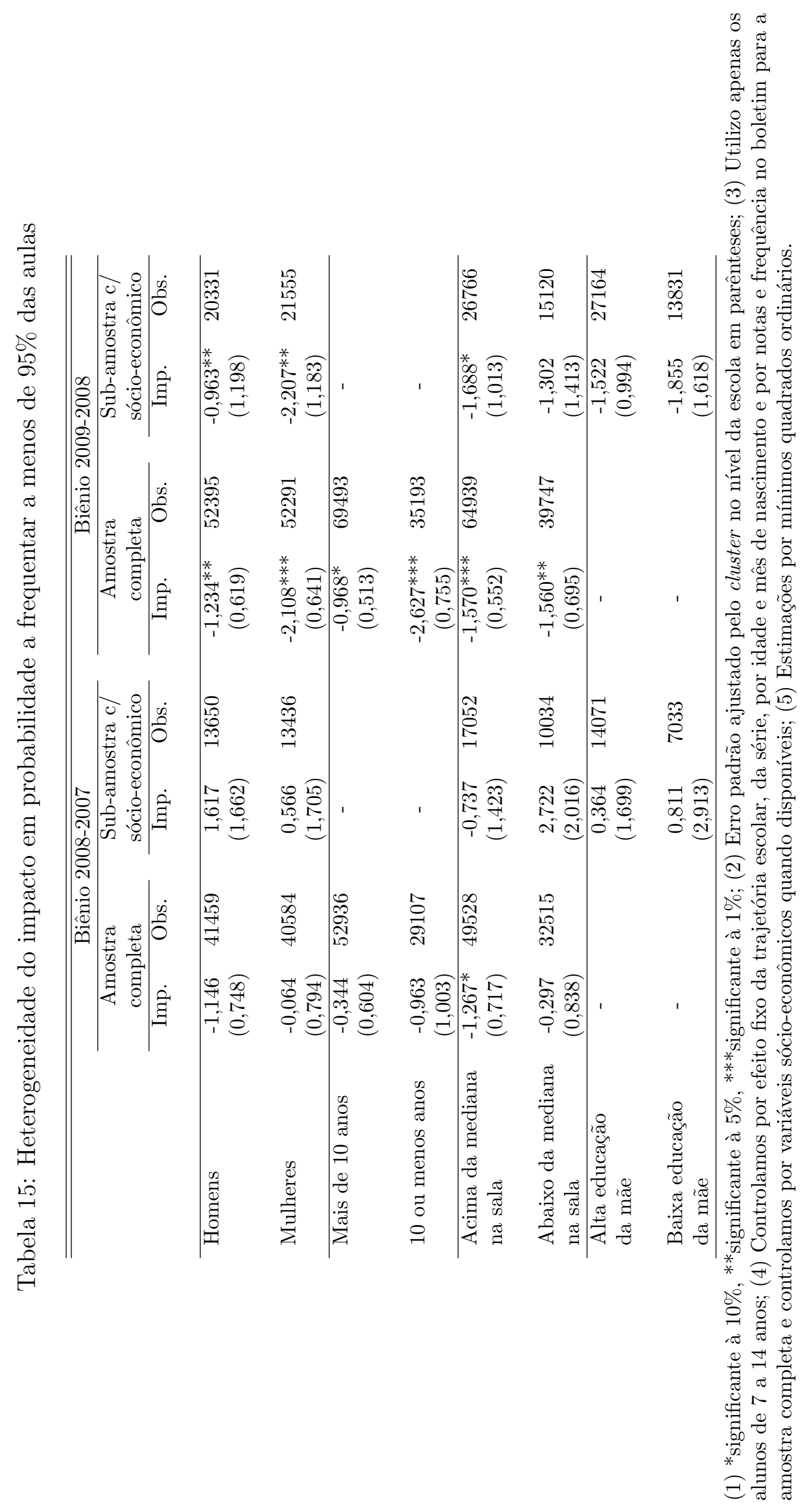




\section{7..3.3 Heterogeneidade do impacto de acordo com as características da escola}

Assim como no caso de abandono, é possível que o impacto do programa esteja concentrado em salas e escolas com perfis específicos. Para avaliar tal possibilidade, extratificamos a amostra para estimar o impacto em grupos diferentes. Primeiramente, sobre os alunos em salas menores. Em seguida, sobre aqueles com mais colegas tratados e, por fim, sobre os que estão em escolas piores em termos de desempenho médio no exame do Saresp.

Com relação ao tamanho da sala, encontramos evidências ambíguas. No biênio de 2008-2007, na estratificação em que usamos a amostra completa, o impacto foi maior e mais significante estatisticamente nas salas grandes em ausência escolar e probabilidade do aluno de frequentar a mais de $85 \%$, mas não sobre a probabilidade de frequentar a menos de $95 \%$. Para o biênio seguinte, entretanto, em todos os casos o coeficiente obtido foi maior e mais significante estatisticamente quando analisamos o grupo de alunos em salas menores. Apesar de possuirmos mais evidências de que o programa tem um impacto concentrado em salas de aulas pequenas, a ambiguidade encontrada em alguns exercícios não nos permite afirmar que este canal teórico esteja, de fato, gerando diferenças no impacto do tratamento na dimensão de frequência escolar.

Com relação ao número de aluno tratados na sala, novamente, obtemos resultados ambíguos. Para o biênio de 2008-2007, analisando a ausência escolar dos alunos, o impacto se concentra em salas com maior proporção de alunos tratados. Entretanto, para o biênio seguinte, o padrão se inverte quando utilizamos a subamostra na qual controlamos por variáveis sócio-econômicas dos alunos. Na probabilidade do aluno de frequentar a mais de $85 \%$ das aulas, também encontramos um efeito ambíguo quando passamos a análise de 2008-2007 para 2009-2008 e, finalmente, para a probabilidade do aluno de frequentar a menos de $95 \%$ das aulas, o efeito foi significante em somente um dos casos.

Por fim, quando verificamos a heterogeneidade do impacto de acordo com o desempenho da escola no Saresp. Para o biênio de 2009-2008, o impacto está concentrado, em todas as variáveis analisadas, sobre as escolas com melhor desempenho. Entretanto, para o biênio anterior, obtemos evidências fracas de que tal canal teórico esteja gerando heterogeneidade do impacto do programa.

Sumariamente, com relação à frequência escolar do aluno, não encontramos um padrão mais definido da heterogeneidade do impacto. Não somente encontramos coeficientes que estatisticamente eram muito próximos, como também encontramos efeitos ambíguos. O 
que tal análise sugere é que, na dimensão da frequência escolar do aluno, a reação ao tratamento não depende das características da escola. 


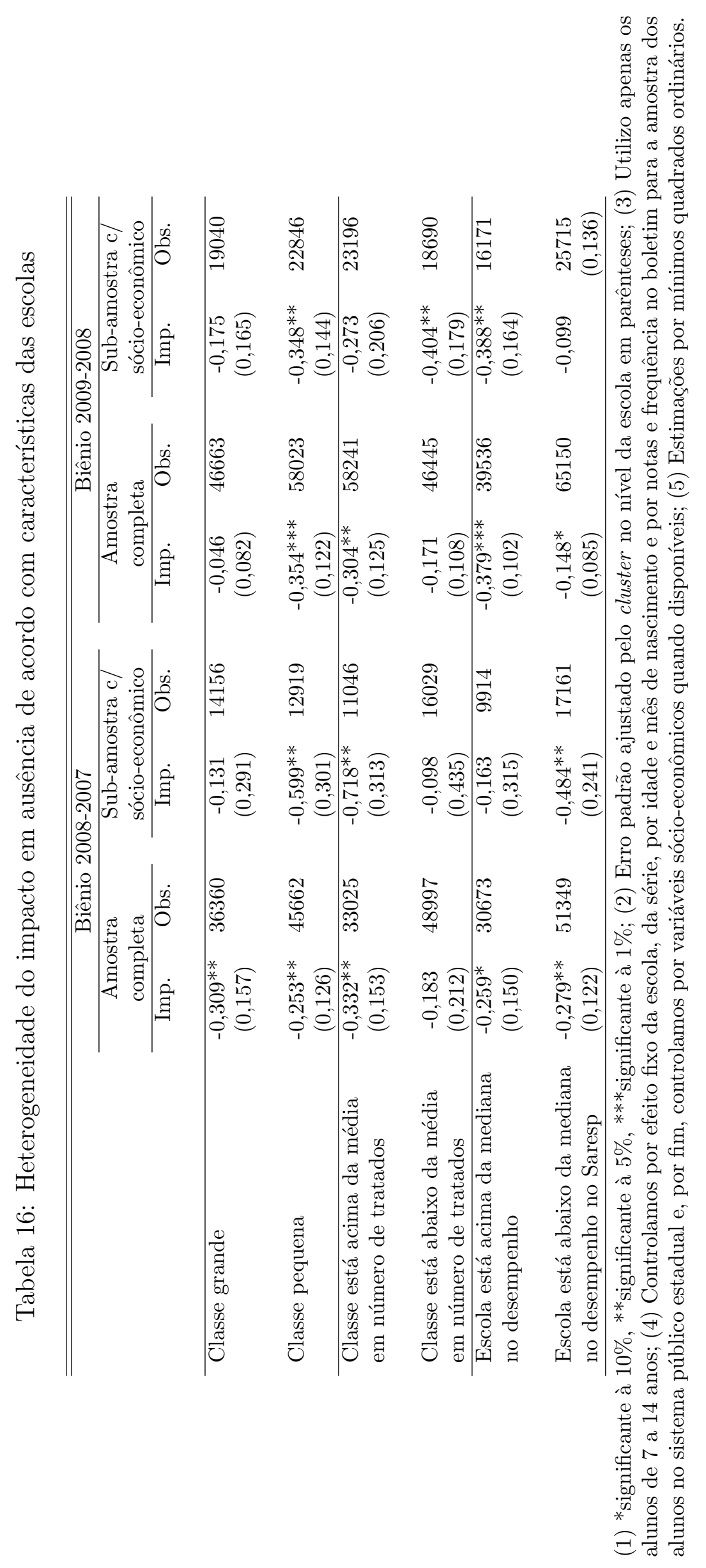




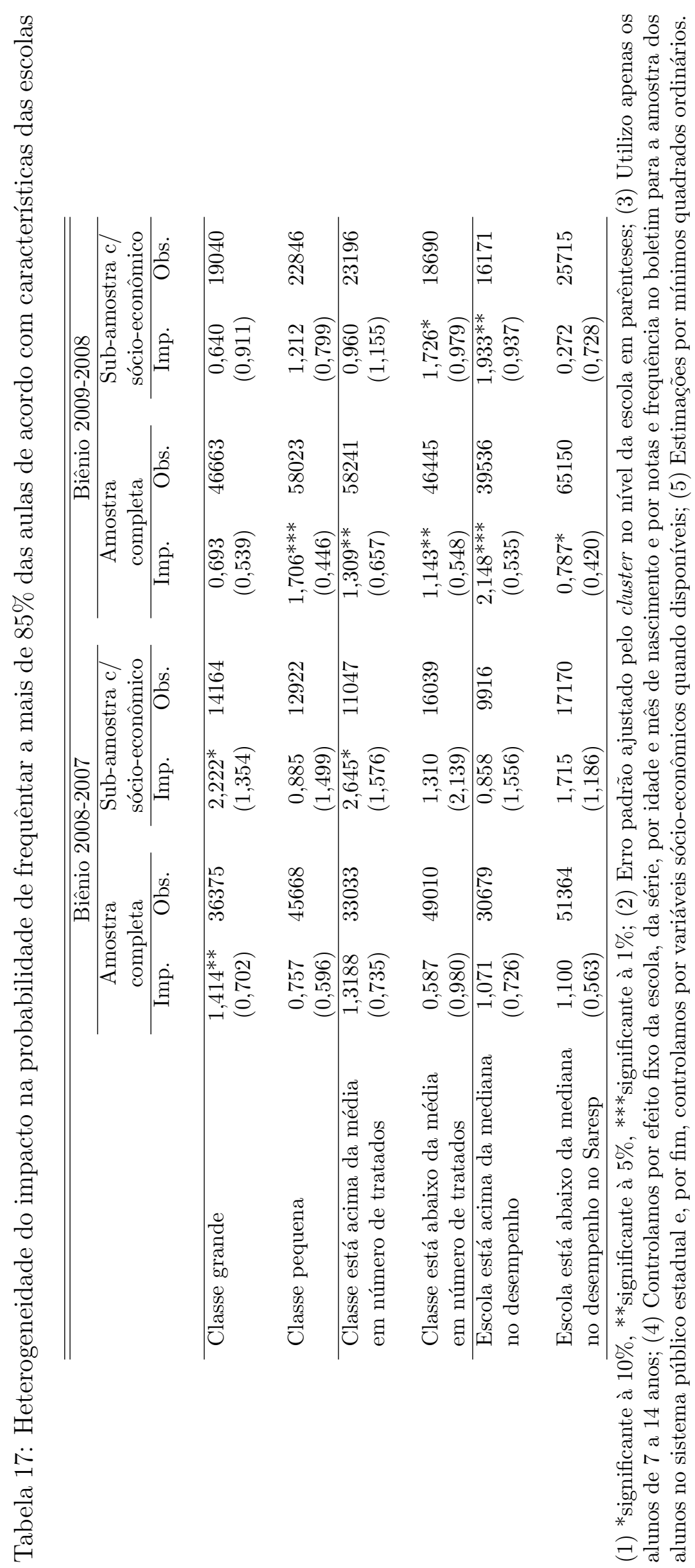




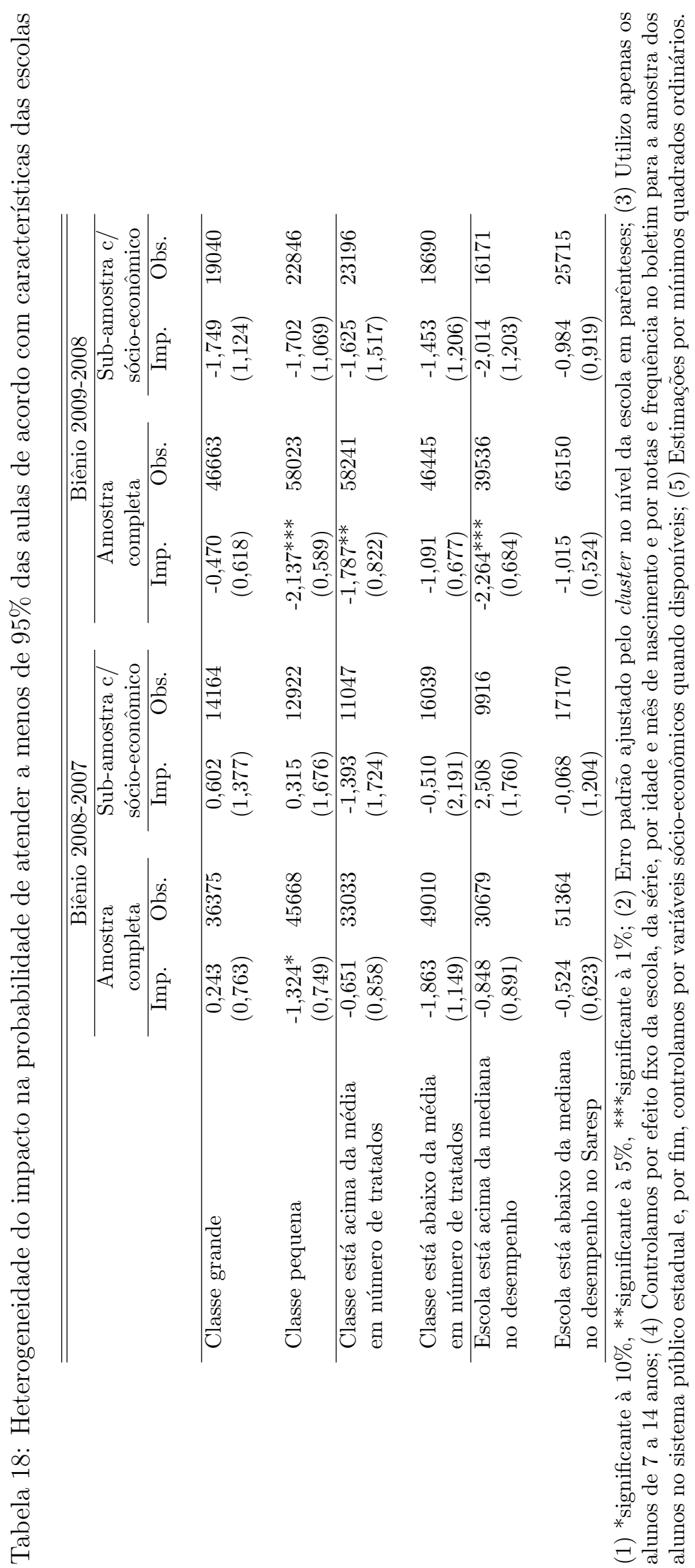




\section{7..4 Impacto sobre o desempenho no boletim escolar}

Nesta seção, investigamos o impacto do programa sobre variáveis de desempenho escolar. Note que a apresentação dos resultados acompanha a extensão esperada do impacto do PBF sobre o comportamento escolar dos alunos. Primeiramente, verificamos se o programa tem um impacto sobre sua condicionalidade mais direta, a matrícula. Em seguida, exploramos o impacto numa margem intensiva, mas também atrelada a uma condicionalidade, que é frequência escolar. Por fim, analisamos se o programa tem um impacto sobre o desempenho dos alunos nas notas obtidas no boletim. Neste último caso, não há exigência por parte do programa para o benefício do aluno. Portanto, qualquer efeito que encontrarmos nessa dimensão, estará ocorrendo por um canal indireto com relação ao desenho do programa.

Assim como na análise sobre frequência, procedemos com regressões de diferença em diferenças aplicando o método de matching posteriormente. Além disso, analisamos a heterogeneidade do impacto de acordo com as características individuais do aluno e com as características da escola que ele frequenta.

\section{7..4.1 Impactos básicos e heterogêneos}

Nas tabelas (19) e (20) reportamos os resultados obtidos quando avaliamos o impacto do programa sobre desempenho escolar. Utilizamos duas medidas de desempenho: uma dummy igual a um se o aluno obtém mais do que 5 no boletim do professor e outra igual a 1 quando o aluno está acima da mediana da classe em termos de desempenho. Uma que representa uma dimensão cardinal da distribuição de notas dadas pelo professor e outra uma dimensão ordinal. Por um lado, o professor pode não estar alterando substancialmente a nota dos alunos tratados, mas alterando a distribuição de notas de modo a melhorar o ranking do aluno na classe. Porém, se considerarmos que o sinal relevante transmitido para o aluno é a nota cardinal que ele obtém no boletim, vale também investigar alterações induzidas pelo programa nessa dimensão.

Para o biênio de 2008-2007, apesar de encontrarmos resultados signficantes estatisticamente em algumas especificações, em todos os casos, eles não se manteram significantes em especificações mais rigorosas controlando por variáveis sócio-econômicas. Além disso, em nenhum dos casos, o desvio padrão foi suficientemente grande para sugerir que há um impacto grande, porém, imprecisamente estimado.

De certo modo, dado que o impacto estimado sobre frequência foi bastante reduzido, 
consideramos razoável que o efeito seja nulo sobre o desempenho no boletim do professor. Apenas um canal teórico bastante específico afetaria o desempenho escolar do aluno nos exames dos professores e não a frequência escolar.

Como as análises anteriores sobre matrícula e frequência indicam, o programa tem um efeito heterogêneo dependendo das características dos alunos e das escolas. No entanto, no caso de desempenho, não rejeitamos a hipótese nula de que o programa tem um efeito nulo em nenhuma das extratificações utilizadas nas seções anteriores ${ }^{21}$.

Entretanto, possivelmente, o resultado obtido é nulo, pois um efeito de composição sobre a amostra está gerando um viés negativo sobre o estimador do impacto do programa. Como foi visto anteriormente, o programa tem um impacto elevado sobre abandono (apesar da proporção de alunos que abandonam a escola ser baixa). Se considerarmos que os alunos marginais que permanecem na escola em decorrência da transferência são, justamente, aqueles com pior desempenho escolar, o grupo de tratamento estará mantendo alunos piores que não possuem uma devida contrapartida no grupo de controle. Mais adiante, testamos tal cenário mantendo os alunos do grupo de controle na amostra e estimando o impacto imputando notas de modo a maximizar o impacto do programa.

\section{7..5 Impactos sobre desempenho num exame padronizado}

Todas as avaliações de impacto dos programas de transferência de renda sobre desempenho que conhecemos se aplicam a exames nos quais os alunos possuem poucos incentivos para se esforçarem. Em nossa última análise, contribuímos com a literatura apresentando o impacto do PBF sobre o desempenho dos alunos no boletim. Note que, neste último caso, há maiores incentivos para o esforço escolar, pois o boletim é, além de um critério de reprovação, apresentado para os pais e responsáveis.

A desvantagem de analisarmos o impacto do PBF sobre o desempenho no boletim é que a comparação entre alunos é influenciada pela distribuição de notas do professor. Um aluno que obtém um desempenho igual a 5 no boletim em uma sala pode não obter o mesmo com outra. Procuramos amenizar tal problema anteriormente utilizando efeitos fixos de trajetória de escola. Esperamos que, de tal modo, o grupo de controle esteja sendo influenciado na mesma medida que o grupo de tratamento por uma potencial mudança no professor e, consequentemente, no padrão de distribuição de notas.

Neste subseção, estimamos o impacto do PBF sobre um exame padronizado. Por um

\footnotetext{
${ }^{21}$ Não reportamos os resultados deste exercício, entretanto, eles podem ser solicitados aos autores.
} 
Tabela 19: Impacto sobre o desempenho no boletim no biênio 2008-2007

\begin{tabular}{|c|c|c|c|c|}
\hline \multicolumn{5}{|c|}{ Amostra completa } \\
\hline \multirow[b]{2}{*}{$\begin{array}{l}\text { Variável } \\
\text { dependente }\end{array}$} & \multicolumn{2}{|c|}{ Língua Portuguesa } & \multicolumn{2}{|c|}{ Matemática } \\
\hline & Acima de 5 & $\begin{array}{l}\text { Acima da } \\
\text { mediana }\end{array}$ & Acima de 5 & $\begin{array}{l}\text { Acima } \\
\text { mediana }\end{array}$ \\
\hline \multirow{2}{*}{$\begin{array}{l}\text { Média do Controle } \\
\text { em } 2008\end{array}$} & 87,85 & 62,13 & 86,50 & 63,06 \\
\hline & $(0,145)$ & $(0,215)$ & $(0,151)$ & $(0,214)$ \\
\hline \multirow[t]{2}{*}{ Base } & $-0,187$ & 0,411 & 0,080 & 0,298 \\
\hline & $(0,352)$ & $(0,419)$ & $(0,369)$ & $(0,419)$ \\
\hline \multirow[t]{2}{*}{+ EF de escola } & $-0,803^{* *}$ & 0,303 & $-0,623$ & 0,108 \\
\hline & $(0,380)$ & $(0,507)$ & $(0,387)$ & $(0,507)$ \\
\hline \multirow[t]{2}{*}{ + EF de série } & $-0,712^{*}$ & 0,324 & $-0,516$ & 0,140 \\
\hline & $(0,380)$ & $(0,508)$ & $(0,387)$ & $(0,508)$ \\
\hline \multirow{2}{*}{$\begin{array}{c}\text { + Ano e mês de nascimento } \\
\text { e gênero }\end{array}$} & $-0,614$ & 0,352 & $-0,406$ & 0,129 \\
\hline & $(0,379)$ & $(0,509)$ & $(0,387)$ & $(0,509)$ \\
\hline \multirow{2}{*}{$\begin{array}{c}\text { + Notas e frequência } \\
\text { em } 2007\end{array}$} & $-0,589^{* *}$ & $-0,247$ & $-0,774^{* *}$ & $-0,599$ \\
\hline & $(0,299)$ & $(0,489)$ & $(0,306)$ & $(0,486)$ \\
\hline \multirow{2}{*}{$\begin{array}{r}\text { EF de trajetória } \\
\text { de escolas }\end{array}$} & $-0,372$ & 0,277 & $-0,626^{*}$ & $-0,389$ \\
\hline & $(0,326)$ & $(0,546)$ & $(0,335)$ & $(0,542)$ \\
\hline Observações & 78119 & 78119 & 78119 & 78119 \\
\hline \multicolumn{5}{|c|}{ Subamostra com informações sócio-econômicas } \\
\hline \multirow{2}{*}{$\begin{array}{l}\text { Média do Controle } \\
\text { em } 2008\end{array}$} & 88,23 & 64,78 & 86,50 & 66,15 \\
\hline & $(0,249)$ & $(0,369)$ & $(0,264)$ & $(0,366)$ \\
\hline \multirow[t]{2}{*}{ Base } & $-1,010$ & 0,858 & $-0,777$ & 0,409 \\
\hline & $(0,618)$ & $(0,722)$ & $(0,662)$ & $(0,738)$ \\
\hline \multirow[t]{2}{*}{ + EF de escola } & $-1,255$ & 0,734 & $-0,899$ & 0,388 \\
\hline & $(0,796)$ & $(0,974)$ & $(0,835)$ & $(0,965)$ \\
\hline \multirow[t]{2}{*}{ + EF de série } & $-1,204$ & 0,759 & $-0,903$ & 0,459 \\
\hline & $(0,796)$ & $(0,975)$ & $(0,834)$ & $(0,967)$ \\
\hline \multirow{2}{*}{$\begin{array}{c}+ \text { Ano e mês de nascimento } \\
\text { e gênero }\end{array}$} & $-0,969$ & 0,866 & $-0,606$ & 0,573 \\
\hline & $(0,793)$ & $(0,976)$ & $(0,831)$ & $(0,968)$ \\
\hline \multirow{2}{*}{$\begin{array}{c}+ \text { Notas e frequência } \\
\text { em } 2007\end{array}$} & $-0,484$ & 0,450 & $-0,834$ & $-0,039$ \\
\hline & $(0,604)$ & $(0,923)$ & $(0,655)$ & $(0,929)$ \\
\hline \multirow{2}{*}{$\begin{array}{r}+ \text { EF de trajetória } \\
\text { de escolas }\end{array}$} & $-0,377$ & 0,927 & $-0,777$ & 0,162 \\
\hline & $(0,681)$ & $(1,068)$ & $(0,723)$ & $(1,066)$ \\
\hline \multirow[t]{2}{*}{ + Variáveis SE } & $-0,258$ & 1,071 & $-0,640$ & 0,317 \\
\hline & $(0,682)$ & $(1,076)$ & $(0,722)$ & $(1,071)$ \\
\hline Observações & 26031 & 26031 & 26031 & 26031 \\
\hline
\end{tabular}

(1) *significante à $10 \%, * *$ significante à $5 \%, * * *$ significante à $1 \%$; (2) Erro padrão ajustado pelo cluster no nível da escola em parênteses; (3) Utilizo apenas os alunos de 7 a 14 anos em cada ano; (4) Estimações por mínimos quadrados ordinários. 
Tabela 20: Impacto sobre o desempenho no boletim no biênio 2009-2008

\begin{tabular}{|c|c|c|c|c|}
\hline \multicolumn{5}{|c|}{ Amostra completa } \\
\hline \multirow[b]{2}{*}{$\begin{array}{l}\text { Variável } \\
\text { dependente }\end{array}$} & \multicolumn{2}{|c|}{ Língua Portuguesa } & \multicolumn{2}{|c|}{ Matemática } \\
\hline & Acima de 5 & $\begin{array}{l}\text { Acima da } \\
\text { mediana }\end{array}$ & Acima de 5 & $\begin{array}{l}\text { Acima } \\
\text { mediana }\end{array}$ \\
\hline \multirow{2}{*}{$\begin{array}{l}\text { Média do Controle } \\
\text { em } 2008\end{array}$} & 89,52 & 62,40 & 87,96 & 63,78 \\
\hline & $(0,149)$ & $(0,235)$ & $(0,158)$ & $(0,233)$ \\
\hline \multirow[t]{2}{*}{ Base } & $-0,222$ & 0,031 & $-0,232$ & 0,396 \\
\hline & $(0,273)$ & $(0,353)$ & $(0,279)$ & $(0,351)$ \\
\hline \multirow[t]{2}{*}{+ EF de escola } & $-0,142$ & 0,200 & $-0,501$ & 0,545 \\
\hline & $(0,279)$ & $(0,400)$ & $(0,286)$ & $(0,394)$ \\
\hline \multirow[t]{2}{*}{ + EF de série } & $-0,116$ & 0,216 & $-0,499^{*}$ & 0,579 \\
\hline & $(0,279)$ & $(0,399)$ & $(0,286)$ & $(0,393)$ \\
\hline \multirow{2}{*}{$\begin{array}{c}\text { + Ano e mês de nascimento } \\
\text { e gênero }\end{array}$} & $-0,111$ & 0,217 & $-0,498^{*}$ & 0,588 \\
\hline & $(0,279)$ & $(0,399)$ & $(0,285)$ & $(0,393)$ \\
\hline \multirow{2}{*}{$\begin{array}{c}\text { + Notas e frequência } \\
\text { em } 2007\end{array}$} & $-0,308$ & 0,147 & $-0,410^{*}$ & $0,690^{*}$ \\
\hline & $(0,222)$ & $(0,382)$ & $(0,232)$ & $(0,379)$ \\
\hline \multirow{2}{*}{$\begin{array}{r}\text { + EF de trajetória } \\
\text { de escolas }\end{array}$} & $-0,197$ & 0,127 & $-0,183$ & $0,716^{*}$ \\
\hline & $(0,242)$ & $(0,418)$ & $(0,246)$ & $(0,412)$ \\
\hline Observações & 104686 & 104686 & 104686 & 104686 \\
\hline \multicolumn{5}{|c|}{ Subamostra com informações sócio-econômicas } \\
\hline \multirow{2}{*}{$\begin{array}{l}\text { Média do Controle } \\
\text { em } 2008\end{array}$} & 91,25 & 64,20 & 90,19 & 65,38 \\
\hline & $(0,217)$ & $(0,368)$ & $(0,228)$ & $(0,366)$ \\
\hline \multirow[t]{2}{*}{ Base } & $-0,139$ & $-0,171$ & $-0,777$ & $-0,594$ \\
\hline & $(0,402)$ & $(0,423)$ & $(0,566)$ & $(0,553)$ \\
\hline \multirow[t]{2}{*}{+ EF de escola } & $-0,021$ & $-0,323$ & $-0,489$ & 0,048 \\
\hline & $(0,459)$ & $(0,481)$ & $(0,685)$ & $(0,676)$ \\
\hline \multirow[t]{2}{*}{ + EF de série } & 0,054 & $-0,250$ & $-0,460$ & 0,099 \\
\hline & $(0,459)$ & $(0,480)$ & $(0,217)$ & $(0,676)$ \\
\hline \multirow{2}{*}{$\begin{array}{c}+ \text { Ano e mês de nascimento } \\
\text { e gênero }\end{array}$} & $-0,111$ & $-0,498^{*}$ & 0,217 & 0,588 \\
\hline & $(0,279)$ & $(0,285)$ & $(0,399)$ & $(0,393)$ \\
\hline \multirow{2}{*}{$\begin{array}{c}\text { Notas e frequência } \\
\text { em } 2008\end{array}$} & $-0,041$ & $-0,041$ & $-0,295$ & 0,569 \\
\hline & $(0,360)$ & $(0,383)$ & $(0,648)$ & $(0,641)$ \\
\hline \multirow[t]{2}{*}{+ EF de trajetória } & 0,046 & 0,211 & $-0,228$ & 0,377 \\
\hline & $(0,411)$ & $(0,429)$ & $(0,742)$ & $(0,730)$ \\
\hline \multirow[t]{2}{*}{ + Variáveis SE } & 0,049 & 0,219 & $-0,235$ & 0,396 \\
\hline & $(0,410)$ & $(0,428)$ & $(0,740)$ & $(0,730)$ \\
\hline Observações & 41886 & 41886 & 41886 & 41886 \\
\hline
\end{tabular}

(1) *significante à $10 \%, * *$ significante à $5 \%, * * *$ significante à $1 \%$; (2) Erro padrão ajustado pelo cluster no nível da escola em parênteses; (3) Utilizo apenas os alunos de 7 a 14 anos em cada ano; (4) Estimações por mínimos quadrados ordinários. 
lado, os alunos não possuem incentivos para se esforçarem do mesmo modo que nos exames dos professores. Por outro, o exame padronizado permite uma comparação direta entre o desempenho de diferentes alunos. Além disso, como estimamos o impacto do programa por diferença em diferenças, o fato dos alunos não se esforçarem para o exame não viola as hipóteses a não ser que o programa tenha efeito sobre o esforço.

\section{7..6 Impactos básicos e heterogêneo}

Na tabela (21) apresento os resultados do impacto do PBF sobre o desempenho nos exames padronizados do Saresp. Nossa variável dependente é a diferença na proficiência dos alunos em z-score entre o exame de 2009 e 2007. Portanto, a interpretação do coeficiente fica em termos de desvios padrões. Como podemos notar, em nenhumas das especificações o impacto estimado é estatisticamente significante a 10\%. Porém, isso se deve menos a imprecisão de nossa estimação do que à magnitude do coeficiente. Em todos os casos, para o desempenho em língua portuguesa ou matemática, o intervalo de confiança a 95\% do coeficiente estimado ficou entre -0,031 e 0,047. Mesmo quando utilizamos a estimação por matching, não rejeitamos a hipótese de que o programa tem um impacto nulo sobre o desempenho.

Assim como no caso anterior em que avaliamos o impacto do programa sobre as notas dos alunos no boletim, quando analisamos o impacto do programa em diferentes estratificações de nossa amostra não encontramos nenhum efeito significante a $10 \%{ }^{22}$.

\section{Testes de robustez}

\section{8..1 Análise de tendência pré-tratamento}

A principal hipótese utilizada para a identificação do impacto do programa a partir do método de diferença em diferenças é a de que o grupo de tratamento teria a mesma tendência do grupo de controle na ausência de tratamento. Se por um lado não é possível testar diretamente tal hipótese, por outro, podemos analisar a tendência de tais grupos no período pré-tratamento. Caso a tendência seja a mesma, é pouco razoável que ela fosse diferente no período de tratamento.

Assim, para este exercício, utilizamos uma subamostra de indivíduos para os quais

\footnotetext{
${ }^{22}$ Os resultados podem ser obtidos sob solicitação.
} 
Tabela 21: Impacto do programa sobre desempenho num exame padronizado

\begin{tabular}{lcc}
\hline \hline & Língua portuguesa & Matemática \\
Média do Controle & 0,081 & 0,064 \\
em 2008 & $(0,008)$ & $(0,007)$ \\
\hline Base & $-0,004$ & 0,001 \\
& $(0,007)$ & $(0,008)$ \\
+ EF de escola & $-0,002$ & $-0,004$ \\
& $(0,007)$ & $(0,008)$ \\
+ EF de série & $-0,001$ & $-0,004$ \\
& $(0,007)$ & $(0,008)$ \\
+ Ano e mês de nascimento & 0,001 & $-0,002$ \\
e gênero & $(0,007)$ & $(0,008)$ \\
+ Notas e frequência & 0,001 & $-0,003$ \\
$\quad$ em 2007 & $(0,007)$ & $(0,008)$ \\
+ EF de trajetória & 0,001 & $-0,005$ \\
de escolas & $(0,008)$ & $(0,009)$ \\
Observações & 118486 & 119474 \\
\hline
\end{tabular}

(1) *significante à $10 \%,{ }^{* *}$ significante à $5 \%,{ }^{* * *}$ significante à $1 \%$; (2) Erro padrão ajustado pelo cluster no nível da escola em parênteses; (3) Utilizo apenas os alunos de 7 a 14 anos em cada ano; (4) Estimações por mínimos quadrados ordinários.

Tabela 22: Impacto do programa sobre desempenho num exame padronizado

\begin{tabular}{lccccc}
\hline \hline \multirow{3}{*}{ Impacto } & \multicolumn{2}{c}{ Língua portuguesa } & & \multicolumn{2}{c}{ Matemática } \\
& DID & MDID & & DID & MDID \\
\cline { 2 - 3 } \cline { 5 - 6 } Observações & $-0,003$ & $-0,003$ & & $-0,003$ & 0,004 \\
& $(0,009)$ & $(0,008)$ & & $(0,009)$ & $(0,009)$ \\
& \multicolumn{2}{c}{113688} & & \multicolumn{2}{c}{114640} \\
\hline
\end{tabular}

(1) *significante à $10 \%,{ }^{* *}$ significante à $5 \%, * * *$ significante à $1 \%$; (2) Erros padrão ajustados pelo cluster no nível da escola em parênteses; (3) Todas as regressões estimadas por DID estão controladas por efeito fixo de série, trajetória de escola, frequência e notas no ano base, gênero e variáveis sócio-econômicas; (4) Utilizo apenas os alunos de 7 a 14 anos em cada ano; (5) Utilizo 4 vizinhos para o matching. 
possuímos informações nos anos de 2007, 2008 e 2009. Definimos como grupo de tratamento os indivíduos que receberam auxílio do programa no primeiro semestre de 2009 e, como controle, aqueles que só participam do programa a partir do primeiro semestre de 2010. Realizamos as regressões para o biênio de 2008-2009 e, em seguida, conduzimos as mesmas regressões para o biênio de 2008-2007, quando nenhum dos dois grupos recebeu tratamento. Reportamos os resultados destes exercícios nas tabelas (20) e (21).

Como podemos observar, os resultados permaneceram bastante semelhantes para o biênio 2009-2008 com os obtidos anteriormente. Há um impacto do programa sobre ausência escolar e sobre a probabilidade do aluno de atender a frequência mínima exigida pelo programa, mas não sobre variáveis de desempenho escolar. No entanto, para o biênio de 2008-2007, quando nenhum dos dois grupos recebeu tratamento, encontramos diferença na tendência de somente uma das variáveis analisadas, a probabilidade do aluno de frequentar a mais de $85 \%$ das aulas. Para amenizar o possivel viés gerado pela diferença nas tendências, realizamos um procedimento de estimação por diferença tripla. Nessa análise, subtraímos da diferença nas diferenças no período de 2009-2008 a diferença nas diferenças do período de 2008-2007. De tal modo, retiramos o viés gerado por diferença na tendência entre os grupos analisados. Os resultados desse exercício estão reportados no terceiro conjunto de resultados da tabela e, neste caso, encontramos efeito do programa somente sobre a variável de ausência escolar.

\section{8..2 Imputando dados para os alunos que abandonaram a escola}

Um dos primeiros impactos apresentados nesse artigo foi sobre o abandono escolar. Inclusive, este foi o impacto com maior magnitude entre os avaliados. Isto tem efeito sem contrapartida no grupo de controle sobre a composição dos alunos tratados que per-

manecem na escola. Neste caso, teríamos um viés negativo sobre nossa estimação se considerarmos que o PBF tem um impacto justamente sobre aqueles alunos que estão na margem de sair da escola, ou seja, sobre alunos com pior desempenho escolar.

Por outro lado, a proporção de alunos que abandonam a escola é baixa (3,25\% no grupo de controle contra 2,04\% no grupo de tratamento no biênio de 2008-2007 e 3,86\% contra 3,4\% no de 2009-2008). Isto significa que o efeito de composição teria que ser grande o suficiente sobre este pequeno grupo de alunos para que os resultados obtidos anteriormente se alterassem.

De tal modo, para analisar se os resultados obtidos estão comprometidos por um viés 
Tabela 23: Análise de tendência pré-tratamento

\begin{tabular}{|c|c|c|c|}
\hline \multicolumn{4}{|c|}{ Amostra completa } \\
\hline $\begin{array}{l}\text { Variável } \\
\text { dependente }\end{array}$ & $\begin{array}{l}\text { Ausência } \\
(0-100 \%)\end{array}$ & $\begin{array}{l}\text { Acima de } 85 \\
\text { de frequência }\end{array}$ & $\begin{array}{l}\text { Abaixo de } 95 \\
\text { de frequência }\end{array}$ \\
\hline \multicolumn{4}{|c|}{ Impactos 2009-2008 } \\
\hline Especificação completa & $\begin{array}{c}-0,272^{* * *} \\
(0,086)\end{array}$ & $\begin{array}{c}0,903^{* *} \\
(0,447)\end{array}$ & $\begin{array}{c}-1,309 * * \\
(0,576)\end{array}$ \\
\hline \multicolumn{4}{|c|}{ Impactos 2008-2007 } \\
\hline Especificação completa & $\begin{array}{l}-0,087 \\
(0,078)\end{array}$ & $\begin{array}{l}0,792^{*} \\
(0,440)\end{array}$ & $\begin{array}{l}-0,392 \\
(0,588)\end{array}$ \\
\hline \multicolumn{4}{|c|}{ Diferença Tripla } \\
\hline Especificação completa & $\begin{array}{c}-0,324^{* * *} \\
(0,123)\end{array}$ & $\begin{array}{c}0,515 \\
(0,747)\end{array}$ & $\begin{array}{l}-1,027 \\
(1,036)\end{array}$ \\
\hline Observações & 58196 & 58196 & 58196 \\
\hline
\end{tabular}

(1) *significante à $10 \%,{ }^{* *}$ significante à $5 \%, * * *$ significante à $1 \%$; (2) Erro padrão ajustado pelo cluster no nível da escola em parênteses; (3) Utilizo apenas os alunos de 7 a 14 anos em 2008; (4) Estimações por mínimos quadrados ordinários.

Tabela 24: Análise de tendência pré-tratamento

\begin{tabular}{|c|c|c|c|c|}
\hline \multirow[t]{2}{*}{ Variável } & \multicolumn{2}{|c|}{ Língua Portuguesa } & \multicolumn{2}{|c|}{ Matemática } \\
\hline & $\begin{array}{c}\text { Acima } \\
\text { de } 5\end{array}$ & $\begin{array}{c}\text { Acima da } \\
\text { mediana }\end{array}$ & $\begin{array}{c}\text { Acima } \\
\text { de } 5\end{array}$ & $\begin{array}{l}\text { Acima da } \\
\text { mediana }\end{array}$ \\
\hline \multicolumn{5}{|c|}{ Impactos 2009-2008 } \\
\hline Especificação completa & $\begin{array}{c}0,120 \\
(0,327)\end{array}$ & $\begin{array}{c}0,733 \\
(0,587)\end{array}$ & $\begin{array}{c}0,217 \\
(0,330)\end{array}$ & $\begin{array}{c}0,572 \\
(0,573)\end{array}$ \\
\hline \multicolumn{5}{|c|}{ Impactos 2008-2007 } \\
\hline Especificação completa & $\begin{array}{l}-0,050 \\
(0,315)\end{array}$ & $\begin{array}{c}0,532 \\
(0,577)\end{array}$ & $\begin{array}{c}0,509 \\
(0,318)\end{array}$ & $\begin{array}{c}0,286 \\
(0,583)\end{array}$ \\
\hline \multicolumn{5}{|c|}{ Diferença Tripla } \\
\hline Especificação completa & $\begin{array}{c}0,433 \\
(0,488)\end{array}$ & $\begin{array}{c}-0,101 \\
(1,025)\end{array}$ & $\begin{array}{c}0,483 \\
(0,494)\end{array}$ & $\begin{array}{c}0,895 \\
(1,001)\end{array}$ \\
\hline Observações & 58196 & 58196 & 58196 & 58196 \\
\hline
\end{tabular}

(1) *significante à $10 \%, * *$ significante à $5 \%, * * *$ significante à $1 \%$; (2) Erro padrão ajustado pelo cluster no nível da escola em parênteses; (3) Utilizo apenas os alunos de 7 a 14 anos em 2008; (4) Estimações por mínimos quadrados ordinários. 
de composição da amostra, procedemos com exercícios hipóteticos que maximizariam o impacto do programa sobre o grupo de tratamento com relação à nota no boletim do professor. Primeiramente, imputamos para os alunos no grupo de controle que abandonaram a escola em 2008 a última nota verificada no sistema de boletins. A nota de do aluno em um ano é o melhor previsor para a nota do aluno no ano seguinte, numa regressão linear simples o R quadrado é de mais de 0,40. Em seguida, reduzimos em um ponto a nota imputada de todos que abandonaram a escola limitando o mínimo em 0 para que os alunos que ficaram com 0 em 2007 não possuissem uma nota negativa em 2008. De tal modo, este exercício gera uma tendência negativa sobre tal grupo (se há indivíduos com notas diferente de zero). Assim por diante, retiramos gradualmente 1 ponto sobre a nota dos alunos que abandonaram a escola até chegarmos ao ponto em que todos alunos vão de sua nota em 2007 para zero em 2008. Neste caso, quando imputamos zero sobre a nota desses alunos em 2008, estamos encontrando um limite superior para o tamanho do impacto do programa. Realizamos, então, exatamente o mesmo exercício para o biênio de 2008-2009.

Na tabela (25), apresentamos o resultado deste exercício de robustez. As regressões apresentadas possuem a especificação de diferença em diferenças completa com todos os efeitos fixos incorporados nas seções anteriores. Como podemos observar, quando imputamos a mesma nota que o aluno obteve no ano base no ano para o ano seguinte, nenhum dos resultados se alteraram: continuamos não rejeitando a hipótese nula de que o impacto do programa é igual a zero. Quando retiramos 1 ponto da nota, não identificamos nenhum impacto signficante a $1 \%$ sobre o desempenho do aluno no biênio de 2008-2007. Para o biênio de 2009-2008, encontramos um efeito positivo e significante a $1 \%$ de significância em todos os casos. Porém, a magnitude é baixa dada a média do grupo de controle. O impacto positivo sobre a nota fica num intervalo entre 1,4 e $2,2 \%$. No cenário em que todos os alunos do grupo de controle permanecem na escola e obtém zero no segundo período, o que maximiza o impacto do programa, o efeito no biênio de 2008-2007 fica em torno de 2 e 2,7\% sobre os quatro casos avaliados. Já para o biênio de 2009-2008, o efeito seria maior e estaria em torno de, aproximadamente, $4 \%$.

O exercício empírico nesta seção sugere que, se há um impacto positivo sobre o desempenho dos alunos, ele é bastante reduzido. No cenário mais razoável, em que todos os alunos do grupo de controle mantém o mesmo desempenho de um ano para o outro, não rejeitamos a hipótese nula de que o efeito do programa é nulo. No cenário em que todos os alunos que abandonaram a escola permanecem na escola e obtém um desempenho nulo no segundo período, o maior impacto encontrado foi de, aproximadamente, $4 \%$ sobre as 
Tabela 25: Impacto sobre a nota do boletim imputando a notas para o grupo de controle que abandonou a escola

\begin{tabular}{|c|c|c|c|c|}
\hline \multicolumn{5}{|c|}{$2008-2007$} \\
\hline \multirow[b]{2}{*}{$\begin{array}{l}\text { Nota imputada } \\
\text { para } 2008\end{array}$} & \multicolumn{2}{|c|}{ Língua Portuguesa } & \multicolumn{2}{|c|}{ Matemática } \\
\hline & Acima de 5 & $\begin{array}{c}\text { Acima da } \\
\text { mediana }\end{array}$ & Acima de 5 & $\begin{array}{c}\text { Acima da } \\
\text { mediana }\end{array}$ \\
\hline \multirow{2}{*}{ Nota de 2007} & $-0,180$ & 0,038 & $-0,479$ & $-0,317$ \\
\hline & $(0,326)$ & $(0,532)$ & $(0,335)$ & $(0,528)$ \\
\hline \multirow{2}{*}{ Nota de 2007 - 1} & 0,653 & 0,698 & 0,449 & 0,433 \\
\hline & $(0,330)$ & $(0,536)$ & $(0,339)$ & $(0,530)$ \\
\hline \multirow{2}{*}{ Zero (upper bound) } & $2,132^{* * *}$ & $1,707^{* * *}$ & $1,826^{* * *}$ & $1,485^{* * *}$ \\
\hline & $(0,344)$ & $(0,539)$ & $(0,351)$ & $(0,536)$ \\
\hline \multirow[t]{2}{*}{ Observações } & 81647 & 81647 & 81647 & 81647 \\
\hline & \multicolumn{4}{|c|}{$2009-2008$} \\
\hline \multirow[b]{2}{*}{$\begin{array}{l}\text { Nota imputada } \\
\text { para } 2009\end{array}$} & \multicolumn{2}{|c|}{ Língua Portuguesa } & \multicolumn{2}{|c|}{ Matemática } \\
\hline & $\begin{array}{c}\text { Acima de } 5 \\
\text { no boletim }\end{array}$ & $\begin{array}{c}\text { Acima da média } \\
\text { da classe } \\
\text { no boletim }\end{array}$ & $\begin{array}{c}\text { Acima de } 5 \\
\text { no boletim }\end{array}$ & $\begin{array}{c}\text { Acima da média } \\
\text { da classe } \\
\text { no boletim }\end{array}$ \\
\hline \multirow[t]{2}{*}{ Nota de 2008} & $-0,028$ & 0,206 & 0,005 & 0,522 \\
\hline & $(0,240)$ & $(0,414)$ & $(0,246)$ & $(0,415)$ \\
\hline \multirow[t]{2}{*}{ Nota de 2008 - 1} & $1,276^{* * *}$ & $1,658^{* * *}$ & $1,397^{* * *}$ & $1,402^{* * *}$ \\
\hline & $(0,248)$ & $(0,426)$ & $(0,254)$ & $(0,440)$ \\
\hline \multirow[t]{2}{*}{ Zero (upper bound) } & $3,574^{* * *}$ & 2,872 & $3,507^{* * *}$ & $2,545^{* * *}$ \\
\hline & $(0,275)$ & $(0,434)$ & $(0,279)$ & $(0,446)$ \\
\hline Observações & 110061 & 110061 & 110061 & 110061 \\
\hline
\end{tabular}

(1) *significante à $10 \%,{ }^{* *}$ significante à $5 \%, * * *$ significante à $1 \%$; (2) Erro padrão ajustado pelo cluster no nível da escola em parênteses; (3) Utilizo apenas os alunos de 7 a 14 anos; (4) Controlamos por efeito fixo da escola, da série, por idade e mês de nascimento e por notas e frequência no boletim para a amostra dos alunos no sistema público estadual e, por fim, controlamos por variáveis sócio-econômicos quando disponíveis; (5) Estimações por mínimos quadrados ordinários.

variáveis analizadas.

\section{Conclusões e implicações de políticas públicas}

A principal condicionalidade dos programas de transferência de renda condicionais adotados ao redor do mundo é a exigência da matrícula e de uma frequência escolar mínima do aluno beneficiário. Este desenho tem por objetivo gerar maior acumulação de capital humano, o que potencialmente diminui a pobreza e a desigualdade no médioprazo, pois as novas gerações possuirão melhores condições para competir no mercado de trabalho por salários melhores.

Nesse sentido, diversos programas de transferência de renda foram avaliados com a intenção de quantificar o impacto de tais políticas sobre variáveis escolares dos alunos 
beneficiários. Em geral, encontra-se uma evidência sistemática de que programas de transferência de renda aumentam a matrícula e reduzem o abandono escolar. Entretanto, para os poucos estudos realizados até o momento sobre o impacto de tais políticas no desempenho em exames, não se rejeita a hipótese de que o efeito é nulo sobre tal dimensão.

Nessa dissertação, procuramos contribuir com a literatura, primeiramente, avaliando o impacto do PBF, um programa de grandes proporções ainda pouco estudado. Em adição, com dados do boletim dos alunos da rede de ensino estadual do Estado de São Paulo, fomos capazes de extender a análise dos efeitos dos programas de transferência de renda sobre aspectos qualitativos como o desempenho dos alunos nos exames dos professores e em exames padronizados. A riqueza de nossos dados nos permitiu usar diferentes procedimentos estatísticos para testar a validade de nossos resultados e, ainda, estratificar a amostra para investigar diferentes canais teóricos no nível do indivíduo e da escola que podem estar gerando os efeitos encontrados.

Em geral, os impactos estimados para o PBF corroboram os identificados anteriormente pela literatura para outros programas implementados no mundo. Há um impacto significativo sobre abandono escolar que, na especificação mais rigorosa do nosso trabalho, representou uma redução de $22 \%$. Em ausência escolar, entretanto, encontramos um impacto negativo e pequeno de aproximadamente $3 \%$.

Em nossa interpretação, os resultados encontrados sobre tais variáveis foram pequenos, em parte, pois o esforço de democratização do ensino a partir do final da década de 90 fez com que, no Estado de São Paulo, a maioria dos alunos já frequentassem a escola. Como foi visto, a porcentagem de abandono escolar é baixa até a oitava série e a maioria dos alunos já frequentam a maior parte das aulas. De tal modo, o programa é desenhado para alterar o comportamento educacional sobre dimensões onde há pouca margem para impacto.

Além disso, a análise de heterogeneidade sugere que há espaço para melhorias no desenho das condicionalidades e das transferências. O programa possui o mesmo formato em termos de condicionalidades e benefício para os alunos com até 15 anos. De tal modo, o PBF fornece o mesmo contrato para beneficiários muito diferentes. Quando analisamos o impacto em diferentes grupos (mas sobre um mesmo regime de transferências e condicionalidades), encontramos um efeito maior para aqueles com menores custos de oportunidade, ou seja, meninas e alunos com 10 ou menos anos. Em nossa perspectiva, este fenômeno pode estar relacionado ao trabalho infantil. Estudos apontam, por exemplo, que a idade crítica para a entrada no mercado de trabalho infantil ocorre entre os 10 e 
14 anos (UDRY, 2006). Assim, tal concentração do impacto sobre grupos específicos pode estar sendo gerada pois o programa não compensa suficientemente o salário que alguns grupos de alunos obteriam caso fossem para o mercado de trabalho.

Quando seguimos a avaliação para variáveis que estão menos atreladas às condicionalidades do programa, como o desempenho no boletim e em exames padronizados, o impacto identificado foi nulo. Além disso, em nenhuma de nossas estratificações encontramos um impacto significante do PBF a 10\%. Como apresentamos anteriormente, nossa estimação está potencialmente subestimando o impacto do programa devido a mudança de composição de amostra induzida pela redução no abandono. Se o PBF mantém alunos piores na escola, o programa está alterando a composição do grupo de tratamento ao longo do tempo sem uma devida contrapartida no grupo de controle. Para avaliar esta possibilidade, imputamos notas para os alunos que abandonaram a escola. Mesmo na situação extrema em que todo o grupo de controle que abandonou a escola obtém um desempenho igual a zero no boletim, estimamos um impacto positivo na ordem de $4 \%$ na probabilidade do aluno tirar mais que 5 no exame do professor ou de ficar acima da mediana da classe.

Retomando nossa questão inicial, gostaríamos de saber se o PBF ameniza a transmissão intergeracional da pobreza a partir de maior acumulação de capital humano dos filhos beneficiários. Entretanto, o efeito encontrado do programa parece insuficiente para quebrar com o ciclo da pobreza por tal via. Isto é, não obtemos evidências de que o programa gera por si só os mecanismos que o tornarão desnecessário para gerações futuras das famílias beneficiárias. Apesar da redução no abandono escolar, isto ocorre sobre uma base pequena. Se considerarmos que o programa inclui aproximadamente 1.750 .000 alunos no ano de 2007, e que o abandono é de $3 \%$ nesse grupo, uma redução de $25 \%$ no abandono mantém 12.750 alunos nas escolas. Se por um lado este é um ganho significativo para tal grupo; por outro, seria importante também que houvesse algum impacto escolar no desempenho do restante da população beneficiária que não abandonaria a escola mesmo na ausência da política.

Por fim, diversos estudos demonstraram impactos cruciais dos programas de transferência de renda condicionais sobre nutrição, trabalho infantil, matrícula e saúde. As transferências de renda aliviam a pobreza no curto-prazo garantindo que as necessidades materiais mínimas da população em extrema pobreza sejam atendidas. Os resultados dessa dissertação, entretanto, sugerem que o programa é insuficiente para atingir seu objetivo de amenizar ou quebrar com a transmissão intergeracional da pobreza a partir de um impacto positivo na educação dos alunos beneficiários. De forma geral, identificamos 
um efeito positivo sobre variáveis escolares quantitativas que estão diretamente atreladas às condicionalidades do $\mathrm{PBF}$, o que reforça a importância do desenho da política pública para se atingir um objetivo específico. Por outro lado, não encontramos efeito sobre variáveis relacionadas ao desempenho escolar dos alunos beneficiários. Se isto reforça a importância do desenho da política pública para se atingir um objetivo específico, isto também demonstra que os impactos dela podem estar limitados por tal. 


\section{Referências Bibliográficas}

ANGELUCCI, M. et al. Family networks and school enrolment: Evidence from a randomized social experiment. Journal of Public Economics, Elsevier, v. 94, n. 3-4, p. 197-221, 2010. ISSN 0047-2727.

ASHENFELTER, O.; HARMON, C.; OOSTERBEEK, H. A review of estimates of the schooling/earnings relationship, with tests for publication bias. Labour economics, JSTOR, v. 75, n. 5, p. 1016-1030, 1985. ISSN 0002-8282.

BEHRMAN, J.; BIRDSALL, N. The quality of schooling: quantity alone is misleading. The American Economic Review, JSTOR, v. 73, n. 5, p. 928-946, 1983.

BEHRMAN, J.; PARKER, S.; TODD, P. Medium-term impacts of the oportunidades conditional cash transfer program on rural youth in mexico. Poverty, inequality, and policy in Latin America, MIT Press: Cambridge, MA, p. 219-70, 2008.

BEHRMAN, J.; ROSS, D.; SABOT, R. Improving quality versus increasing the quantity of schooling: Estimates of rates of return from rural pakistan. Journal of Development Economics, Elsevier, v. 85, n. 1-2, p. 94-104, 2008.

BEHRMAN, J.; SENGUPTA, P. The impact of progresa on achievement test scores in the first year. International Food Policy Research Institute, 2000.

BLUNDELL, R.; DIAS, M. Alternative approaches to evaluation in empirical microeconomics. Journal of Human Resources, v. 44, n. 3, p. 565, 2009.

BOISSIERE, M.; KNIGHT, J.; SABOT, R. Earnings, schooling, ability, and cognitive skills. The American Economic Review, JSTOR, v. 75, n. 5, p. 1016-1030, 1985. ISSN 0002-8282.

BOURGUIGNON, F.; FERREIRA, F.; LEITE, P. Conditional cash transfers, schooling, and child labor: micro-simulating brazil's bolsa escola program. The World Bank Economic Review, World Bank, v. 17, n. 2, p. 229, 2003.

BURSZTYN, L.; COFFMAN, L. The schooling decision: Family preferences, intergenerational conflict, and moral hazard in the brazilian favelas. unpublished manuscript, 2011.

CARDOSO, E.; SOUZA, A. The impact of cash transfers on child labor and school attendance in brazil. University of Vanderbilt, 2004.

CHAUDHURY, N.; PARAJULI, D. Conditional cash transfers and female schooling: the impact of the female school stipend program on public school enrollments in punjab, pakistan. World, 2006.

De Janvry, A.; SADOULET, E. When to use a CCT versus a CT approach? In: CITESEER. University of California at Berkeley and DECRG World Bank, note presented at the Third International Conference on Conditional Transfers in Istanbul. [S.1.], 2006. p. $26-30$.

DEATON, A. Instruments, randomization, and learning about development. Journal of Economic Literature, American Economic Association, v. 48, n. 2, p. 424-455, 2010. ISSN 0022-0515. 
FISZBEIN, A.; SCHADY, N.; FERREIRA, F. Conditional cash transfers: reducing present and future poverty. [S.l.]: World Bank Publications, 2009.

GALIANI, S.; GERTLER, P.; SCHARGRODSKY, E. Water for life: the impact of the privatization of water services on child mortality. Journal of Political Economy, v. 113, n. 1, p. 83-120, 2005. ISSN 0022-3808.

GAVIRIA, A.; RAPHAEL, S. School-based peer effects and juvenile behavior. Review of Economics and Statistics, MIT Press, v. 83, n. 2, p. 257-268, 2001.

GLEWWE, P.; KASSOUF, A. The impact of the bolsa escola/familia conditional cash transfer program on enrollment, drop out rates and grade promotion in brazil. 2011.

GLEWWE, P.; OLINTO, P. Evaluating the impact of conditional cash transfers on schooling: An experimental analysis of honduras' praf program. Unpublished manuscript, University of Minnesota, 2004.

HECKMAN, J.; HOTZ, J. Alternative methods for evaluating the impact of training programs. Journal of the American Statistical Association, v. 84, n. 408, p. 862-880, 1989.

HECKMAN, J. et al. Characterizing selection bias using experimental data. [S.l.]: National Bureau of Economic Research Cambridge, Mass., USA, 1998.

HECKMAN, J.; ICHIMURA, H.; TODD, P. Matching as an econometric evaluation estimator: Evidence from evaluating a job training programme. The Review of Economic Studies, Oxford University Press, v. 64, n. 4, p. 605, 1997. ISSN 0034-6527.

HECKMAN, J.; MASTEROV, D. The productivity argument for investing in young children. Applied Economic Perspectives and Policy, Oxford University Press, v. 29, n. 3, p. 446, 2007. ISSN 2004-5790.

HECKMAN, J.; TODD, P. A note on adapting propensity score matching and selection models to choice based samples. Econometrics Journal, Wiley Online Library, v. 12, p. S230-S234, 2009. ISSN 1368-423X.

HECKMAN, J.; URZUA, S. Comparing IV with structural models: what simple IV can and cannot identify. Journal of Econometrics, Elsevier, v. 156, n. 1, p. 27-37, 2010. ISSN 0304-4076.

HOLLAND, P. Statistics and causal inference. Journal of the American Statistical Association, JSTOR, v. 81, n. 396, p. 945-960, 1986. ISSN 0162-1459.

IMBENS, G. Better LATE than nothing: Some comments on Deaton (2009) and Heckman and Urzua (2009). Journal of Economic Literature, American Economic Association, v. 48, n. 2, p. 399-423, 2010. ISSN 0022-0515.

MALUCCIO, J.; FLORES, R. Impact evaluation of a conditional cash transfer program: The Nicaraguan Red de Protección Social. [S.1.]: International Food Policy Research Insitute, 2005.

PARKER, S.; RUBALCAVA, L.; TERUEL, G. Evaluating conditional schooling and health programs. Handbook of Development Economics, Elsevier, v. 4, p. 3963-4035, 2007. 
PARKER, S.; SKOUFIAS, E. The impact of progresa on work, leisure and time allocation. IFPRI Final Report on Progresa, 2000.

RAVALLION, M.; WODON, Q. Does child labour displace schooling? evidence on behavioural responses to an enrollment subsidy. The Economic Journal, Wiley Online Library, v. 110, n. 462, p. 158-175, 2000.

RAWLINGS, L.; RUBIO, G. Evaluating the Impact of CCT Programs: Lessons from Latin America. [S.l.]: Washington DC: World Bank, 2003.

ROSENBAUM, P.; RUBIN, D. The central role of the propensity score in observational studies for causal effects. Biometrika, Biometrika Trust, v. 70, n. 1, p. 41, 1983. ISSN 0006-3444.

SACERDOTE, B. Peer effects with random assignment: Results for dartmouth roommates*. Quarterly Journal of Economics, MIT Press, v. 116, n. 2, p. 681-704, 2001.

SCHULTZ, P. School subsidies for the poor: evaluating the Mexican Progresa poverty program. Journal of Development Economics, Elsevier, v. 74, n. 1, p. 199-250, 2004.

SKOUFIAS, E. et al. Is Progresa Working: Summary of the Results of an Evaluation by IFPRI. [S.l.]: Citeseer, 2001.

UDRY, C. Child labor. Understanding poverty, Oxford University Press, USA, p. 243, 2006. 


\section{Cruzamento das bases de dados}

A base de dados utilizada foi elaborada a partir de quatro fontes: (1) a base de dados de matrícula dos alunos nas escolas do Estado de São Paulo; (2) a base de dados com os boletins dos alunos do sistema público estadual de ensino; (3) a base de dados com o questionário sócio-econômico e desempenho dos alunos no exame do Saresp; (4) a base de dados com informações sobre as transferências do governo federal para as famílias incluídas no Programa Bolsa Família. As primeiras três bases de dados foram fornecidas sob condições de sigilo pela Secretaria de Educação do Estado de São Paulo e possuem um identificador único dos alunos: um número de registro atribuido a cada aluno quando é matriculado no sistema. Portanto, o cruzamento de informações entre tais bases é realizado de forma direta pelos comandos usuais disponíveis no programa estatístico. Porém, a última base de dados com informações sobre os beneficiários do PBF não possui um identificador único dos beneficiados. Porém, ambas as bases de matrícula e das transferência possuem o nome, a data de nascimento, a cidade de residência e o nome do responsável. Aplicamos algoritmos de aproximação imperfeita de células informacionais sobre tais variáveis para cruzar os dados.

\section{1..1 Descrição do algorítmo}

A falta de um identificador único da população tornou necessário utilizar outras informações dos indivíduos para que conseguissemos cruzar as informações de diferentes bases de dados: nome, data de nascimento, nome do responsável e cidade de residência. No entanto, tais variáveis podem estar comprometidas por erros, transferência dos responsáveis ou migração de uma cidade para outra. Isto torna necessária a aplicação de algoritmos de aproximação perfeita e imperfeita de células. Vamos apresentar tais métodos ilustrando os procedimentos com a seguinte base de dados ficticia.

Bases de dados ilustrativas

Base de dados 1

Base de dados 2

\begin{tabular}{lcccc}
\hline & Nome & Ano de nasc. & Nome & Ano de nasc. \\
1 & Adam Smith & 1723 & Adam Smith & 1723 \\
2 & David Ricardo & 1772 & David Ricardo & 1772 \\
3 & David Ricardo & 1772 & David Ricardo & 1772 \\
4 & John Maynard Keynes & 1883 & John M Keynes & 1883 \\
5 & John Nevile Keynes & 1852 & John Neville Keynes & 1852
\end{tabular}


A observação 1 pode ser pareada com uma na base 2 sem problemas, pois há uma combinação única de variáveis em ambas as bases. As observações 2 e 3, por outro lado, são homônimos perfeitos. Neste caso, não há uma possibilidade de pareamento. As observações 4 e 5 possuem uma contrapartida na base 2, mas um procedimento de matching perfeito não faria o pareamento em decorrência da abreviação do nome (Maynard para M) e do erro de digitação (Neville e Nevile). Nestes casos, podemos proceder com duas técnicas.

Em primeiro lugar, poderiamos aplicar o pareamento perfeito usando somente o primeiro e último nome junto com o ano de nascimento. Note que a base de dados ficará com o seguinte formato.

Bases de dados ilustrativas 2

Base de dados 1

Base de dados 2

\begin{tabular}{ccccc}
\hline & Nome & Ano de nasc. & Nome & Ano de nasc. \\
1 & John Keynes & 1883 & John Keynes & 1883 \\
2 & John Keynes & 1852 & John Keynes & 1852
\end{tabular}

Com as bases de dados ilustrativas 2, todas as informações são unicamente identificadas e podemos aplicar os programas estatísticos convencionais. Com tal técnica, eu eliminei ambos os problemas de digitação e de abreviação.

A segunda técnica possível é a de distância entre células (chamado na literatura de probabilistic merge). Utilizando algum critério de distância, determinamos a probabilidade de duas observações em bases de dados diferentes serem a mesma e consideramos o pareamento entre as células com menor distância entre si. O critério usado foi de aproximação silábica que é definido como a soma duas entradas em número, letra ou espaço seguidas, iguais entre duas variáveis do tipo string dividido pela quantidade máxima de sílabas iguais em potencial. Por exemplo, a palavra Gato e Gatu possuem 0,66 de distância, pois possuem duas sílabas iguais em 3 possíveis.

Distâncias

$\begin{array}{lc}\text { John Maynard Keynes } 1883 & \text { John M Keynes } 1883 \\ \text { John Nevile Keynes } 1852 & \text { John Neville Keynes } 1852\end{array}$

Esta última técnica exige muita capacidade computacional quando as bases de dados são grandes, pois é realizada uma distância para cada observação de uma base com todas as outras da base auxiliar. Por exemplo, quando temos duas bases de dados com 10 observações cada, serão construidas $10 \times 10=100$ distâncias. Quando ambas bases possuem 
10.000 observações, temos $10.000 \times 10.000=100.000 .000$ distâncias. Nossas base de dados de matrícula possuem por volta de 10.000.000 alunos em cada ano e a base do bolsa família por volta de 2.500.000. Portanto, criamos um método que concilia as vantagens computacionais do primeiro com a precisão do segundo. Basicamente, cortamos as células em pedaços identificáveis (primeiro nome, sobrenome, ano e mês de nascimento e assim por diante) e conduzimos o pareamento utilizando apenas parte dessas variáveis. Entretanto, mantemos os fragmentos não utilizados de cada base para elaborar um critério de qualidade do pareamento pós-pareamento. O critério utilizado é exatamente o mencionado acima de distância silábica. Quando a qualidade do pareamento é baixa, retornamos as observações para suas respectivas bases e iniciamos o processo novamente utilizando novos critérios. Note que, de tal forma, com duas bases de 10.000 observações onde encontramos 5000 pareamentos, teremos que construir somente 5000 distâncias (e não 10.000.000).

\section{Tabelas e Figuras}




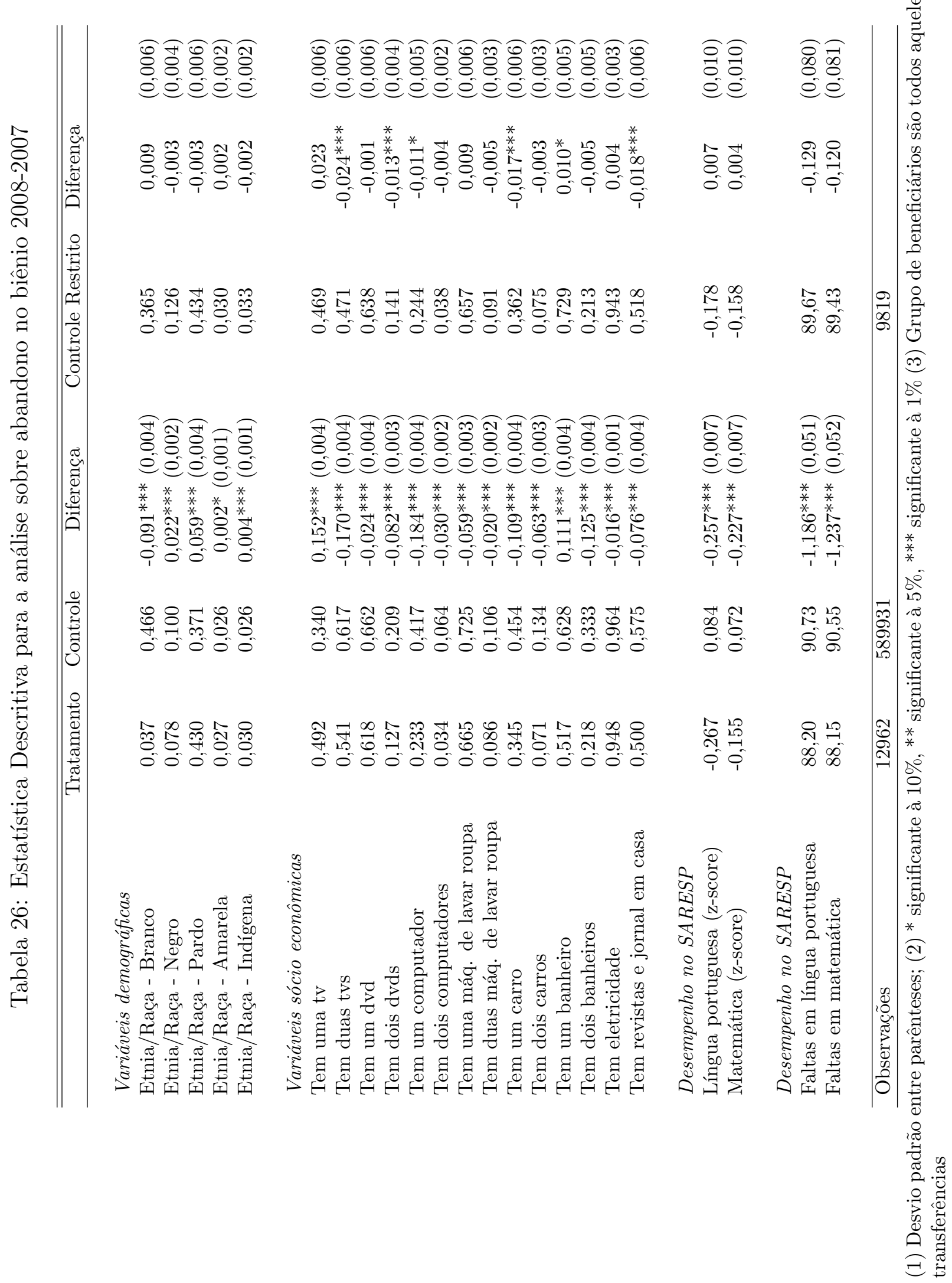




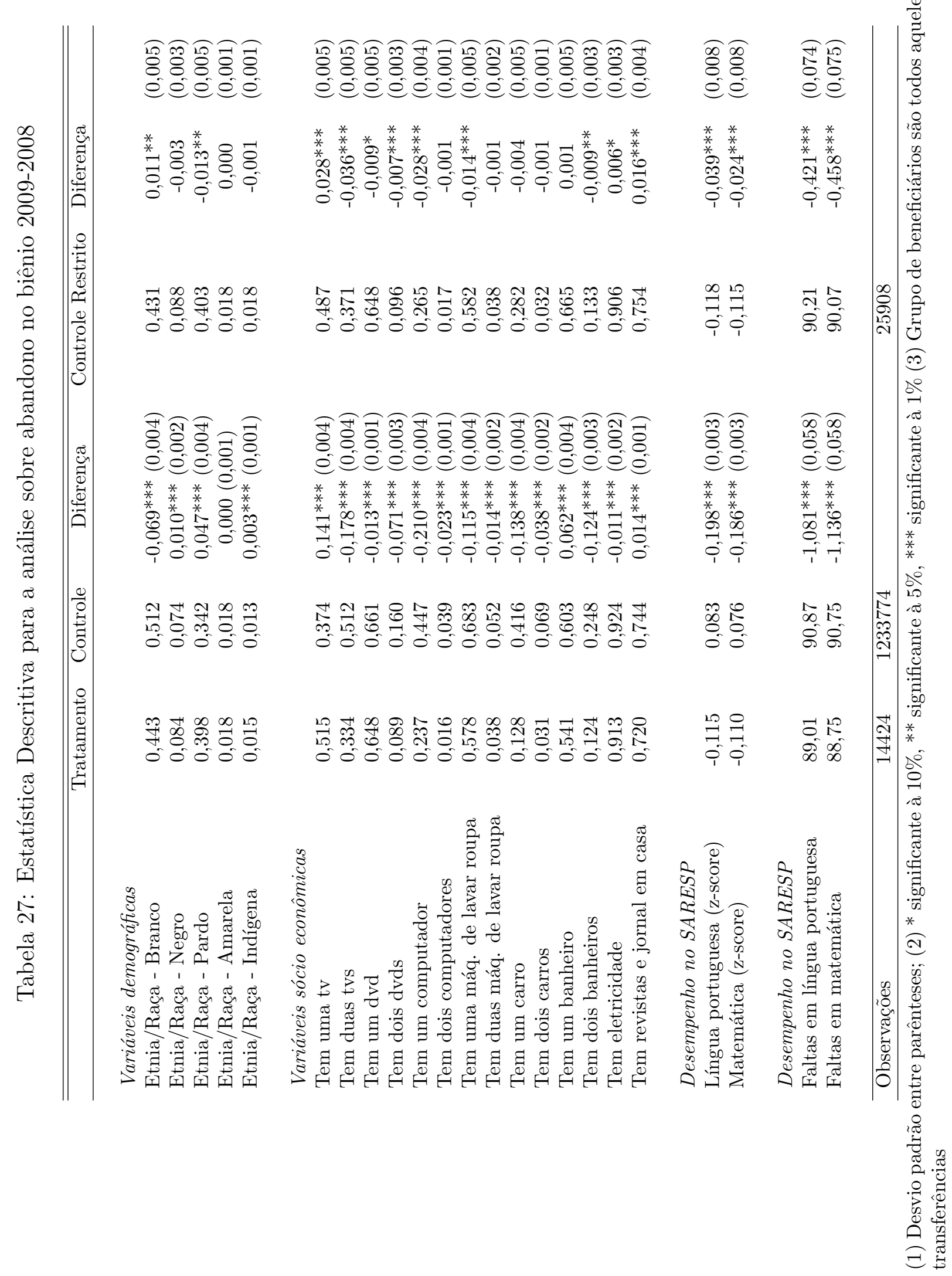


Tabela 28: Estatística Descritiva I (perfil do aluno beneficiado em 2007)

\begin{tabular}{|c|c|c|c|}
\hline Variável & Média & Média & \\
\hline & Beneficiário & Não beneficiário & Diferença \\
\hline \multicolumn{4}{|l|}{ Variáveis demográficas } \\
\hline Ano de nascimento & $12.88(1.700)$ & $12.87(1.801)$ & $-0.011^{* * *}(0.0041)$ \\
\hline Cor/Raça - Branca & $0.359(0.479)$ & $0.474(0.499)$ & $-0.115^{* * *}(0.0011)$ \\
\hline Cor/Raça - Negra & $0.132(0.339)$ & $0.101(0.302)$ & $0.030^{* * *}(0.0007)$ \\
\hline Cor/Raça - Pardo ou Mulato & $0.444(0.496)$ & $0.365(0.481)$ & $0.078 * * *(0.0011)$ \\
\hline Cor/Raça - Indígena & $0.029(0.169)$ & $0.025(0.157)$ & $0.004^{* * *}(0.0003)$ \\
\hline Cor/Raça - Amarela (oriental) & $0.028(0.165)$ & $0.027(0.163)$ & $0.001(0.0003)$ \\
\hline Cor/Raça - Não respondeu & $0.005(0.070)$ & $0.004(0.065)$ & $0.001^{* * *}(0.0001)$ \\
\hline \multicolumn{4}{|l|}{ Ambiente familiar } \\
\hline Membros na família & $5.36(1.395)$ & $4.838(1.389)$ & $0.525^{* * *}(0.0033)$ \\
\hline Mãe sem escolarização & $0.025(0.157)$ & $0.014(0.120)$ & $0.010 * * *(0.0003)$ \\
\hline Mãe com 4 anos ou menos de educação & $0.283(0.450)$ & $0.179(0.383)$ & $0.104^{* * *}(0.0009)$ \\
\hline Mãe com 5 a 8 anos de educação & $0.305(0.460)$ & $0.268(0.443)$ & $0.036^{* * *}(0.0010)$ \\
\hline Mãe com ensino médio & $0.137(0.344)$ & $0.228(0.419)$ & $0.090^{* * *}(0.0009)$ \\
\hline Mãe com educação superior & $0.047(0.213)$ & $0.118(0.323)$ & $-0.070^{* * *}(0.0006)$ \\
\hline Não sabe educação da mãe & $0.192(0.394)$ & $0.183(0.387)$ & $0.008^{* * *}(0.0009)$ \\
\hline Não respondeu educação da mãe & $0.008(0.090)$ & $0.007(0.084)$ & $0.001^{* * *}(0.0001)$ \\
\hline Pai sem escolarização & $0.030(0.157)$ & $0.018(0.133)$ & $0.013^{* * *}(0.0003)$ \\
\hline Pai com 4 anos ou menos de educação & $0.226(0.418)$ & $0.147(0.0354)$ & $0.078 * * *(0.0008)$ \\
\hline Pai com 5 a 8 anos de educação & $0.274(0.446)$ & $0.239(0.426)$ & $0.034^{* * *}(0.0010)$ \\
\hline Pai com ensino médio & $0.126(0.332)$ & $0.211(0.408)$ & $-0.084^{* * *}(0.0009)$ \\
\hline Pai com educação superior & $0.057(0.232)$ & $0.125(0.331)$ & $-0.065^{* * *}(0.0006)$ \\
\hline Não sabe educação do pai & $0.275(0.446)$ & $0.251(0.433)$ & $0.023^{* * *}(0.0010)$ \\
\hline Não respondeu educação do pai & $0.007(0.087)$ & $0.006(0.080)$ & $0.001^{* * *}(0.0001)$ \\
\hline Começou a estudar na pré escola & $0.760(0.426)$ & $0.851(0.355)$ & $-0.090 * * *(0.0008)$ \\
\hline Começou a estudar no fundamental & $0.230(0.420)$ & $0.141(0.348)$ & $0.088^{* * *}(0.0008)$ \\
\hline Observações & 247943 & 728260 & 976203 \\
\hline
\end{tabular}

(1) Desvio padrão entre parênteses; $(2) *$ significante à $10 \%, * *$ significante à $5 \%$, *** significante à $1 \%$

(3) Grupo de beneficiários são todos aqueles que receberam transferências. 
Tabela 29: Estatística Descritiva II (perfil do aluno beneficiado em 2007)

\begin{tabular}{|c|c|c|c|}
\hline Variável & Média & Média & \\
\hline & Beneficiário & Não beneficiário & Diferença \\
\hline \multicolumn{4}{|l|}{ Variáveis sócio econômicas } \\
\hline Tem uma tv & $0.503(0.499)$ & $0.335(0.472)$ & $0.167 * * *(0.0011)$ \\
\hline Tem duas tvs & $0.437(0.496)$ & $0.625(0.483)$ & $-0.188^{* * *}(0.0011)$ \\
\hline Tem um dvd & $0.640(0.490)$ & $0.664(0.472)$ & $-0.023^{* * *}(0.0011)$ \\
\hline Tem dois dvds & $0.121(0.326)$ & $0.213(0.409)$ & $-0.092^{* * *}(0.0009)$ \\
\hline Tem um computador & $0.234(0.423)$ & $0.435(0.495)$ & $-0.201^{* * *}(0.0011)$ \\
\hline Tem dois computadores & $0.036(0.186)$ & $0.070(0.255)$ & $-0.034^{* * *}(0.0005)$ \\
\hline Tem uma máq. de lavar roupa & $0.657(0.474)$ & $0.727(0.445)$ & $-0.070 * * *(0.0010)$ \\
\hline Tem duas máq. de lavar roupa & $0.078(0.269)$ & $0.102(0.302)$ & $-0.023^{* * *}(0.0006)$ \\
\hline Tem um celular em casa & $0.428(0.494)$ & $0.349(0.476)$ & $-0.079 * * *(0.0011)$ \\
\hline Tem dois celulares em casa & $0.377(0.484)$ & $0.529(0.499)$ & $-0.151^{* * *}(0.0011)$ \\
\hline Tem um carro & $0.326(0.468)$ & $0.457(0.498)$ & $-0.131^{* * *}(0.0011)$ \\
\hline Tem dois carros & $0.065(0.247)$ & $0.138(0.345)$ & $-0.073^{* * *}(0.0007)$ \\
\hline Tem um banheiro & $0.747(0.434)$ & $0.621(0.485)$ & $0.125^{* * *}(0.0010)$ \\
\hline Tem dois banheiros & $0.201(0.401)$ & $0.344(0.475)$ & $-0.142^{* * *}(0.0010)$ \\
\hline Tem rua pavimentada & $0.705(0.455)$ & $0.823(0.380)$ & $-0.118^{* * *}(0.0009)$ \\
\hline Tem água encanada & $0.894(0.307)$ & $0.921(0.269)$ & $-0.026^{* * *}(0.0006)$ \\
\hline Tem eletricidade & $0.949(0.218)$ & $0.969(0.171)$ & $-0.019^{* * *}(0.0004)$ \\
\hline Tem revistas e jornal em casa & $0.475(0.499)$ & $0.559(0.496)$ & $-0.083^{* * *}(0.0011)$ \\
\hline Tem dicionário em casa & $0.833(0.371)$ & $0.896(0.304)$ & $-0.063^{* * *}(0.0007)$ \\
\hline Tem internet em casa & $0.217(0.412)$ & $0.426(0.494)$ & $-0.208^{* * *}(0.0011)$ \\
\hline Tem área de estudo em casa & $0.772(0.419)$ & $0.820(0.384)$ & $-0.047^{* * *}(0.0009)$ \\
\hline Tem mais de vinte livros & $0.409(0.291)$ & $0.478(0.499)$ & $-0.069^{* * *}(0.0011)$ \\
\hline \multicolumn{4}{|l|}{ Desempenho no SARESP } \\
\hline Língua portuguesa (z-score) & $-0.257(0.974)$ & $0.103(0.994)$ & $-0.361^{* * *}(0.0023)$ \\
\hline Língua portuguesa (\% acertos) & $53.49(18.89)$ & $60.64(19.25)$ & $-7.148^{* * *}(0.0445)$ \\
\hline Língua portuguesa (percentil na sala) & $0.448(0.293)$ & $0.519(0.297)$ & $-0.070 * * *(0.0006)$ \\
\hline Matemática (z-score) & $-0.219(0.948)$ & $0.089(1.009)$ & $-0.308^{* * *}(0.0023)$ \\
\hline Matemática (\% acertos) & $43.41(17.31)$ & $47.78(18.96)$ & $-4.369^{* * *}(0.0431)$ \\
\hline Matemática (percentil na sala) & $0.456(0.294)$ & $0.515(0.298)$ & $-0.058^{* * *}(0.0006)$ \\
\hline Observações & 247943 & 728260 & 976203 \\
\hline
\end{tabular}

(1) Desvio padrão entre parênteses; $(2) *$ significante à $10 \%, * *$ significante à $5 \%$, *** significante à $1 \%$

(3) Grupo de beneficiários são todos aqueles que receberam transferências 
Tabela 30: Estatística Descritiva III (perfil da escola do aluno beneficiado em 2007). Características selecionadas.

\begin{tabular}{ccc}
\hline \hline Variável & Média & Média \\
\hline
\end{tabular}

Desempenho médio da escola no SARESP

Língua portuguesa (z-score)

Língua portuguesa (percentil)

$-0.069$

0.437

$0.030-0.099 * * *(0.0007)$

Matemática (z-score)

$-0.058$

$0.527-0.089 * * *(0.0006)$

Matemática (percentil)

0.451

$0.026-0.084^{* * *}(0.0008)$

Características demográficas

e sócio-econômicas

Média de alunos com duas tv's

Média de alunos com dois dvd's

0,518

0,178

0,458

Média de alunos com dois celulares

0,099

$0.521-0.070^{* * *}(0.0006)$

Média de alunos com dois carros

0,274

Média de alunos com dois banheiros

0,753

Média de alunos com rua pavimentada

0,321

0,542

0,162

$-0,024^{* * *}(0,000)$

$0,016^{* * *}(0,000)$

$0,454-0,011^{* * *}(0,000)$

$0,106-0,007^{* * *}(0,000)$

Média de alunos com internet

0,280

$-0,006^{* * *}(0,000)$

$0,767-0,014^{* * *}(0,000)$

$0,337-0,016^{* * *}(0,000)$

Observações

247943

728260

976203

(1) Desvio padrão entre parênteses; $(2) *$ significante à $10 \%$, ** significante à $5 \%$, *** significante à $1 \%$

(3) Grupo de beneficiários são todos aqueles que receberam transferências

Tabela 31: Variáveis incluídas na estimação do propensity score.

\begin{tabular}{l|l}
\hline \hline \multicolumn{1}{c}{ Cross-section } \\
\hline Variáveis sócio-econômicas & Variáveis demográficas \\
Posse de bens duráveis & Etnia/Raça \\
& Ano de nascimento \\
Ambiente familiar & Mês de nascimento \\
Educação do pai & Gênero \\
Educação da mãe & Variáveis da escola \\
Quantidade de irmãos & Média das variáveis sócio-econômicas \\
Idade da mãe & Média das variáveis de ambiente familiar \\
& \\
Interações & \\
Idade com série & \\
Idade ao quadrado & \\
Idade com gênero & \\
\end{tabular}

Diferença em diferenças

Todas variáveis usadas na especificação em cross-section mais as seguintes

Variáveis de desempenho escolar

Desempenho do aluno no ano base

Frequência do aluno no ano base
Desempenho médio no Saresp em língua portuguesa no ano base Desempenho médio no Saresp em matemática no ano base Média de alunos beneficiados pelo programa no ano base 